\begin{tabular}{|c|c|c|}
\hline Beitr. Ent. & Keltern & ISSN 0005- 805X \\
\hline $51(2001) 1$ & S. $73-154$ & 14.09 .2001 \\
\hline
\end{tabular}

\title{
Revision of the Megaselia giraudii and $M$. densior species complexes of Europe, including ecological notes
}

\section{(Diptera, Phoridae)}

With 3 tables, 135 Figs on 18 Plates

\author{
MATTHIAS BUCK and R. HENRY L. DISNEY
}

\section{Summary}

The Megaselia girandiz and $M$. densior species groups are revised to include a total of twenty-one described European species. Eight species are new to science: $M$. citrinella BUCK sp. n., $M$. glabrimargo BucK sp. n., $M$. bexanopbila BUCK sp. n., M. immodensior DISNEY sp. n. ( $=M$. densior auctt., nec SCHMITZ), M. labellaspinata DISNEY sp. n. (= M. septentrionalis auctt, nec SCHMITZ), $M$. mimodensior BUCK sp. n., M. raruvesiculae DISNEY sp. n., and $M$. xanthophila BUCK sp. n.. Megaselia phoenicura (SCHNTTZ), M. badia SCHNITZ and $M$. bayleyensis DISNEY (all described from males only) are synonymised with $M$. quadriseta (SCHMTTZ) (previously only known in the female sex). Many specimens previously assigned to $M$. badia are recognised as being $M$. densior SCHMITZ, and $M$. coulsoni DISNEY is synonymised with this species. Lectotypes are designated for $M$. albicans (WOOD), $M$. densior, $M$. offuscata SCHMITZ, $M$. phoenicura and $M$. quadriseta, and a neotype is designated for $M$. comosa (SCHMTTZ). The males of $M$. mubricornis (SCHMTZ) and females of $M$. correlata (SCHMTTZ), $M$. baraldlundi DISNEY and $M$. parnassia DISNEY are described for the first time. The putative male of $M$. sanguinea (SCHMITZ) and the putative female of $M$. albicans are also described for the first time. The recognition of other species is clarified including four species that do not belong to the girandii/densior complex ( $M$. nigrescens (WOOD), $M$. opacicornis SCHMIZ, $M$. rubida (SCHMITZ), and $M$. ustulata (SCHMTTZ)). A revised key to males and a new key to females is provided, utilising the novel taxonomic character of the subcuticular sensilla inside the third antennal segment, and giving special attention to the morphology of the female ovipositor and vaginal sclerite. Biological data (breeding substrates of larvae, bait, colour and habitat preference of adults) are reported for most species.

\section{Keywords}

Diptera, Phoridae, Megaselia, taxonomy, rearing, saprophages, bait trap, Europe

\section{Zusammenfassung}

Die Megaselia giraudii/densior-Artengruppe umfaßt 21 beschriebene Arten in Europa. Acht Arten werden neu beschrieben: $M$. citrinella BUCK sp. n., M. glabrimargo BUCK sp. n., M. bexanophila BUCK sp. n., M. immodensior DISNEY sp. n. ( $=M$. densior auct., nec SCHMITZ), M. labellaspinata DISNEY sp. n. (= M. septentrionalis auctt., nec SCHMITZ), M. mimodensior BUCK sp. n., $M$. raruvesiculat DISNEY sp. n. und $M$. xanthophila BUCK sp. n. Megaselia pboenicura (SCHMTTZ), $M$. badia SCHMITZ und $M$. bayleyensis DISNEY (alle allein von Männchen beschrieben) werden synonymisiert mit $M$. quadriseta (SCHMITZ) (bisher nur bekannt im weiblichen Geschlecht). Viele Individuen, die früher für $M$. badia gehalten wurden, gehören tatsächlich zu $M$. densior SCHMITZ, und $M$. coulsoni DISNEY wird mit letzterer synonymisiert. Lectotypen werden festgelegt für $M$. albicans (WOOD), $M$. densior, $M$. offuscata SCHMITZ, $M$. phoenicura und $M$. quadriseta, sowie ein Neotyp für 
M. comosa (SCHMITZ). Die Männchen von M. rubricornis (SCHMITZ) und Weibchen von M. correlata (SCHMTTZ), M. baraldlundi DISNEY und $M$. parnassia DISNEY wetden erstmals beschrieben. Das mutmaßliche Männchen von $M$. sanguinea (SCHMITZ) und wahrscheinliche Weibchen von $M$. albicans werden ebenfalls zum ersten Mal beschrieben. Die Identität anderer Arten wird aufgeklärt inklusive vier Arten, die nicht zum giraudiil densior-Komplex gehören (M. nigrescens (WOOD), M. opacicomis SCHMITZ, M. rubida (SCHMITZ) und $M$. ustalata (SCHMTZ)). Ein revidierter Bestimmungsschlüssel für Männchen und ein neuer Schlüssel für Weibchen werden vorgestellt. Dabei wird neuen taxonomischen Merkmalen wie den subkutikularen Sensillen innerhalb des dritten Fühlersegments sowie der Morphologie des weiblichen Ovipositors bzw. Vaginalsklerite besondere Beachtung geschenkt. Für die meisten Arten werden außerdem Informationen zur Biologie mitgeliefert (Brutsubstrate der Larven, Köder-, Farb- und Biotoppräferenzen der Imagines).

\section{Introduction}

The giant genus Megaselia Rondani has been described as "the Diptera enfant terrible" (SMITH, 1984). The difficulties, however, are largely manmade, in that the pinned material of the past does not allow one to observe critical fine details, with the result that type series are frequently found to contain more than one species. In addition, these flies being sexually dimorphic, the describing of species on the basis of females alone has been a recipe for generating synonyms. Furthermore, with species that vary in size consequential allometric effects have been assigned unwarranted taxonomic weight. The Handbook on the males of the British species (DISNEY, 1989a) represented a pioneering attempt at a new approach to the identification of Megaselia species based upon slide mounted specimens, instead of the traditional dried specimens on micropins or card points. Subsequent revisionary studies include a closer scrutiny of the male penis complex (DISNEY, 1999).

The present paper deals with a relatively small group of species within this genus that comprises $M$. girandii (EGGER), $M$. densior SCHMITZ and their related species. The former complex falls in the artificial "Abteilung VI" of Megaselia (SCHMITZ \& DELAGE, 1981) that is characterised by a bare mesopleuron and the presence of four scutellar bristles. The recognition of species of the $M$. giraudii/densior group is rendered difficult by the fact that in males the anterior pair of scutellar bristles is often reduced to hairs. Consequently, several species are only known in one sex, or males and females have been described under different names.

The present work was originally stimulated by an ecological investigation on small saprophagous flies (BUCK, 1997b), during which a surprisingly high number of species and specimens of the above complex was obtained in trapping and rearing experiments. 'The identification of this material proved to be difficult, because pre-existing keys only cover males of the hitherto known species (DISNEY, 1989a) or rely on characters of little taxonomic value (SCHMTZ \& DELAGE, 1981). Furthermore some key voucher specimens (including paratypes) previously examined have subsequently proved to be different from the holotypes or lectotypes. Thus, our taxonomic investigations have resulted in a partial revision of the "Abteilung VI", including the description of eight new species. Apart from the taxonomic results new biological data (larval breeding substrates, bait, habitat and colour preferences of adults) are presented for many species. 


\section{Taxonomy}

\subsection{Materials and Methods}

Techniques. The specimens were preserved in $70 \%$ alcohol, and subsequently mounted on slides in Berlese Fluid, as detailed elsewhere (DISNEY, 1994). Material collected by MB was previously fixed in a solution of picric and nitric acid $(7 \mathrm{~g}$ and $7 \mathrm{ml}$, respectively, in $\left.11 \mathrm{H}_{2} \mathrm{O}\right)$. Pinned museum specimens were soaked in Barber's fluid before slide mounting (DISNEY, 1983). In order to be able to pull out the ovipositor of previously pinned females their abdomens were macerated in $10 \% \mathrm{KOH}\left(15-30 \mathrm{~min}\right.$ at $\left.20^{\circ} \mathrm{C}\right)$ before mounting. Female specimens should be mounted with the ovipositor extruded and in a dorso-ventral position (preferably upside down) to enhance observation of critical characters (sternum 8 , vaginal sclerite). Some specimens deposited in the ZFMK were critical-point dried and glued to the side of a pin (BROWN, 1992).

Abbreviations of morphological terms. al - antero-lateral bristle(s); ant - antial bristle(s); sa - supraantennal bristle(s); SPS - subcuticular pit sensilla (of third antennal segment); $\mathrm{T}$ - tergite; $\mathrm{S}$ - sternite; CI - costal index; CR - costal ratios; cc - costal cilia; ax - hairs of axillary ridge of wing; cal - hairs of upper calypter.

Acronyms of depositories (in concordance with ARNETT et al, 1993). BNNH - British Museum (Natural History) (now known as the Natural History Museum), London, England; DEBU - University of Guelph, Guelph, Canada; NHMM - Naturhistorisches Museum Mainz, Mainz, Germany; NHMW - Naturhistorisches Museum Wien, Wien, Austria; CUMZ - University Museum of Zoology, Cambridge, England; SNMB - Staatliches Naturhistorisches Museum, Braunschweig, Germany; USNM - United States National Museum, Washington D.C., U.S.A. (on indefinite loan to B.V. Brown, Natural History Museum of Los Angeles County); ZFMK - Zoologisches Forschungsinstitut und Museum Alexander Koenig, Bonn, Germany; ZMAN - Zoologisch Museum, Amsterdam, The Netherlands.

Characterisation of the revised species complex. Before going into details the authors wish to make clear that the $M$. giraudii/densior species complex as defined here is not monophyletic. It is a phenetic group which has been established merely for practical reasons and can be recognised on the basis of characters which are of questionable value for phylogenetic analysis (e.g., the bare mesopleuron and long anterior scutellar setae). The group under study comprises the majority of species of the former "Abteilung VI" of Megaselia (SCHMiTz \& DelaGE, 1981) which itself is an artificial grouping. The giraudii/ densior group excludes those species of Section VI possessing unusual characters (see below). There is also no doubt that the genus Megaselia itself is paraphyletic (e.g., BROWN, 1992). The phylogenetic systematization of species currently assigned to this genus is a daunting task when taking into consideration the vast number of species and the poor state of knowledge of these biologically very interesting flies. A phylogenetic analysis was therefore beyond the scope of this paper but the phylogenetic relevance of selected characters will be evaluated briefly in the Discussion Section. In the following we now provide a diagnosis of the Megaselia giraudii/ densior species group:

(1) Pre-ocellar bristles further apart than upper sa. (2) ant between upper sa and al (not lying almost vertically below the latter, and close to eye margin). Mesopleuron bare. (3) Notopleuron with two bristles, males in about one third of the species with cleft. Anterior scutellar setae at least half as long as posterior ones in female, variable in male. (4) Ovipositor not of the parasitic type (i.e. not very long, hairing not reduced, cerci not 
small or stout). Female sternum 8 with a pair of hairy lobes at rear margin. All five segments of front tarsus with longitudinal postero-dorsal hair palisade. (5) Normally some hairs below basal half of hind femur are longer than those of antero-ventral row in distal half (at least they are subequal). (6) Tibiae without rows of enlarged anterodorsal setae. (7) Spines in apical comb of posterior face of hind tibia all simple, not bifurcated. (8) Costa not considerably shortened, CI at least 0.42. (9) Subcosta not reaching $\mathrm{R}_{1}$ (in $M$. densior it sometimes reaches $\mathrm{R}_{1}$ but then its distal fifth is faint). (10) Knob of haltere whitish to dusky yellow (but tip sometimes infuscated in $M$. glabrimargo and offuscata).

By the present diagnosis the following Palaearctic species of Section VI of Megaselia are excluded from the giraudii/ densior group (the numbers in parentheses refer to the characters which are incongruous with this definition):

aequilateralis SCHMITZ $(1,2,6)$, chapmani BORGMEIER $(2,10)$, curtineura (BRUES) (8), emarginata (WOOD) (3, 4), errata (WOOD) (9), fuscinervis (WOOD) (10), bumeralis (ZETTERSTEDT) (5), kuenburgi SCHMTTZ (6), latifemorata (BECKER) (3), meigeni (BECKER) $(1,6)$, opacicornis SCHMITZ (3; aberrant specimens may only have two notopleurals), picta (LEHMANN) $(1,6,7)$, plurispinulosa (ZETTERSTEDT) $(1,6)$, prodroma (LUNDBECK) $(10)$, pseudogirandii (SCHM'TZ) (3, 6), rubida (SCHMTTZ) (3, 4), ruficornis (MEIGEN) (9), scalaris (LOEW) $(1,5,6)$, trivialis (BRUES) (1 only $9,3,6, ? 9)$.

While the above diagnosis enables the recognition of females and of males with welldeveloped anterior scutellar bristles, it is not sufficient for males in which the anterior scutellars are reduced to hairs. In this case the key to British Megaselia (DISNEY, 1989a) can be used for an initial assignment of a species to this complex. In this key species of the $M$. giraudii/densior complex will run out at couplets 151-160 and 222-225. The revised key to males which is provided below replaces these couplets and refers to some figures in the key to British species.

Morphology. The basic morphological features for the identification of phorids have been outlined by DISNEY (1994). In the present study some additional characters were used that require further comments.

Antennal sensilla. Various kinds of sense organs and sensilla are located on the antennae. PFeIL et al. (1994) gave a detailed account of the types and distribution of sensilla in the antennae of Megaselia halterata (WOOD). During the present study it was discovered that one kind of sensilla, the 'subcuticular pit sensilla' of PFEIL et al., is of outstanding taxonomic significance. These sensilla are present in most species examined and are recognised as subspherical vesicles inside the third antennal segment. The vesicles are in fact subcuticular pits which open through a small pore to the exterior. They are most commonly encountered on the inner face of the third antennal segment. The number and the size of these sensilla proved to be species-specific. In three species the SPS are exceptionally large (e.g., $M$. quadriseta, Fig. 9). In about one third of the species their number is greatly reduced (e.g., M. baraldlundi, Fig. 8) and in one (M. rubricornis) they are completely missing. The special importance of this character lies in the fact that the morphology of the SPS is basically the same in both sexes (but their number is usually somewhat reduced in females). The SPS must not be confused with the much smaller 'bulbous peg sensilla' of PFEIL et al. which have bases that look like minute, clear, round spots in the integument. Another type of sensilla, the 'domed pit sensilla' of PFEIL et al., 
may also be useful in some cases. A pair of these sensilla is located on the swollen base of each third aristomere. Usually they are well separated from each other but in one species ( $M$. correlata, Fig, 6) they are closely approximated. However, aberrant specimens with closely approximated sensilla can be found in most other species, too.

Labella. In the species descriptions the number of spinules below the labella is reported. The count is made for a single labellum and neither includes the spinules at the distal end of each pseudotrachea nor the small hairs near the lateral margin. The usual condition is only a few spinules below the labella (13-30) in both males and females. Species with densely spinose labella are sexually dimorphic with regard to the number of spinules. In these species the male labella bear 50-200 spinules whereas females only have about half to third this number. In transitional species (males with 30-50 spinules) females also have fewer spinules (ca. 20-30). In order to get a clear view of the lower side of the labella it may be necessary to mount the proboscis separately.

Notopleural cleft. In the past, different types of notopleural clefts were merely characterised in terms of 'weakly" or 'strongly developed'. There are, however, clear morphological differences which are highly species-specific. One important feature is the course of the cleft in its posterior half. Usually it is straight (Figs 13-14) but in one species it is distinctly curved upward and forward (Fig. 12). Another relevant feature is the presence or absence of sclerotised ridges. In most species heavily sclerotised ridges are lacking ('weak notopleural cleft'). However, in $M$. albicans the lower rim of the cleft is fortified posteriorly by a strongly sclerotised ridge (Fig. 12). In two species a small V-shaped ridge is lying immediately behind the cleft (Fig. 13).

Hypopygium. Shape of epandrium: In many species the hind and lower margins of the epandrium form an acute or right angle on the left face just at the ventral base of the anal tube (e.g., Figs 38,42). In some species the hind margin of the epandrium continues straight below the ventral base of the anal tube to form a rounded lobe which is called here the postero-ventral lobe (Fig. 30). Because of asymmetry of the hypopygium the situation on the right side is somewhat different. On this side the hind margin of the epandrium usually continues straight below the anal tube, and normally it is more or less arched (e.g., Figs 20, 31), angled rarely (Fig. 16), or strongly receding (Figs 18, 29). On the right side the hairy lobe which forms the lowermost portion of the epandrium is called the postero-ventral lobe (e.g., Figs 16, 29, 31, 43). Micropubescence: A further character of importance is the micropubescence of the hypandrial lobes and the lower face of the proctiger. The microtrichia may be decumbent (i.e. they raise from the surface at an angle of about $10-30^{\circ}$ ), semi-erect (dto., 30-80') (Fig. 40), or erect (dto., ca. $90^{\circ}$ ). Recurved microtrichia are curved forward apically.

Female ovipositor. In contrast to tergite and sternite 7 which are quite variable intraspecifically and therefore of limited use, the sternum 8 of the female ovipositor is of highest importance for identification. In the investigated group it always terminates in two posterior lobes. These lobes vary in chaetotaxy and morphology. In many species the surface of these lobes is more or less raised above the level of the hind margin to form a bulge. Sometimes the bulge projects laterally beyond the hind margin (e.g., Figs 72, 77). In all species the posterior lobes bear some more or less enlarged hairs. The distance of these hairs to each other and to the edge of the bulge or - if there is no bulge - to the hind margin of the lobe is species-specific. To avoid confusion the term hind margin is not applied to the edge of the bulge but is exclusively used for the margin of the segment (which is directly contiguous to the genital opening) (Figs 72, 77). This margin is 
almost always glabrous (i.e. devoid of microtrichia) whereas the edge of the sternal bulge bears relatively long microtrichia in most species. The degree of sclerotisation is also characteristic. In some species the hind margin is more strongly sclerotised than the rest of the lobe, yet in other species the inner face of the lobe (i.e. a small area of the hindmost part of the wall of the genital chamber) is sclerotised (Figs 70-72). A further important character is the micropubescence of sternum 8 . It varies according to species from completely glabrous to completely covered in microtrichia.

Female internal genitalia. As important as the ovipositor are the various-shaped sclerites within the female vagina. They are highly species-specific and are present in most species. In some species weakly sclerotised tubular or cylindrical structures can be found (Figs 110-113). The homologies of this unpaired organ are unknown. It could represent a modified spermatheca, some kind of ventral receptacle, or a modified accessory gland. Further investigation is necessary to resolve this problem. In the meantime we use the neutral term 'tubular organ'.

Keys. Two keys, for males and females, are presented below. The keys cover the European fauna but it should be noted that no extra-European Palaearctic species have been described from this group. The key to males can be used as a replacement for couplets 151-160 and 222-225 of the key to British species (DISNEY, 1989a). Figure numbers preceded by ' $\mathrm{D}$-' refer to figures in the latter publication. $M$. labellaspinata sp. $\mathrm{n}$., $M$. malbamensis, $M$. offuscata, and $M$. trojani are only known in the male sex and are therefore not considered in the key to females, $M$. septentrionalis is only known in the female sex. The female key includes seven species which cannot be named at present. Some of them may represent the females of species which are only known in the other sex, some of them are new species which will only be formally described when the male is known.

\section{Revised key to males of the European species of the Megaselia giraudii/ densior complex}

1 A notopleural cleft present in front of anterior notopleural bristle (Figs 12-14). When the cleft is inconspicuous this region of the notopleuron is bare. ........... 2

1* Notopleural cleft absent, its position occupied by hairs like those on rest of scutum.

2 Labella densely spinose below (each labellum with 90-150 blunt spinules). Third antennal segment with less than 13 SPS which are about as large as sockets of

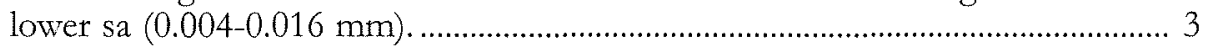

$2^{*} \quad$ Labella only with few $(<30)$ pale spinules below. Third antennal segment with more than 13 SPS. ....................................................................................... 4 Note: the hitherto unknown male of $M$. septentrionalis will have densely spinose labella and ca. 20 large SPS (0.009-0.030 mm) (see also note below couplet 8).

3 Notopleural cleft curved upward and forward in posterior half, fortified with strong sclerotised ridges (Fig. 12). Cerci broad and each bearing more than ten hairs (Fig. D-397). Micropubescence below basal half of proctiger erect to recurved. albicans (WOOD)

3* Notopleural cleft straight in posterior half, without distinctly sclerotised ridges (similar to Fig. 14). Cerci narrower, with 7-8 hairs (Fig. 19). Micropubescence below proctiger semi-erect, inclined rearwards. offuscata SCHMT'Z 
4 SPS inside third antennal segment about as large as sockets of upper sa (0.012$0.031 \mathrm{~mm}$ ). Thoracic scutum yellow to yellowish brown, distinctly paler than brown abdominal tergites. Anal tube long, inclined downwards (Figs 15, 16). Notopleural cleft without sclerotised ridges (similar to Fig. 14).......... bexanophila BUCK sp. n.

4* SPS inside third antennal segment only about as large as sockets of lower sa $(<0.015 \mathrm{~mm})$. Scutum as dark as abdominal tergites. Anal tube shorter, at most a little inclined. Notopleural cleft often with sclerotised ridges.

5 Posterior end of notopleural cleft cut short by a transverse, short, curved ridge embracing its tip (Figs 13, D-401). Microtrichia below left hypandrial lobe long, erect to recurved. Cerci with 7-11(-12) hairs. Epandrium on each side with a stronger, more bristle-like hair....

5* Posterior end of notopleural cleft gradually fading out (Fig. 14). Microtrichia below left hypandrial lobe semi-erect to decumbent. Cerci with 7(-8) hairs. Epandrium sometimes without a more bristle-like hair on each side.

6 Microtrichia below proctiger recurved. Hind margin of left side of epandrium extends ventrally more than width of base of anal tube before it curves forwards (Fig. D-400). Hind margin on right side also more vertical (Fig. 20). Left hypandrial lobe distinctly infuscated, medium brown. Cerci with 8-11(-12) hairs. .... parnassia DisNEY

6* Microtrichia below proctiger semi-erect, pointing rearwards. Postero-ventral border of left side of epandrium almost immediately curves forward from just below base of anal tube (Fig. 17). Hind margin on right side more receding below anal tube (Fig. 18). Left hypandrial lobe more or less translucent, greyish. Cerci with 7 $9(-10)$ hairs. giraudii (EGGER)

7 Palps somewhat inflated, with relatively short bristles (Fig. 1). The longest hair on left side of epandrium only weakly differentiated and not quite as strong as those on cerci. Microtrichia at apex of left hypandrial lobe decumbent and relatively short (Fig. D-393). malhamensis DISNEY

$7^{*} \quad$ Palps normal, with long bristles (Fig. 2). Hairing of left side of epandrium either more or less uniform or with a differentiated, bristle-like hair that is distinctly stronger than the rest of the hairs. Microtrichia of left hypandrial lobe variable.

undescribed species

Note: at least four undescribed species key out at this lead. Only very few specimens were available to the authors so the description of these species will be postponed until more material becomes available.

8 With only a few $(<20)$ or no SPS inside third antennal segment. SPS small to medium size $(0.005-0.016 \mathrm{~mm})$. Labella normally with ca. 30 blunt spinules on lower surface (but rarely as few as 20) ........................................................... 9

8* With many (>30) SPS inside third antennal segment. Labella always with few spinules below (normally ca. 25, rarely up to 33 ).............................................. 15 Note: the hitherto unknown male of $M$. septentrionalis will have ca. 20 large SPS $(0.009$ $0.030 \mathrm{~mm}$ ) and densely spinose labella (see also note below couplet 2).

9 Labella densely spinose below (each labellum with $>50$ blunt spinules).

9* Labella without dense fields of blunt spinules (each labellum with $<45$ spinules). 
10 Third antennal segment large, with diameter exceeding $0.15 \mathrm{~mm}$ (Fig. 5), and dark brown. Palps with area surrounding field of sensilla on external face brown. Anal tube about as long as dorsal face of epandrium (Fig. 22). Hypandrial lobes short and of subequal length. Left side of epandrium without a differentiated, more bristle-like hair that is clearly stronger than rest of hairing. Legs medium brown. labellaspinata DISNEY sp. n.

10* Third antennal segment smaller, with diameter less than $0.15 \mathrm{~mm}$ (e.g., Fig. 4), and paler brown. Palps essentially yellow, including area surrounding field of sensilla. Anal tube distinctly shorter than dorsal face of epandrium (Figs 21, 32). Left hypandrial lobe longer than right one. Left side of epandrium may have a differentiated, more bristle-like hair. At least front legs pale yellowish brown........ 11

11 Left side of epandrium with a stronger, more bristle-like hair on left side (Fig. 21). Microtrichia below left hypandrial lobe erect to recurved. Anal tube somewhat inclined downwards. raruvesiculae DISNEY sp. $n$.

11* Left side of epandrium with weak hairs only (Fig. 32). Microtrichia below left hypandrial lobe more or less decumbent. Anal tube somewhat pointing upwards. xanthopbila BUCK sp. n.

12 Epandrium with a well developed postero-ventral lobe on left side (Fig. D-403). Right hypandrial lobe longer than left one. Penis complex with a long slender process (Fig. 25). Sensilla on swollen base of third aristomere closely approximated (Fig. 6). Anterior scutellar bristles as long as posterior ones.

correlata (SCHNIT'Z)

$12^{*} \quad$ No postero-ventral lobe on left side of epandrium. Right hypandrial lobe at most as long as left one, usually shorter. Penis complex at most with a small process. Sensilla at base of third aristomere usually well separated (closely approximated only in aberrant specimens). Anterior scutellar bristles usually distinctly shorter than posterior ones.

13 Third antennal segment yellow, with ca. 10-20 small SPS $(0.004-0.011 \mathrm{~mm})$. Thorax yellow, distinctly paler than dark brown abdominal tergites. Each side of epandrium with a differentiated, more bristle-like hair (Figs 36, 37). Microtrichia below left hypandrial lobe long, erect to recurved. Anterior scutellar setae distinctly shorter than posterior ones. ......... putative male of sanguinea (SCHMITZ)

13* Third antennal segment brown or reddish yellow, SPS different. Thorax brown, about same colour as abdominal tergites. Epandrium with more uniform hairing. Microtrichia below left hypandrial lobe erect or decumbent. Anterior scutellar setae long or short.

14 Third antennal segment reddish yellow, without SPS. Anterior scutellar bristles as long as posterior ones. Hypopygium very large (Figs 23-24). Left hypandrial lobe with erect to recurved microtrichia. Penis complex with a short slender process. rubricornis (SCHMITZ)

14* Third antennal segment brown, with 3-6 small to large SPS $(0.004-0.020 \mathrm{~mm})$ (Fig. 8). Anterior scutellars distinctly shorter than posterior ones. Hypopygium smaller (Fig. 28, 29). Left hypandrial lobe with decumbent micropubescence. Penis complex without process. baraldlundi DISNEY 
Note: A few males of $M$. opacicornis SCHMTZ have two not three notopleurals, the middle one being reduced or absent. Its hypopygium as Fig. 11. The SPS number at least 20 and are small (ca. $0.005-0.012 \mathrm{~mm}$ ). A generally brown to dark brown species, including the third antennal segments, the legs and anal tube.

15 Epandrium without a differentiated bristle-like hair on each side (e.g., Figs 33, 34). Left hypandrial lobe at most a little longer than right one........................ 16

15* Epandrium with a differentiated, more bristle-like hair on each side (e.g., Figs 38, 42). Hypandrial lobes subequal or left lobe distinctly longer than right one... 19

16 Third antennal segment with SPS that are larger than usual $(0.010-0.024 \mathrm{~mm})$, being about as large as basal sockets of upper sa (Fig. 9). Left side of epandrium with well developed postero-ventral lobe (Figs 30, D-454). Left hypandrial lobe with short decumbent microtrichia and glabrous hind margin.

$16^{*}$ SPS of third antennal segment smaller $(0.004-0.015 \mathrm{~mm})$, being only about as large as sockets of lower sa or less (Fig. 3). Postero-ventral lobe of left side of epandrium not developed (e.g., Figs 33, 34). Left hypandrial lobe sometimes with erect to recurved microtrichia.

17 Middle third of terminal hairs of proctiger flattened and usually somewhat twisted (Fig. D-402). Microtrichia of left hypandrial lobe long, mostly erect to recurved. Penis complex with a short slender process above right hypandrial lobe. Anterior scutellar bristles as long as posterior ones. breviseta (WOOD)

17* Terminal hairs of proctiger not, or only very slightly, flattened in middle third. Microtrichia of left hypandrial lobe short and decumbent, often absent near tip. Penis complex without slender process. Anterior scutellars distinctly shorter than posterior ones.

18 Epandrium on both sides with short hairs that are distinctly shorter than longest hair of cerci (Fig. 33). Left hypandrial lobe a little longer than right one. Anal tube distinctly shorter than dorsal face of epandrium. Knob of haltere normally with brownish tip. Legs pale brown. glabrimargo BUCK sp. $\mathrm{n}$.

18* Hairing of epandrium relatively long, on both sides with some long hairs that are subequal to longest hair of cerci (Figs 34-35, D-456, D-465). Hypandrial lobes subequal in length. Anal tube almost as long as dorsal face of epandrium. Knob of haltere pale yellow. Legs yellow. densior SCHMITZ

19 Left hypandrial lobe clearly longer than right one (e.g., Fig. 38) ..................... 20

19* Left hypandrial lobe subequal to or slightly longer than right lobe (e.g., Fig. 34).

Note: in assessing the relative lengths of these lobes take account of parallax.

20 Microtrichia below left hypandrial lobe long, erect to recurved (Fig. 38). Left hypandrial lobe 0.89-1.18x as long as proctiger (Note: the length of the proctiger is measured at its lower edge, from the base to the insertion point of the terminal hairs). Legs pale brownish yellow to yellowish brown. immodensior DISNEY sp. $\mathrm{n}$. Note: if third antennal segment is yellow and anal tube is relatively shorter when compared to dorsal face of epandrium (Fig. 36) check for $M$. cf. sanguinea, couplet 13. 
20* Microtrichia below left hypandrial lobe shorter, decumbent to semi-erect (Fig. 39). Left hypandrial lobe $0.55-0.75 x$ as long as proctiger. Legs brown.

mimodensior BUCK sp. $\mathrm{n}$.

21 Thorax (including metafurcae) yellow to yellowish brown, much paler than brown frons. Hypopygium as Figs 42-43. Microtrichia below proctiger erect to recurved (Fig. 42). Postero-ventral lobe of right side of epandrium narrower, more convex, and more projecting posteriorly. Penis complex without brush-like structure. citrinella BUCK sp. n.

21* Thorax and internal metafurcae (Fig. 10) brown, of about same colour as frons. Hypopygium as Figs 40-41. Microtrichia below proctiger semi-erect (Fig. 40). Postero-ventral lobe of right side of epandrium broader, more flattened, and less projecting posteriorly. Penis complex with peculiar brush-like structure on right side.

trojani DISNEY

\section{Key to females of the European species of the Megaselia giraudii/densior complex}

1 Posterior lobes of sternum of abdominal segment 8 only with 1-2 long hairs and sometimes with an additional shorter one.

1* Posterior lobes of sternum 8 with three long hairs, though the third long hair is sometimes shifted to an extreme latero-basal position (Figs 74, 88) or there may be no clear-cut division between long and short hairs (Fig. 80). Lobes usually with additional shorter hairs.

2 Posterior lobes of sternum 8 with one long hair in basal position, lacking microtrichia (Fig. 68). Vaginal sclerite small, triangular, without hole (Fig. 99).

Posterior lobes of sternum 8 with two long hairs. Vaginal sclerite different. ... 3

3 Third antennal segment with $>20$ SPS. Labella only with few $(<25)$ blunt spinules below. T7 (Fig. 53) and S7 not very long. Posterior lobes of sternum 8 completely covered by micropubescence (Fig. 73). Vaginal sclerite small, fenestrate (Fig. 100).

Megaselia sp. 7

3* Third antennal segment only with 2-6 SPS. Labella with numerous $(>50)$ pale spinules. T7 and S7 elongate (Figs 51, 60). Posterior lobes of segment 8 bare or at most with some scattered microtrichia around bases of long hairs (Fig. 69). Vaginal sclerite large and elongate, without a distinct hole (Fig. 119).

putative female of albicans (WOOD)

4 Posterior lobes of sternum 8 sclerotised on internal surface (e.g., Figs 71, 72). 5

4* Lobes of sternum 8 not sclerotised on internal surface, at most narrowly sclerotised along margins.

Note: in $M$. immodensior the internal surface is sometimes weakly sclerotised, but in this species the enlarged hairs of the sternal lobes are broadly separated from hind margin (Fig. 81).

5 Lobes of sternum 8 with a postero-laterally projecting bulge, sclerotised area small (Fig. 72). Vaginal sclerite a small, weakly sclerotised ring (Fig. 101). Hairs of hypoproct not crowded towards anterior margin (cf. Fig. 93)....... Megaselia sp. 3 
5* Bulge of sternal lobes at most indistinctly projecting postero-laterally, sclerotised area larger (Figs 70-71). Vaginal sclerite different. Hairs of hypoproct crowded towards anterior margin (cf. Fig. 94). 6

6 SPS of third antennal segment about as large as sockets of upper sa (0.012-0.031 $\mathrm{mm})$. Thorax yellow to yellowish brown, distinctly paler than brown abdominal tergites. T6 0.85-1.1x as broad as long. Sternum 8 completely covered in microtrichia (except bare hind margin of posterior lobes) (Fig. 71). Vaginal sclerite minute $(<0.03 \mathrm{~mm}$ ), with a hole (Fig. 102) ................................. bexanophila BUCK sp. n.

$6^{*} \quad$ SPS of third antennal segment only about as large as sockets of lower sa (0.004$0.015 \mathrm{~mm}$ ). Thorax brown, same colour as abdominal tergites. T6 $1.25-1.4 \mathrm{x}$ as broad as long. Micropubescence of sternum 8 restricted to postero-lateral parts (Fig. 70). Vaginal sclerite much larger, without hole (Fig. 117).

parnassia DISNEY

$7 \quad$ Without vaginal sclerite or tubular organ.

$7^{*} \quad$ Vaginal sclerite present, sometimes weakly sclerotised and easily overlooked, if missing with distinct tubular organ (Fig. 110).

8 Posterior lobes of sternum 8 closely approximated, with at least one enlarged hair well separated from margin (Fig. 74). T7 and S7 (Fig. 67) very narrow. Thorax and abdominal tergites yellow to yellowish brown, T2-6 with distinctive greyish lateral markings that extend down onto the pleura below level of spiracles. (Nearctic).

fisheri (MALLOCH)

8* Posterior lobes of sternum 8 well separated, their enlarged hairs standing close to margin. T7 and S7 broader (e.g., Figs 49, 64). Thorax and abdominal tergites uniformly brown.

9 Posterior lobes of sternum 8 not very prominent, without bulge. Between the lateral ones with an additional weakly developed median lobe (Fig. 75) (the latter may be hard to see if lateral lobes are not spread out). Lobes of Dufour's crop mechanism shorter, with long common base. Megaselia sp. 1

9* Posterior lobes of sternum 8 more prominent, with small postero-laterally projecting bulge (e.g., Fig. 76). No median lobe. Lobes of Dufour's crop mechanism long, with short common base (e.g., Fig. 123).

10 Third antennal segment with $>15$ SPS. ant closer to upper sa than to al. Anterior half to two thirds of sternum 8 devoid of microtrichia. Enlarged hairs of sternal lobes standing almost on the edge of the bulge (Fig. 76). Hairs of hypoproct crowded towards anterior margin (Fig. 94). girandii (EGGER)

10* Third antennal segment only with 3-6 SPS. ant closer to al than to upper sa. Sternum 8 completely covered in microtrichia. Enlarged hairs of sternal lobes standing a little before the edge of the bulge (Fig. 78). Hairs of hypoproct not crowded towards anterior margin (Fig. 93). baraldlundi DISNEY Note: If hind margin of sternal lobes apparently hairy (Fig. 92) check with Megaselia sp. 2 (cf. couplet 25).

11 Internally with well developed tubular organ, whose surface is finely transverserugose (Fig. 110) or striate (Fig. 113). Vaginal sclerite present or absent. Dufour's crop mechanism without posterior lobes, at most slightly emarginate. 0-10 SPS inside third antennal segment. 
11* Tubular organ missing or weakly developed. If a tubular organ is present its surface is usually smooth (Fig. 111), the Dufour's crop mechanism has well developed lobes (e.g., Fig. 129), and the third antennal segment has $>10$ SPS. Vaginal sclerite always present but sometimes weakly sclerotised.

12 Third antennal segment reddish yellow, completely lacking the SPS. Abdominal tergites broad, T6 being subquadrate. T7 and S7 broad and short (Figs 57, 61). Dufour's crop mechanism large, slightly emarginate posteriorly (Fig. 130). Sternum 8 with broad posterior lobes (Fig. 80). Vaginal sclerite present (Fig. 113)...

rubricornis (SCHMITZ)

12* Third antennal segment brown, with few SPS. Width of abdominal tergites strongly decreasing posteriorly, T6 being subtriangular (Fig. 44). T7 (Fig. 50) and S7 almost linear. Dufour's crop mechanism smaller, rounded behind (Fig. 131). Sternal lobes smaller and with fewer hairs (Fig. 79). Vaginal sclerite absent (Fig. 110). correlata (SCHMITZ)

13 Vaginal sclerite postero-laterally with a small, weakly sclerotised ring (Figs 106-108).

13* Vaginal sclerite different.

14 Vaginal sclerite convex towards left side, somewhat irregular-shaped (Fig. 106). Hind margin of sternum 8 bordered by $4-8$ hairs between posterior lobes (Fig. 81). Legs pale brownish yellow to yellowish brown. T10 bare. .... immodensior DISNEY sp. n.

14* Vaginal sclerite more slender, convex towards right side or just a straight transverse bar. Hind margin between sternal lobes bordered by 2-3 hairs. Legs brown. T10 sometimes with 1-2 hairs.

15 Vaginal sclerite larger, with upper leg only slightly shorter than lower one (Fig. 107). Posterior lobes of sternum 8 as Fig. 82. ............... mimodensior BUCK sp. n.

15* Vaginal sclerite smaller, a simple transverse bar or with a short upper leg (Fig. 108). Sternal lobes extremely similar (Fig. 83)................................ Megaselia sp. 5

16 Vaginal sclerite a large, more or less irregular loop, sometimes with long anterior

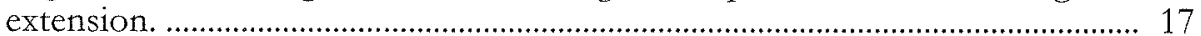

16* Vaginal sclerite at most a small ring or funnel, or not circular at all. ............. 19

17 SPS of third antennal segment about as large as sockets of upper sa $(0.010-0.024$ $\mathrm{mm}$ ). T10 with 1-6 hairs. Vaginal sclerite with long anterior extension (Fig. 109). (Sternal lobes as in Fig. 84). quadriseta (SCHMTZ)

$17^{*}$ SPS of third antennal segment only about as large as sockets of lower sa (0.005$0.015 \mathrm{~mm}$ ). T10 bare. Vaginal sclerite with short posterior extension (e.g., Fig. 115).

18 Posterior lobes of sternum 8 with distinct postero-laterally projecting bulges (Fig. 77). Sternum 8 anteriorly devoid of microtrichia. Dufour's crop mechanism frequently with very short posterior lobes (Figs 133-135). Labella with 22-44 blunt spinules below. Vaginal sclerite as in Fig. 114. xanthopbila BUCK sp. $\mathrm{n}$.

18* Posterior lobes of sternum 8 with much shorter bulges (Fig. 85). Micropubescence of sternum 8 extends up to anterior margin of segment. Lobes of Dufour's crop mechanism longer (similar to Fig. 126). Labella with 17-21 spinules below. Vaginal sclerite as in Fig. 115 glabrimargo BUCK sp. $\mathrm{n}$. 
19 Thorax yellow to yellowish brown, much paler than brown frons................... 20

19* Thorax brown, of about same colour as frons. .................................................. 21

20 Antennae yellow to dusky yellow. Posterior lobes of sternum 8 broad, with many hairs but no bulge (Fig. 86). At least one enlarged hair of lobes standing well before hind margin. Vaginal sclerite roughly semi-circular (Fig. 116). ... sanguinea (SCHMTTZ)

20* Antennae brown. Posterior lobes of sternum 8 narrow, with fewer hairs, bulge present (Fig. 87). Enlarged hairs of sternal lobes close to edge of bulge. Vaginal sclerite transverse, tapered on right side and like the eye of a needle (Fig. 111)... citrinella BuCK sp. n.

21 Vaginal sclerite as a short funnel, with irregular lateral extension (Fig. 112). Anteriorly the tubular organ is not always visible. Enlarged hairs of posterior lobes of sternum 8 broadly separated from hind margin (Fig. 88). Cerci with an apical group of 7-9 short, blunt-tipped hairs. breviseta (WOOD)

21* Vaginal sclerite more simply structured, no tubular organ. Enlarged hairs of sternal lobes closer to hind margin. Cerci frequently only with 3-4 short, blunt-tipped hairs.

22 Vaginal sclerite small, circular or fenestrate. Sternum 8 micropubescent posteriorly, including medial area. Cerci apically only with 3-4 short, blunt-tipped hairs...... 24

22* Vaginal sclerite not as above, large and elongate. Sternum 8 medially devoid of microtrichia. Cerci apically with 5-9 short, blunt-tipped hairs. 23

23 Vaginal sclerite irregular-shaped and well sclerotised (Fig. 121). Posterior lobes of sternum 8 very hairy, apical hairs not clearly differentiated from rest of hairing (Fig. 95). Lobes of Dufour's crop mechanism moderately long (e.g., like Fig. 125). M. raruvesiculae DISNEY sp. n.

23* Vaginal sclerite a simple, weakly sclerotised plate. (Fig. 118). Lobes of sternum 8 only with a few hairs, with the apical three being clearly longer than the rest of hairs (Fig. 89) Lobes of Dufour's crop mechanism very narrow and $>5 \mathrm{x}$ as long as broad. Megaselia sp. 4

24 Vaginal sclerite fenestrate and strongly sclerotised (Fig. 103). T10 with one hair.

24* Vaginal sclerite a small, weakly sclerotised ring. T10 bare. Megaselia sp. 6

25 SPS of third antennal segment about as large as sockets of upper sa (0.009-0.030 $\mathrm{mm}$ ). Labella with $40-50$ blunt spinules below. At least one of the enlarged hairs of lobes of sternum 8 standing well before hind margin (Fig. 91). Vaginal sclerite small (Fig. 104). septentrionalis (SCHMTTZ)

25* SPS of third antennal segment at most as large as sockets of lower sa $(0.004-$ $0.010 \mathrm{~mm}$ ). Labella with $<20$ spinules below. Enlarged hairs of sternal lobes close to hind margin (Fig. 92). Vaginal sclerite larger (Fig. 105). Megaselia sp. 2 


\subsection{Descriptions of species of the $M$. giraudii/densior group}

The diagnoses of the new species are, of necessity, somewhat long as the genus contains about 1,400 described species and an estimate of at least ten times as many undescribed species. To keep this work as concise as possible we refer to previous publications for general descriptions of already known species. In these cases only new information is presented.

\section{Megaselia albicans (WoOD, 1908)}

(Figs 12, 51, 60, 69, 119)

Phora albicans WOOD, 1908: $172\left(0^{*} \%\right)$.

Aphiochaeta albicans (WOOD). BRUES, 1915: 111.

Megaselía albicans (WOOD). SCHMTZ, 1928: 144.

The female of $M$. albicans has not been adequately characterised before. In the Schmitz collection several females attributed to this species were found. They bear the same types of labels and were collected around the same dates as certain albicans males (unfortunately the labels only indicate the collection date). Closer examination revealed that these females belong to three different species (see also below Megaselia sp. 4 and M. girraudii), but at least three specimens are probably true $M$. albicans. Apart from general similarity they share two significant characters with the males (reduced number of SPS in the third antennal segment and densely spinose labella). However, it cannot be ruled out that they belong to the related $M$. offuscata.

\section{Type material}

Lectotype (herewith designated by RHLD): $\%$. Great Britain: England, Stoke Wood, 22.iii. 1905 (remounted) (BMNH). Paralectotypes: not examined.

\section{Material examined}

Germany: đ", North Rhine-Westphalia, Köln-Dünnwald, NSG “Am Hornpottweg”, 11.18.iv.1987, malaise trap, leg. J. Franzen (coll. S. Prescher); ot, Rhineland-Palatinate, Mainz, Lennebergwald, 24.v.-8.vi.1988, emergence trap over soil, beech forest, leg. R. Feldmann (NHMM); ơ, Baden-Württemberg, Ulm, Eselsberg, 6.-20.v.1981, window trap, deciduous forest, leg. R. Grimm (coll. MB). Without locality data (i.e. probably the Netherlands): o , 18.iv.1919, ㅇ, 21.v.1919, đ, 6.vi.1919 (all with red labels); ㅇ, 6.v.1920, 1 o 1 우, 8.v.1920, o , 11.v.1920, o , 12.v.1920 (all with yellow labels), coll. Schmitz (ZFMK).

\section{Description}

For a general description see SCHMTZZ \& DELAGE (1981). ant closer to eye margin than to median furrow and a little closer to al than to upper sa. Third antennal segment only with 2-6, small to medium-sized (0.005-0.016 mm) SPS. Male labella with 130-150 pale spinules, about twice as many as in female (65-75). Notopleural cleft distinctly curved upward and forward in posterior half (Fig. 12). Lower rim of cleft developed as a strongly sclerotised ridge. Abdominal venter hairy on segments 3-6. Male hypopygium figured by DiSNEY (1989a: Fig. 397). Cerci broad, each one bearing 11-14 hairs. Micropube- 
scence of ventral edge of proctiger erect to recurved in basal half. Left hypandrial lobe longer than right one. Microtrichia below left lobe erect to recurved, those of right lobe pointing rearwards. Female abdomen: T6 trapezoid, 1.0-1.3x as broad as long. Anterior notch narrow, its width about a quarter to a sixth of maximum breadth of tergite. T7 very long and narrow (Fig. 51). T8 rectangular, with 13-21 hairs. T10 bare. S7 long and narrow (Fig. 60), with three enlarged hairs at posterior margin. Sternum 8 devoid of microtrichia except in postero-lateral parts. Posterior lobes of sternum 8 only with two long hairs (Fig. 69). Lobes otherwise completely bare or at most with some scattered microtrichia near bases of setae. Hairs of hypoproct somewhat crowded towards anterior margin. Cerci cylindrical, about 2.5-3.5x as long as broad, with usual hairing plus a group of 4-5 short, blunt-tipped hairs at apex. Vaginal sclerite a very long plate (ca. 0.20 $\mathrm{mm}$ ), weakly sclerotised, and widening posteriorly (Fig. 119). On right side with a short cylindrical structure. Four rectal papillae in both sexes. Wing length $1.85-2.4 \mathrm{~mm}$ (male), 2.35-3.15 mm (female). CI 0.48-0.50 (male), 0.50-0.53 (female), CR 2.4-2.8: 1.5-1.8: 1 (male), 2.7-3.3:1.7-1.8: 1 (female). Longest cc $0.15-0.21 \mathrm{~mm}$. 4-10 cal, 4-8 ax. Hair at base of Rs well developed $(0.030-0.100 \mathrm{~mm})$.

\section{Distribution}

Hitherto reported from Great Britain, Ireland, Sweden, Belgium, the Netherlands, Germany (DISNEY, 1991), and Poland (DURSKA, 1996).

\section{Megaselia breviseta (WoOD, 1912)}

(Figs 63, 88, 112)

Apbiocbaeta breviseta WOOD, 1912: 99 (ठ).

Apbiocbaeta breviseta WOOD. SCHNITZ, 1918: $145($ ( )

Megaselia breviseta (WOOD). SCHMITZ, 1928: 144.

\section{Type material}

Previously examined (DISNEY, 1986).

\section{Other material examined}

Germany: Bavaria, Senden Hittistetten, 47 o 36 o emerged 7.vii.-4.viii.1993, 1 o 1 , 11.viii.-8.ix.1993, reared from decaying larval/pupal tents of Yponomenta sp. (Lep.) (collected 23.vi.1993), leg. M. Buck (coll. MB, 1 o 3 \% CUMZ, 3 o 3 क ZFMK).

Females, having not been adequately described before, may be confused with other similar species. Based on a large series of reared specimens a more detailed description of M. breviseta is provided (for general characters see SCHMITZ \& DELAGE, 1981).

\section{Description}

ant of frons midway between upper sa and al, or a little closer to sa. SPS numbering ca. 20-30, arranged in about three irregular rows near base of inner face of third antennal segment, lacking from outer face. SPS less numerous in female (ca. 8-20) and only in 12 irregular rows. Diameter of SPS small to medium $(0.004-0.014 \mathrm{~mm})$. Sensilla on swollen base of third aristomere well separated to closely approximated. Labella in both 
sexes with 16-21 spinules on lower face. Anterior scutellats well developed and as long as posterior ones in both sexes. Abdominal venter hairy on segments 3-6, in female sometimes segment 2, too, but hairs weaker and those of segments 3-4 sometimes reduced to microscopic setulae. Hypopygium see DISNEY (1989a: Fig. 402). Left side of epandrium with 10-21 hairs. Microtrichia of left hypandrial lobe erect to recurved (though usually with some semi-erect ones near outer margin). Micropubescence of right lobe decumbent. Aedeagal complex with a short slender process above right hypandrial lobe. Tip of process a little upcurved. Female abdomen: T6 trapezoid, 0.9-1.1x as broad as long. Anterior notch narrow, width only one fifth to one eighth of maximum breadth of tergite. T7 expanded towards front, shallowly emarginate anteriorly. T8 rectangular, with 10-27 hairs (mainly at or near lateral margins). T10 bare. S7 nartow, with a strongly sclerotised median strip in anterior half to two thirds (rarely missing), and with (2-)4(-5) enlarged hairs at rear (Fig. 63). Posterior third to two thirds of sternum 8 covered in microtrichia. Margins of posterior lobes narrowly sclerotised and devoid of microtrichia. Each lobe with three long hairs that stand well off margin (Fig. 88). Hairs of hypoproct equally distributed over disc. Cerci cylindrical, $3-4 \mathrm{x}$ as long as broad. Apart normal $5+1$ long hairs with apical group of 7-8(-9) short, blunt-tipped hairs. Left portion of vaginal sclerite convex posteriorly (Fig. 112). Right portion funnel-shaped, bearing a curved tubular organ which widens distally. Dufour's crop mechanism somewhat variable, similar to $M$. bexanophila or $M$. densior (cf. Figs 125, 129). Rectal papillae: (2-)3-4 (male), 4 (female). Wing length 1.35-1.85 mm (male), 1.8-2.4 mm (female). CI 0.46-0.49 (male), 0.48-0.51 (female). CR 2.9-3.5: 1.6-2.2: 1 (male), 3.3-4.1 : 1.9-2.4: 1 (female). Longest cc 0.11-0.16 mm. (4-) 5-8(-9) cal, (4- ) 5-6 ax, longest of the latter about as long as longest cc. Hair at base of Rs vestigial $(0.012-0.030 \mathrm{~mm})$, rarely absent.

\section{Remarks}

$M$. breviseta, $M$. correlata and $M$. rubricornis probably form a monophyletic group which is characterised by two putative synapomorphies: (1) penis complex with slender posterior process (most conspicuous in $M$. correlata); (2) female reproductive tract with peculiar tubular organ (ventral receptacle or modified spermatheca?).

\section{Distribution}

Recorded from several Central European countries as well as England, Sweden, Hungary (DISNEY, 1991), and Russia (Kuril Islands) (MiCHAILOVSKAYA, 1998).

\section{Megaselia citrinella BuCK sp. n.}

(Figs 42-43, 87, 111, 124)

Megaselia quadriseta auctt., nec (SCHMITZ, 1918). SCHMITZ, 1918: 143 (partim).

Megaselia badia auctt., nec SCHMTZ, 1938. FELDMANN, 1992: 205 (partim, see also below M. densior and M. baraldhundi).

Megaselia sanguinea auctt., nec (SCHMTTZ, 1922). Schmitz (see below M. quadriseta).

Megaselia fisheri auctt, nec (MALLOCH, 1912). BROWN \& MARSHALL, 1984: 79 (partim). 


\section{Type material}

Holotype: $\sigma^{7}$. Germany: Bavaria, Senden Hittistetten, 19.-26.viii.1993, trap baited with decayed mushrooms (Agaricus bisporus), leg. M. Buck (critical-point dried and glued to the side of a pin) (ZFMK). Paratypes: 26 o 41 \%. Germany: as type locality, of, 13.19.v.1993, on, 22.-29.vii.1993, 3 o , 26.viii.-9.ix.1993, carrion traps baited with kidney; ơ, emerged 21.-28.vii.1993, reared from dead Acheta domesticus (bait exposed from 18.25.vi.1993); 2 o, emerged 9.-16.vi.1993, reared from buried liver bait (exposed 27.iv.12.v.1993); ㅇ, 8.-22.vii.1992, emergence trap set over soil, spruce forest, all leg. M. Buck (all except $1 \sigma^{\text {* }}$ mounted on slides) (most in coll. MB, 1 o 1 \% CUMZ); Baden-Württemberg, on, Ulm, Eselsberg, 20.v.-10.vi.1981, window trap, deciduous forest, leg. R. Grimm (mounted on slide) (coll. MB); Rhineland-Palatinate, Mainz, Lennebergwald, 3 o 30 ㅇ, 20.iv.-25.ix.1988, o, 9.ii.-10.iii.1989, 3 o 4 ㅇ, 26.iv.-9.vi.1989, 7 o 1 ㅇ, 26.vi.-29.ix.1989, emergence traps in pine and beech forests, leg. R. Feldmann $\left(\begin{array}{lllll}6 & 0 & 7 & 9 & \text { mounted on }\end{array}\right.$ slides, rest in alcohol) (most in coll. MB, $10^{*} 1$ \% NHMM, 2 o 3 \% CUMZ). Great Britain: $\sigma^{*}$, England, Oxford, Shotover Plain, grid ref. 42/569059, 7.viii.1976, leg. J.W. Ismay (mounted on slide) (CUMZ). Canada: Ontario, Wellington Co., Guelph, o, 30.v.10.vi.1983, o, 7.-12.ix.1984, mushroom-baited pitfall traps, leg. B.V. Brown (o criticalpoint dried and glued to the side of a pin, o mounted on slide) (DEBU). U.S.A.: Texas, Brazos Co., College Station, Lick Creek Park, 4 ơ, 26.-28.iii.2000, ơ, 30.iii.-5.iv.2000, malaise trap in deciduous forest, leg. M. Buck (coll. MB, DEBU).

\section{Other material examined}

See below $M$. quadriseta (misidentified type material).

\section{Etymology}

The species is named for the yellow colour of its thorax.

\section{Diagnosis}

A bicoloured species with brown frons, yellow to yellowish brown thorax and predominantly brown abdominal tergites. ant about midway between upper sa and al. Third antennal segment brown, with numerous small to medium-sized SPS. Palps yellow, their longest bristles a little longer than their diameter. Labella not inflated, with few spinules below. Notopleuron with two bristles, cleft absent. Scutellum with anterior setae hairlike in male, long in female. Mesopleuron bare. Abdominal venter hairy on segments 36. Epandrium brown, on each side with one stronger, more bristle-like hair which is about as strong as terminal hairs of proctiger. Right side of epandrium with a strongly projecting postero-ventral lobe. Anal tube yellow, shorter than dorsal surface of epandrium. Terminal hairs of proctiger stronger than hairs of cerci. Hypandrial lobes subequal, with decumbent micropubescence. Female T6 subquadrate. T7 Y-shaped. T10 bare. S7 moderately broad, expanded posteriorly. Posterior lobes of sternum of segment 8 each with three enlarged hairs, not sclerotised on internal surface. Vaginal sclerite strongly sclerotised, tapered on right side. Legs yellow, tip of hind femur darkened. Most hairs below basal half of hind femur are longer than those of antero-ventral row in distal half. CI longer than 0.43 . Costal section 1 subequal to sections $2+3$ in both sexes. Subcosta fades away before reaching $\mathrm{R}_{1}$. Hair at base of $\mathrm{Rs}$ short to moderately developed. (2-) 4 ax. Knob of haltere whitish yellow, stem infuscated. 


\section{Description}

Male. Frons about as long as broad, chestnut-brown and strongly contrasting with much paler thorax in mature specimens. Whole frons densely covered in microtrichia, and with 40-75 hairs. ant a little closer to eye margin than to median furrow, rarely midway between them. sa closer together than pre-ocellars. Area around sockets of sa yellowish brown, paler than rest of frons. Cheeks with 3-5 hairs, jowls with 2-3 bristles. Diameter of third antennal segment at most half frontal width. SPS distributed around base of third antennal segment, but most numerous beneath inner face, there being about 4-6 irregular rows. Total number of SPS exceeding 30, diameter $0.005-0.013 \mathrm{~mm}$. Arista brown, with pale basal segments. Cilia hardly longer than diameter of basal joints. Sensilla on base of third aristomere broadly separated. Palps with 5-9 bristles (maximum length $0.048-0.070 \mathrm{~mm}$ ) plus $8-12$ hairs. Prementum with two paits of hairs. Labrum much narrower than diameter of third antennal segment. Each labellum bears 15-20 blunt spinules and some longer hairs on lower surface. Five pairs of pseudotracheae. Ground colour of thorax normally bright yellow (only pteropleura and postnotum slightly tinged brownish). Metafurca pale. Anterior scutellar setae about fourth to (rarely) half as long as posterior ones. Abdominal tergites brown but T1 paler and T5-6 gradually becoming paler towards rear, usually in part yellowish brown. Tergites short-haired but with some stronger setae near postero-lateral corners of T2 and a row of bristles at rear margin of T6. Abdominal venter greyish yellow, sparsely haired but hairs relatively long. Epandrium with 11-17 hairs on left side (Fig. 42). Postero-ventral lobe of right side of epandrium (Fig. 43: pv) strongly convex, well raised above depressed hind margin (Fig. 43: hm). Each cercus with (6-)7(-8) hairs that are weaker than hairs of proctiger. Micropubescence below the latter erect to recurved (Fig. 42). Microtrichia below left hypandrial lobe mostly pointing rearwards, but those near inner margin often directed medially. Four rectal papillae. Postero-dorsal hair palisade present on all segments of front tarsus. Ratios of lengths of the latter about $3.5: 1.6: 1.3: 1.0: 1$. Postero-dorsal setae of hind tibia moderately developed, and spines in apical comb simple. Wing length 1.15$1.65 \mathrm{~mm}$. CI 0.43-0.46. CR 2.1-3.3 : 1.4-2.0 : 1. Longest cc $0.095-0.14 \mathrm{~mm}$. (2-) 3-5 cal. Hair at base of Rs $0.026-0.061 \mathrm{~mm}$ long. Wing membrane lightly tinged grey or brownish (paler than in $M$. bexanophila). First thin vein originates beyond level of Fork of Rs. Female. Differs from male as follows: Third antennal segment a little smaller than in male. SPS less numerous (ca. 15-30), and only in 1-2 rows beneath inner face of third antennal segment. Bristles of palps longer, maximum length $0.056-0.099 \mathrm{~mm}$. Labrum stronger, distinctly broader than third antennal segment. Labella with 13-23 spinules. Anterior scutellars $0.6-0.9 \mathrm{x}$ as long as posterior ones. Abdominal tergites gradually narrowing from $\mathrm{T} 2$ to $\mathrm{T} 6$. The latter about $1.1 \mathrm{x}$ as broad as long. Breadth of anterior notch of T6 one seventh to one eighth of width of tergite. T7 similar to $M$. bexanophila (cf. Fig. 58). T8 with 10-23 hairs. Abdominal S7 with (2-) 4 terminal hairs, similar to $M$. bexanophila (cf. Fig. 65). Sternum 8 covered in microtrichia except margin of posterior lobes and anterior part. Anterior bare area very variable in size. Posterior lobes of sternum 8 (Fig. 87) very similar to $M$. quadriseta. Each lobe with a bulge. Hairs of hypoproct slightly to distinctly crowded towards anterior margin. Cerci $3-4 x$ as long as broad, only with 3-4 short, blunt-tipped hairs at apex. Vaginal sclerite transverse, about $0.12 \mathrm{~mm}$ in greatest extension (Fig. 111). Right side formed as an eye of a needle, encircles the opening of a (hardly visible) tubular organ. Dufour's crop mechanism with moderately long lobes (Fig. 124). Wing length 1.2-2.0 mm. CI 0.45-0.49. CR 2.6 3.4 : 1.6-2.3: 1 . 


\section{Distribution}

Holarctic, hitherto recorded from Germany, the Netherlands, Great Britain, Canada (Ontatio), and the U.S.A. (Texas).

\section{Megaselia correlata (SCHMITZ, 1918)}

(Figs 6, 25, 44, 50, 79, 110, 131)

Apbiochaeta correlata SCHMITZ, 1918: 145 (0).

Megaselia correlata (SCHMITZ). SCHMITZ, 1928: 144.

Megaselia giraudii auctt., nec (EGGER, 1862).

This species was rescued from synonymy with $M$. giraudii by DISNEY (1986), after remounting of the holotype male. Since then a good series of males plus females has been obtained from the canopies of oak trees in England. The female is now described for the first time.

\section{Type material}

Previously examined (DISNEY, 1986).

\section{Other material examined}

Great Britain: England, Oxon, S. Greenwood, Bagley Wood, 3 o 4 o , v.-vi.1983 and vi.1984, leg. T.R.E. Southwood (CUMZ, 1 o 1 \% ZFMK); 3 o 2 \%, Wytham Woods, vi.1983, leg. T.R.E. Southwood (CUMZ); $0^{*}$, Cambridgeshire, Hayley Wood, 20.vi.15.vii.1980, leg. D.M. Unwin (CUMZ); \&, Windsor Great Park, Boar Enclosure, 4.vi.1980, leg. P.J. Chandler (CUMZ), o, Hampshire, New Forest, Keeping Copse, 26.vi.-3.vii.1984, leg. G. Forrester (CUMZ). Germany: ot, Baden-Württemberg, Ulm, 20.v.-10.vi.1981, window trap, deciduous forest, leg. R. Grimm (coll. MB); $\sigma^{\star}$, Rhineland-Palatinate, Mainz, Lennebergwald, 6.-24.v. 1988, emergence trap over soil, pine forest, leg. R. Feldmann (NHMM).

\section{Description}

Ant a little closer to upper sa than to al or exactly midway between these two. Third antennal segment brown, diameter about $0.11-0.12 \mathrm{~mm}$ in both sexes. Less than 10 SPS which are small to medium size $(0.004-0.012 \mathrm{~mm})$. Sensilla on basal part of third aristomere closely approximated (Fig. 6). Labrum of male about as broad as third antennal segment (maximum breadth $0.10 \mathrm{~mm})$, distinctly broader in female $(0.15 \mathrm{~mm})$. Labella bearing 30-40 spinules in male, 30 in female. Thorax brown. Scutellar bristles almost equal in both sexes. Abdominal tergites brown, in female $\mathrm{T} 5$ partly and $\mathrm{T} 6$ often almost entirely yellowish orange. Abdominal venter hairy on segments 3-6, in female hairs of segments 3-5 reduced to microscopic setulae. Hypopygium see DISNEY (1989a: Fig. 403). Left side of epandrium with 18-30 hairs but no stronger bristle-like hair. A postero-ventral lobe developed on left side. Microtrichia below proctiger semi-erect, pointing rearwards. Right hypandrial lobe slightly longer than left one. Micropubescence of the latter erect to recurved, that of right lobe pointing rearwards. Aedeagus with very long slender process (Fig. 25). Female abdominal tergites 2-6 as Fig. 44. T6 subtriangular, anterior notch indistinct. T7 very narrow (Fig. 50). T10 usually bare, but rarely with 1 or very rarely with 2 hairs. S7 a brown long narrow strip that widens a little at rear end, 
which is usually a little paler than rest. Lobes at rear of sternum 8 with three long and 23 shorter hairs standing in front of rear margin (Fig. 79). Lobes covered in microtrichia except marginal fringe, area in front of lobes devoid of micropubescence. Lobes without bulges. Hairs of hypoproct not crowded towards anterior margin. Cerci with usual 5+1 hairs plus group of 6-7 short blunt-tipped hairs at apex. Vaginal sclerite absent but a lightly pigmented tubular organ present (Fig. 110). Dufour's crop mechanism rounded behind (Fig. 131). Rectal papillae: 4 (male), 3-4 (female). Legs brown. Wing length 1.35$1.7 \mathrm{~mm}$ (male), 1.9-2.2 mm (female). CI 0.465-0.495 (male), 0.48-0.52 (female). CR 2.0$3.0: 1.5-1.8: 1$ (male), 3.0-4.1:2.0-2.5: 1 (female). cc of costal section $30.11-0.14 \mathrm{~mm}$. 3-6 cal, 4-6 ax. A normal hair at base of Rs $(0.067-0.083 \mathrm{~mm})$.

\section{Remarks}

See below $M$. breviseta.

\section{Distribution}

Only known from Germany, Great Britain and the Netherlands.

\section{Megaselia densior SCHMITZ, 1927}

(Figs 3, 34-35, 45, 55, 66, 68, 99, 129)

Megaselia densior SCHMTTZ, 1927: $131\left(0^{*}+\right.$ ).

Megaselia coulsoni DISNEY, 1987b: 135 (đ). Syn. n.

Megaselia nigrescens auctt., nec (WOOD, 1910). DISNEY, 1985: 244.

Megaselia badia auctt., nec SCHMTZ, 1938. FAIN \& GREENWOOD, 1991: 195; DISNEY, 1994: 165; FELDMANN, 1992: 205 (partim, see also below M. citrinella and M. baraldlundi).

This species was recorded from Britain (DISNEY, 1985) after comparison of material from Scotland and England with a male from Limbricht (Holland) attributed to this species by Schmitz (but actually being a misidentified $M$. immodensior sp. n.). Since then RHLD has borrowed and remounted a male syntype of $M$. densior. This proves to be a different species to the previously examined voucher specimen, and has been designated the lectotype of $M$. densior. The species erroneously attributed to this species in Britain are described as new (see $M$. immodensior sp. n. and $M$. raruvesiculae sp. n.). The true $M$. densior has been previously recorded as $M$. badia and $M$. coulsoni.

As previously reported (DISNEY, 1993), the unique holotype of $M$. coulsoni only has two, not three, notopleural bristles. Furthermore the subcosta runs to $\mathrm{R}_{1}$. Consequently it runs to couplet 212 of the key to British species (DISNEY, 1989a). However, the examination of a greater range of material serves to indicate that the apical third of the subcosta in M. coulsoni' is variably developed. Indeed, it now seems that it typically has the subcosta free and so most specimens key out at couplet 225 (to $M$. badia) instead. The greatly reduced micropubescence of the hypandrial lobes in the males of this species will immediately distinguish it from several related species. It is now clear that many specimens from Great Britain attributed to $M$. badia are in fact $M$. densior. Furthermore these include the holotype of $M$. coulsoni, which is therefore herewith synonymised with $M$. densior. The true $M$. badia is synonymised with $M$. quadriseta below. 


\section{Type material}

$M$. densior. Lectotype (herewith designated by RHLD): o". "Megaselia densior SCHMITZ Syntype", "Cotype", no data label (i.e. probably either from Eberswalde in Germany or from Sittard in the Netherlands, see SCHMITZ, 1927) (remounted) (ZFMK). Paralectotypes (not examined): 2 \% 2 ㅇ. Germany: 옹, Brandenburg, Eberswalde, ex Bupalus piniarius pupae (Lep.); $0^{*}$, Rhineland-Palatinate, Bendorf, 16.vi.1920, this specimen is not labelled as a syntype but was mentioned in SCHMrTZ's original description (hypopygium badly damaged). The Netherlands: 9 , Sittard, 2.ix.1919. Without locality: o" "65 13" (all ZFMK).

M. coulsoni. Holotype: đ. Great Britain: England, Cumbria, Tail Brigg, 22.ix.1976, leg. J.C. Coulson (mounted on slide) (CUMZ).

\section{Other material examined}

Germany: Bavaria, Senden Hittistetten, ox, 22.vii.-5.viii.1992, emergence trap over soil, spruce forest; ${ }^{*}$, emerged 4.-11.ix.1992, reared from dead Arianta arbustorum (bait exposed 30.vii.-12.viii.1992); 1 o 1 \% , emerged 28.vii.-4.viii.1993, reared from dead Arion ater (bait exposed 15.vi.-6.vii.1993); 11 o 12 ㅇ, emerged 1.-22.ix.1993, reared from buried liver baits (exposed 30.vii.-13.viii.1993), all leg. M. Buck ( 7 \% 5 coll. MB, 3 o 3 o CUMZ, 4 of 5 \& ZFMK). Ca. 750 further specimens from the same locality (see Tables 1, 2). Rhineland-Palatinate, Mainz, Lennebergwald, ${ }^{*}, 26$. vii.-10.viii.1988, 우, 15.30.viii.1989, emergence trap over soil, pine forest, leg. R. Feldmann (NHMM). The Netherlands: Linschoten, 17.vi.1922, leg. J.C.H. de Meijere (misidentified as M. offuscata by Schmitz) (ZMAN). Great Britain: 5 \%, England, N. Yorkshire, Malham Tarn, Kitchen Garden Wood, grid ref. 34/892674, 26-28.vii.1983, leg. RHLD, one with mite larva of Microtrombidium sp. B attached (host fly misidentified as M. badia) (CUMZ); $\sigma^{*}$, Malham Tarn Fen, grid ref. 34/8867, 29.vii.1977, on flowers of Angelica sylvestris (misidentified as M. badia) (CUMZ); o*, Essex, Epping Forest, Cuckoo Pits, 25.1x.1982, leg. I.F.G. McLean (CUMZ).

\section{Description}

The description provided by SCHMITZ \& DELAGE (1981) is to be complemented as follows: ant of frons closer to al than to upper sa. Antenna as in Fig. 3. SPS numerous $(>30)$, distributed around base of third segment. SPS most frequent on inner face of segment, there being arranged in 4-5 (male) or 2-3 irregular rows (female). Diameter 0.004-0.015 mm (Fig. 3). Labella with 20-33 blunt spinules, slightly less in female (1924). Notopleural cleft absent. Abdominal venter hairy on segments 3-6 (in female rarely some hairs on segment 2 as well), those of posterior row of segment 6 enlarged. Hypopygium as in Figs 34-35. Epandrium with 11-23 hairs on left side. Hairs weaker than strongest hairs of abdominal segment 6 . Cercus normally with seven hairs which are about as strong as stronger hairs of epandrium. Terminal hairs of proctiger a little stronger than the latter. Microtrichia below proctiger semi-erect, pointing rearwards. Hypandrial lobes of subequal length. Microtrichia of ventral surface of lobes short and decumbent, pointing rearwards. Female abdominal tergites 2-6 gradually decreasing in width posteriorly. T6 trapezoid, 0.8-1.1x as broad as long (Fig. 45). Breadth of anterior notch one third to one fourth of maximum breadth of tergite. $T 7$ moderately expanded towards anterior margin (Fig. 55). T8 rectangular, with 8-26 hairs, mainly standing at or close to lateral margins. $T 10$ bare. S7 linear, with 2(-3) enlarged hairs at posterior margin 
(Fig. 66). Segment 8 covered in microtrichia except posterior lobes of sternum (Fig. 68). Each lobe with only one enlarged hair standing well off posterior margin. Lobes without bulge, and margin somewhat sclerotised, tinged brownish. Hairs of hypoproct somewhat crowded towards anterior margin. Cerci cylindrical, about $3 \mathrm{x}$ as long as broad. Each cercus with $5+1$ long hairs and with a group of three short and stout, somewhat blunt-tipped hairs at apex. Internal vaginal sclerite roughly triangular, with rounded posterior margin, gradually unsclerotised towards anterior corner (Fig. 99). Dufour's crop mechanism with short, widely separated lobes (Fig. 129). Number of rectal papillae: 2-4 (male), 4 (female). Wing length 1.2-1.85 mm (male), 1.4-2.2 mm (female). CI 0.43-0.475 (male), 0.445-0.49 (female). CR 2.1-3.3 : 1.2-1.7 : 1 (male), 2.7-3.8 : 1.7-2.4:1 (female). Subcosta indistinct in distal fifth, sometimes reaching $\mathrm{R}_{1}$ (in female usually somewhat better developed than in male). Maximum length of cc 0.085-0.13 mm. 3-6(-8) cal, (2-)3$4(-5)$ ax. Hair at base of Rs small (0.018-0.055 mm), rarely absent.

\section{Recognition}

While this species is distinguished from similar species in the keys above, males with subcosta reaching $\mathrm{R}_{1}$ will be found to run to couplet 212 of the key to British Megaselia (DISNEY, 1989a), to $M$. largifrontalis SCHMITZ, 1939. The latter, however, has a different hypopygium (DISNEY, 1989a: Fig. 441) and much browner femora.

\section{Distribution}

The true $M$. densior is hitherto only known from Germany, the Netherlands and England. The records from other countries need confirmation.

\section{Megaselia fisheri (MALLOCH, 1912)}

(Figs 67, 74)

Aphiochaeta fisheri MALLOCH, 1912: $463(\%)$.

Apbiocbaeta inaequalis MALLOCH, 1912: 464 (\% क). Primary homonym of M. inaequalis Brunetti, 1912. Apbiocbaeta tertia BRUES, 1915: 134 (nom. n. for inaequalis MALLOCH). BORGMEIER, 1966: 34 (synonymy). Megaselia fisheri (MALLOCH). BRUES, 1950: 71.

\section{Type material}

M. fisheri. Holotype: +. U.S.A.: Maryland, Plummers Island, 16.v.1907, leg. A.K. Fisher (remounted) (USNM). Paratype (not examined): ㅇ, same locality as holotype, 30.v.1907, leg. W.L. McAtee (USNM).

$M$. tertia. Not examined. The synonymy of this species with $M$. fisheri needs confirmation.

The Nearctic $M$. fisheri had to be included in the present revision because published descriptions of this species are too superficial to distinguish it from the Holarctic M. citrinella sp. n.

\section{Description}

Female. As described by BORGMEIER (1966) with the following additions: Frons a little broader than long. ant closer to al than to upper sa and closer to eye margin than to median furrow. SPS of third antennal segment small to medium-sized (ca. $0.008 \mathrm{~mm}$ ), 
moderately numerous. Labella normal, each with 23 relatively long spinules below. Thorax with two notopleural bristles. Abdominal tergites 2-6 brownish yellow, laterally a little darkened. The darkened area extends laterally on the pleura below level of spiracles. Venter hairy on segments 3-6, hairs well developed. T7 long and narrow, expanded anteriorly, similar to $M$. cf. albicans (Fig. 51). T10 bare. S7 narrow, with three enlarged hairs posteriorly (Fig. 67). Sternum 8 covered in microtrichia except rear margin of posterior lobes. The latter are closely approximated (Fig. 74) unlike any other species covered by the present work. Each lobe bears three enlarged hairs, the middle of which is inserted well before the hind margin. Lobes somewhat bulging but bulges not projecting behind hind margin. Hairs below hypoproct more or less evenly spaced, not crowded towards anterior margin. Cerci with normal $5+1$ long hairs plus three short blunt hairs near apex. Vaginal sclerite apparently absent (a triangular sclerite of $0.032 \mathrm{~mm}$ length in segment 6 of the holotype female probably represents an abnormal development). Dufour's crop mechanism with two lobes. Hairs below basal half of hind femur longer than those of antero-ventral row in distal half. Wing length $2.65 \mathrm{~mm}$. CI 0.48 . CR 3.6-3.7 : 2.2 : 1. Longest cc $0.15 \mathrm{~mm}$ long. $6-7 \mathrm{cal}, 4-5$ ax. Hair at base of Rs small.

\section{Distribution}

Nearctic (U.S.A., Canada). Published records are not reliable as the Nearctic Megaselia species are badly in need of revision.

\section{Megaselia giraudii (EGGER, 1862)}

(Figs 13, 17-18, 27, 47, 49, 64, 76, 94, 122-123)

Phora giraudii EGGER, 1862: 1235 ( $\%$ ).

Aphiochata giraudii (EGGER). BRUES, 1904: 366.

Megaselia giraudii (EGGER). SCHMTTZ, 1929: 197.

Pbora rata Collin in WOOD, 1908: 172 (o* $\%$ ). SCHMTTz, 1929: 198 (synonymy).

Apbiochaeta dyari MALLOCH, 1912: 493 (ळ). BORGMEIER, 1962: 484 (synonymy).

Aphiochaeta comosa Santos Abréu, 1921: 52 (o). Syn. n.

SANTOS ABRÉU (1921) described a number of species from the Canary Islands, but these descriptions have frequently proved inadequate for the recognition of species in the light of subsequent knowledge of the complexities of Megaselia taxonomy. Furthermore most of the type material has been lost. SANTOS ABRÉU \& SCHNITZ (1934) therefore provided a critically evaluated list of the Phoridae of the Canary Islands prior to a detailed paper by SCHMITZ (1936) based upon it and much fresh material collected by R. Frey. Two of the species described by SANTOS ABRÉU were $M$. comosa and $M$. intermedia, the former on the basis of the male sex only and the latter from both sexes. The type material of both species has been lost. The existing voucher material, therefore, is that collected by Frey and then attributed to these species by SCHMITZ (1936). A series of both sexes was referred to $M$. comosa but with the following amendments. The females were attributed to $M$. intermedia but the males to $M$. comosa. As the male clearly differed from the description of M. intermedia, and as it was assumed that the males and females collected by Frey were conspecific, SANTOS ABRÉU \& SCHMTTZ (1934) synonymised the females of $M$. intermedia with $M$. comosa but not the males. They assumed that SANTOS ABRÉU had originally associated the male and female attributed to $M$. intermedia in error 
and that Frey's series of males and females, which they attributed to $M$. comosa, were correctly associated. The implication was that the lost male of $M$. intermedia represented the only recorded specimen of this species and its female was unknown. BORGMEIER (1968) documented this but did not then list $M$. intermedia either as a valid species or under species dubiae. Subsequently, therefore, $M$. intermedia was listed under doubtful species (DISNEY, 1991).

In the Museum Koenig a series of females and a male collected by Frey are placed under $M$. comosa, along with a specimen labelled $M$. intermedia but which has lost its abdomen. The male is one of the specimens listed by SCHMITZ (1936) and has therefore been designated the neotype of $M$. comosa. This specimen and a female also listed by SCHMITZ (labelled "Gr. Canaria, Atalaya, 25.VI. R. Frey. Fl. 359 M. comosa") have been remounted on slides. This neotype male proves to be $M$. girandii. Accordingly $M$. comosa is herewith synonymised with $M$. giraudii.

The remounted female does not even belong to the $M$. giraudii complex, as evidenced by the rear margin of abdominal sternum 8 having a single large lobe bearing numerous bristle-like hairs, in place of two small lobes with fewer and shorter hairs. It is concluded, therefore, that this female is $M$. intermedia. It is accordingly designated the neotype of this species. All the other females in the series in the Museum Koenig are conspecific. As $M$. intermedia does not belong to the $M$. giraudii complex a new description will be published by RHLD elsewhere.

\section{Type material}

M. giraudii. Lectotype (desig. DISNEY, 1986: 116): +. Austria: no data, "Alte Sammlung" (remounted) (NHMW). Paralectotypes: not examined.

M. rata. Lectotype (herewith designated by RHLD): o . Great Britain: England, Stoke Wood, 11.viii.1905 "Phora rata J.H. WoOD", "cotype", "BMNH(ㅇ) 239014" (BMNH). Paralectotypes: not examined.

M. dyari. Holotype: o . Canada: British Columbia, Kaslo, 29.v. (no year given), leg. H.G. Dyar, "USNM 14891" (remounted) (USNM).

M. comosa. Neotype (herewith designated by RHLD): o*. Spain: Islas Canarias, Tenerife, Tacoronte, "210 1353" (remounted) (ZFMK).

\section{Other material examined}

Germany: Baden-Württemberg, Ulm, Eselsberg, ơ, 13.-27.ix.1982, emergence trap over soil, spruce forest, leg. M. Roth; o emerged 16.-24.vii.1992, đ, 14.-21.viii.1992, reared from dead Helicella itala (bait), leg. M. Buck; 2 + , Langenau, 15.vii.-5.viii.1993, trap baited with lignicolous fungus Dacrymyces stillatus growing on agar plate, leg. R. Sipple; Bavaria, Senden Hittistetten, 3 o, 14.-28.vi.1993, odour trap with n-hexane; $9,26 .-28 . i v .1993$, carrion trap baited with Helix pomatia; o , 5.-12.viii.1993, 1 o 2 o , 26.viii.-16.ix.1993, carrion trap baited with kidney; 103 \% , emerged 2.-9.vi.1993, reared from buried liver baits (exposed 27.iv.-12.v.1993); 1 \% 1 9, emerged 14.-21.vii.1993, reared from decaying larval/pupal tents of Yponomeuta sp. (Lep.) (collected 23.vi.1993); Ca. further 570 specimens from same locality see Tables 1, 2, all leg. M. Buck (coll. MB); $0^{*}$, RhinelandPalatinate, Eifel mountains, near Adenau, 15.vii.1990, emergence trap over soil, spruce forest, leg. M. Engel; o*, Lower Saxony, Solling, 17.-24.viii.1967, emergence trap over soil, beech forest; 20 , North Rhine-Westphalia, Köln-Poll, 19.-26.iv.1994, malaise trap, leg. J. Franzen (all in coll. G. Weber). The Netherlands: + , Valkenburg, 4.v.1933 (misidentified as $M$. albicans) (ZFMK). 
Although $M$. giraudii is the commonest and probably the most widely distributed species in its group it has never been adequately characterised. It is extremely similar to $M$. parnassia and can only be reliably distinguished from the latter by the new characters given in the refined keys above. It should be noted that Fig. 399 in DISNEY (1989a) was from a specimen that has proved to be $M$. parnassia, the hypopygium being tilted away from the observer. Fig. 400 of $M$. parnassia is with the hypopygium tilted towards the observer.

\section{Description}

As in SCHMITZ \& DELAGE (1981) plus following amplifications: ant of frons closer to upper sa than to al. SPS very numerous ( $>30$, in male usually $>50$ ), tightly packed and distributed around base of third antennal segment, but most common on inner face; there being arranged in 3-6 (male), or 2-3 irregular rows (female). SPS of small to medium size, diameter $0.004-0.012 \mathrm{~mm}$. Sensilla on swollen base of third antennal segment usually well separated. Bristles of palps relatively short in male (maximum length 0.05$0.07 \mathrm{~mm}$ ), not shortened in female (max. 0.07-0.105 mm). Labella with 17-28 blunt spinules in male and female. Notopleural cleft with a small V-shaped ridge behind (Fig. 13). Abdominal venter hairy on segments 3-6. Hypopygium as in Figs 17-18. Left side of epandrium with 13-27 hairs (i.e. as numerous as in $M$. parnassia). Cerci with 7-9(-10) hairs. Microtrichia of ventral face of proctiger semi-erect, pointing rearwards (cf. Fig. 40). Hypandrium as in Fig. 27. Left hypandrial lobe more or less translucent, at most slightly tinged greyish. Microtrichia of right lobe semi-erect to decumbent. Female abdomen: T6 1.20-1.45x as broad as long (Fig. 47). Anterior notch small, breadth one fifth to one seventh of breadth of tergite near anterior margin. T7 Y-shaped, shallowly notched anteriorly (Fig. 49). T8 rectangular, with 9-32 hairs, mainly at lateral margins or close to it. T10 bare. S7 relatively broad, with (2-)3-4 enlarged hairs at apex (Fig. 64), sometimes anterior sixth to third with a stronger sclerotised median stripe. Sternum 8 micropubescent in posterior half to third, including area between posterior lobes. Sternal lobes not sclerotised on internal surface, each one with a small, somewhat posterolaterally projecting bulge (Fig. 76). The latter with three (exceptionally four) enlarged hairs, that stand very close to each other on the apex of the bulge. Hairs of hypoproct notably crowded towards anterior margin (Fig. 94), microtrichia lacking between the crowded hairs. Cerci cylindrical, about $3-4 \mathrm{x}$ as long as broad, with normal $5+1$ long hairs plus (2-)3(-4) short blunt-tipped hairs at apex. Vaginal sclerite lacking. Posterior lobes of Dufour's crop mechanism long (Fig. 123), but frequently little or not divergent (Fig. 122). Four rectal papillae in both sexes. Wing length $1.15-1.95 \mathrm{~mm}$ (male), $1.5-2.4 \mathrm{~mm}$ (female). CI relatively low, $0.44-0.47$ in male, $0.44-0.48$ in female. CR 2.5-3.9: 1.4-2.1:1 (male), 3.0-3.8: 1.6-2.2: 1 (female). Longest cc 0.10-0.175 mm. (2-)3-6(-8) cal, (3-)4-5(7) ax, the latter slightly shorter or equal to longest costal cilia. Hair at base of Rs $0.030-$ $0.124 \mathrm{~mm}$ long, exceptionally missing.

\section{Distribution}

M. giraudii is widely distributed in the Holarctic Region (DISNEY 1991) including Israel and the Canary Islands (Tenerife). The only record from the Oriental Region (Nepal) (DISNEY, 1991) was based on a misidentified specimen which belongs to an undescribed species. 


\section{Megaselia glabrimargo BUCK sp. n.}

(Figs 33, 85, 115)

\section{Type material}

Holotype: đ. Sweden: Torne Lappmark, Abisko, 13.-17.vii.1991, yellow water trap, low Salix/Vaccinium scrub, leg. M. von Tschirnhaus (mounted on slide) (ZFMK). Paratypes: 3 o 4 ㅇ. As holotype except 1 o from white water trap (coll. MB).

\section{Etymology}

The species is named for the bare hind margin of the left hypandrial lobe of the male hypopygium.

\section{Diagnosis}

A generally brown species. ant a little closer to al than to upper sa. Third antennal segment with numerous ( $>30$ ) SPS of small to medium size. Palps dusky yellow, with longest bristles longer than maximum width of palp. Labella normal. Two notopleural bristles, no cleft. Anterior scutellar bristles long in female, short in male. Mesopleuron bare. Abdominal venter hairy on segments 3-6. Epandrium only with short hairs that are weaker and shorter than those of cerci. Anal tube pale brown, relatively short. Terminal hairs of proctiger stronger than those of cerci. Left hypandrial lobe longer than right one. Microtrichia of both lobes decumbent, pointing rearwards. Left lobe with bare area at postero-lateral margin. Female T6 subquadrate, anteriorly notched. T10 bare. T7 Yshaped. S7 bar-like, expanded posteriorly. Posterior lobes of sternum 8 with three long hairs. Vaginal sclerite forming a large loop. Legs pale brown, apical part of hind femur darkened. Longest hairs below basal half of hind femur a little longer than those of antero-ventral row in distal part. CI at least 0.44. Costal section 1 about as long as $2+3$, relatively longer in female. cc of normal length. Subcosta does not reach $\mathrm{R}_{1}$. Hair at base of Rs usually present. (2-)3(-4) ax, about as long as cc of section 3. Knob of haltere dusky yellow, tip usually brownish; stem brown.

\section{Description}

Male. Frons a little broader than long, with 28-65 hairs, dulled by dense microtrichia. ant closer to eye margin than to median furrow. sa closer together than pre-ocellars. Third antennal segment brown, diameter a little less than half frontal width. SPS not as densely packed as in $M$. giraudii but distributed around third segment, from base to about level of insertion point of arista. Only a few vesicles near dorsal face, highest density beneath inner face where they are arranged in 4-5 loose irregular rows. Diameter small to medium $(0.005-0.015 \mathrm{~mm})$. Arista brown. Pubescence of third aristomere about as long as diameter of basal segments. Sensilla at base of third aristomere usually well separated. Palps with 5-8 bristles and some small hairs. Maximum length of bristles $0.085-0.095$ mm. Prementum with two pairs of hairs. Width of labrum about half diameter of third antennal segment. Labella with 5 pseudotracheae, 20-23 spinules and some longer hairs on lower face. Anterior scutellar setae longer than hairs of scutum, $0.25-0.45 \mathrm{x}$ as long as posterior ones. Abdominal venter grey, with short hairs except those at rear of segment 6 which are bristle-like. Tergites short-haired with some longer hairs at postero-lateral corners of $\mathrm{T} 2$ and a row of long bristles at rear margin of $\mathrm{T} 6$. The latter are stronger 
than any hair of hypopygium. Hypopygium as Fig. 33. Left side of epandrium with 1623 hairs. Hairing of epandrium relatively uniform, gradually becoming a little stronger towards lower margin. Left side of epandrium without postero-ventral lobe. Cerci with 7(-9) hairs. Micropubescence below proctiger semi-erect, inclined rearwards. 2-3 rectal papillae. Fore tarsus with postero-dorsal hair palisade on all five segments. Ratios of lengths of front tarsal segments ca. $2.6: 1.3: 1.15: 0.95: 1$. Postero-dorsal bristles of hind tibia moderately developed, spines in apical comb simple. Wing length $1.35-1.55$ $\mathrm{mm}$. CI $0.44-0.47$. CR. 2.2-2.5 : 1.2-1.4 : 1. Longest cc $0.10-0.115 \mathrm{~mm}$ long. $3-4$ cal. Hair at base of Rs variable, minute to moderately developed (0.019-0.056 mm), sometimes missing. Wing membrane lightly tinged brownish. First thin vein originates beyond fork of Rs. Female. Similar to male but differs at follows: SPS less numerous than in male, beneath inner face only in 2-3 irregular rows. Labrum stronger than in male, about as broad as third antennal segment. Labella only with 17-21 spinules below. Anterior scutellar bristles relatively short, only $0.58-0.68 \mathrm{x}$ as long as posterior ones. Width of abdominal tergites gradually decreasing from T2 to T6. The latter is $1.2-1.3 \mathrm{x}$ as broad as long, and only a little narrower posteriorly than anteriorly. Width of anterior notch about one fifth of maximum breadth of tergite. Hairs of abdominal venter scarce and short except posterior row of segment 6. T7 broadly expanded anteriorly, similar to $M$. bexanophila (Fig. 58). T8 rectangular, with 7-15 hairs. S7 relatively broad, distinctly expanded and with 4(-5) enlarged hairs posteriorly, similar to $M$. giraudii (Fig. 64). Sternum 8 covered in microtrichia except bare hind margin of posterior lobes (Fig. 85). Each lobe with a bulge that slightly projects laterally. Bulges with three long hairs at or very close to apex. Hairs of hypoproct a little crowded anteriorly. Cerci about $3 \mathrm{x}$ as long as broad, with $5+1$ long hairs and an apical group of 3(-5) short blunt hairs. Vaginal sclerite posteriorly with an irregular extension (Fig. 115). Dufour's crop mechanism similar to $M$. quadriseta (Fig. 126). (3-) 4 rectal papillae. Wing length $1.6-1.75 \mathrm{~mm}$. CI 0.46-0.47. CR 2.8-3.1 : 1.4-1.9 : 1 .

\title{
Distribution
}

Only known from the type locality in Swedish Lapland.

\section{Megaselia haraldlundi DISNEY, 1995}

(Figs 8, 28-29, 78, 93)

\author{
Megaselia baraldlundi DISNEY, 1995: $113\left(0^{*}\right)$. \\ Megaselia badia auctt, nec SCHNITZ, 1938. SCHMTZ, 1938: 193 (partim); FELDMANN, 1992: 205 (partim, see \\ also below $M$. citrinella and $M$. densior).
}

This species was only known from the type series (two males). Among new material the hitherto unknown female was discovered. It is described below.

\section{Type material}

Holotype: $\sigma^{\top}$. Germany: North Rhine-Westphalia, Eifel mountains, near Adenau, 20.v.3.vi.1990, emergence trap over soil, spruce forest, leg. M. Engel (mounted on slide) (CUMZ). Paratype: $0^{*}$, same data as holotype.

\section{Other material examined}

Germany: ㅇ, Bavaria, Allgäu, Illasberg, 3.vi.1941, “septentrionalis?”, “65 20”, one wing mounted on separate slide (ZFMK); Baden-Württemberg, Ulm, Eselsberg, 2 o", 27.v.- 
10.vi.1981, yellow water trap, 2 o, 27.vv-10.vi.1981, white water trap, o, 5.-10.vi.1981, blue water trap, deciduous forest, leg. R. Grimm (coll. MB); Langenau, ơ, 20.v.-8.vi.1998, emergence trap over dead wood, of, 18.-29.vi.1998, water trap, of, 4.-18.vi.1998, trap baited with agar plate, 4 \% , 18.vi.-9.vii.1998, trap baited with lignicolous fungus Fomitopsis pinicola growing on agar plate, 20 , 18.-29.vi.1998, $0^{*}, 9 .-23$.vii. 1998, traps baited with lignicolous fungus Ophiostoma piceae growing on agar plate, leg. A. Kopf (coll. MB); Rhineland-Palatinate, Mainz, Lennebergwald, 9 or 8 o , 20.iv.-8.vi.1988, 7 o 6 o , 10.iv.26.v.1989, emergence traps over soil, beech-pine and pine forest, leg. R. Feldmann (coll. MB, 1 o 1 क NHMM, 1 o 1 ㅇ CUMZ); ơ, Lower Saxony, Solling, 29.vi.-6.vii.1967 (SNMB). Ireland: misidentified paratype of $M$. badia (see below this species). Norway: o, without locality, vii.1991, reared from sheep carcass (or the soil beneath), leg. M. Drolshammer (CUMZ).

\section{Description}

The original description can be supplemented as follows: Third antennal segment in female smaller than in male, diameter $(0.11-0.14 \mathrm{~mm})$ a little less than half frontal width. This species is unusual in having only 3-6 SPS in the third antennal segment (Fig. 8). SPS small to large $(0.004-0.020 \mathrm{~mm})$, normally situated beneath medial face of third antennal segment. The upper SPS are smaller than the lower ones. Sensilla at base of third aristomere well separated, exceptionally closely approximated. Labrum in female better developed than in male, $0.13-0.18 \mathrm{~mm}$ broad, broader than third antennal segment. Number of spinules below labella a little higher than usual, 21-34 in male, 20-30 in female. Anterior pair of setae of scutellum $0.32-0.45 \mathrm{x}$ (male) or $0.62-0.81 \mathrm{x}$ (female) as long as posterior pair of bristles. The hypopygium is as Figs 28-29. Left side of epandrium with 20-30 hairs. On right side hind margin below anal tube strongly receding, not vertical or convex as in many other species. Cerci with $7(-9)$ hairs. Microtrichia below proctiger mostly semi-erect and pointing rearwards, except in middle third where they are erect to recurved. Width of tergites of female abdomen gradually decreasing from segment 2 to 6 . Female venter hairy on segments (2-)3-6, the hairs being well developed. $T 6$ trapezoid, $1.2-1.3 \mathrm{x}$ as broad as long, anteriorly only a little broader than posteriorly. Width of anterior notch one third to one fifth of tergal width. T7 Y-shaped, not very broad anteriorly, similar to $M$. giraudii (Fig. 49). T8 rectangular, with $14-20$ hairs. T10 bare. S7 relatively broad, similar to $M$. girandii (Fig. 64), but rarely with stronger sclerotised median stripe anteriorly. Segment 8 completely covered in microtrichia, except bare hind margin of sternal lobes (Fig. 78). Sternal lobes bulging, the bulges projecting laterally. Each bulge with three enlarged hairs that are not as closely approximated to each other and not as close to apex as in $M$. giraudii. Hairs of hypoproct hardly crowded towards anterior margin (Fig. 93). Cerci about $3 x$ as long as broad, with usual $5+1$ long hairs plus an apical group of 3(-4) short blunt-tipped hairs. No vaginal sclerite. Lobes of Dufour's crop mechanism shorter than in $M$. giraudii, similar to $M$. bexanophila (Fig. 125). In both sexes usually with four rectal papillae, one very small male specimen only had two. Wing length 1.35-2.0 mm (male), 1.9-2.6 mm (female). CI 0.47-0.48 (male), 0.47-0.495 (female). CR 2.6-3.4 : 1.5-1.9: 1 (male), 2.9-3.3: 1.6-2.0: 1 (female). Longest cc 0.125-0.175 mm. (3-) 4-8(-9) cal, (2-)3-5 ax. Hair at base of Rs minute to well developed (0.018-0.070 $\mathrm{mm})$, rarely absent.

\section{Distribution}

So far only known from Germany, Ireland and Norway. 


\section{Megaselia hexanophila BUCK sp. $\mathbf{n}$.}

(Figs 15-16, 26, 58, 65, 71, 102, 125)

Megaselia quadriseta auctt, nec (SCHMTZ, 1918).

Megaselia sanguinea auctt., nec (SCHMITZ, 1922).

\section{Type material}

Holotype: ${ }^{*}$. Germany: Bavaria, Senden Hittistetten, 16.-23.viii.1993, odour trap baited with $\mathrm{n}$-hexane, leg. M. Buck (critical-point dried and glued to the side of a pin) (ZFMK). Paratypes: $630^{\star}, 62$ o. Germany: same locality as holotype, o , 5.-10.v.1993, $3 o^{*} 1$, 19.-24.v.1993, o , 24.v.-1.vi.1993, odour trap baited with n-hexane/1-PE; o , 24.v.1.vi.1993, o , 2.-9.viii.1993, 4 o 3 o , 9.-16.viii.1993, odour trap baited with n-hexane; 9 , 22.-29.vii.1993, cartion trap baited with kidney (mounted on slides); further 55 o 52 \% , 5.v.-20.ix.1993, odour traps, all leg. M. Buck (most in coll. MB [in alcohol], 3 ơ 3 o CUMZ [mounted on slides], 10 o 9 क ZFMK [critical-point dried and glued to the side of a pin]). The Netherlands: Valkenburg, ๆ, 25.v.1942, "phoenicura", \&, 10.vii.1941, "Meg. (M.) quadriseta SCHMTZ”, leg. H. Schmitz (remounted) (ZFMK).

\section{Other material examined}

Germany: Ca. further 40 specimens from the type locality (see Tables 1,2). The Netherlands: o , Valkenburg, 9.vi.1942, "sanguined" (ZFMK); see also below M. quadriseta (misidentified type material).

\section{Etymology}

The species is named after its preference for traps baited with n-hexane.

\section{Diagnosis}

A distinctly coloured species with orange-yellow thorax, chestnut-brown head and brown abdomen. ant slightly lower on frons than al, about midway between upper sa and al. Third antennal segment of normal size, with enlarged but not very numerous SPS. Palps yellow with longest bristles slightly longer than maximum diameter. Labella not inflated. Notopleuron with two bristles. Notopleural cleft of male long but weakly developed. Anterior scutellars long and bristle-like in female, variable in male (normally hair-like but sometimes enlarged). Mesopleuron bare. Abdominal venter hairy on segments 3-6. Epandrium brown, with one enlarged hair on each side. Anal tube dusky yellow, longer than dorsal face of epandrium, and pointing downwards. Terminal hairs of proctiger stronger than hairs of cerci, about as strong as strongest hair of epandrium. Left hypandrial lobe longer than right one, with long erect to recurved micropubescence. Female T6 trapezoid, anteriorly notched. T7 Y-shaped. T10 bare. S7 bar-like, expanded near posterior margin. Sternal lobes of segment 8 internally sclerotised, each with three long hairs posteriorly. Vaginal sclerite minute, apparently encircling a gland opening. Legs yellow, tip of hind femur darkened (often also tip of hind tibia). Most hairs below basal half of hind femur longer than those of antero-ventral row in distal half. Costa long, CI more than 0.46 . Costal section 1 shorter to equal to sections $2+3$ in male, relatively longer in female. cc long. Subcosta does not reach $\mathrm{R}_{1}$. Usually with a very small hair at base of Rs. (2-)3-4(-5) ax, subequal to cc of section 3. Knob of haltere pale yellow, stem brownish. 


\section{Description}

Male. Frons brown, usually paler anteriorly, slightly longer than wide, with 50-90 hairs, and dulled by dense microtrichia. ant a little closer to eye margin than to median furrow. sa closer together than pre-ocellars. The latter as far apart from each other as from the medio-lateral. Cheeks bearing 2-7 hairs, jowls with 1-3 bristles. Third antennal segment brown, subglobose, maximum diameter about half frontal width. With about 10-20 SPS in a single irregular row around base of segment, diameter 0.012-0.031 mm. Arista brown, basal two segments paler. Pubescence of third segment slightly longer than diameter of basal joints. Sensilla on base of third aristomere normally well separated, exceptionally closely approximated. Palps pale dusky yellow, with $6-14$, short to medium long bristles of (maximum length 0.05-0.09 mm), and 6-13 hairs. Prementum with two pairs of hairs. Width of labrum distinctly less than diameter of third antennal segment. Each labellum with 5 pseudotracheae, ca. 20 pale spinules, and some longer hairs below. Ground colour of thorax orange-yellow (except medium brown postnotum), normally with at least partially brownish pleura. Typically the anterior part of the mesopleura (below and in front of the 'mesopleural furrow') and a spot above the upper margin of the sternopleura and the hypopleura is paler than the rest of the pleura. Rarely the whole thorax is more or less infuscated. Anterior scutellar setae always somewhat longer than hairs of scutum, normally $0.3-0.5 \mathrm{x}$ (rarely up to $0.85 \mathrm{x}$ ) as long as posterior bristles. Distance between the latter more than twice the distance between the anterior and posterior ones. Abdominal venter greyish. Hairs short except those at hind margin of segment 6 . Tergites also short-haired but with 1-4 longer hairs at postero-lateral corner of T2 and a row of bristle-like hairs at rear margin of T6. Hypopygium as Figs 15-16. Epandrium with 1324 hairs on the left side. Hind margin of epandrium continues some distance below anal tube in postero-ventral direction forming a distinct angle below the proctiger. Each cercus with 7(-8) hairs. Microtrichia below proctiger semi-erect, pointing rearwards. Left hypandrial lobe slightly curved medially (Fig. 26), inner margin upcurved near tip. Right hypandrial lobe with semi-erect to decumbent microtrichia. Four rectal papillae. Fore tarsus with postero-dorsal hair palisade on all segments. Ratios of lengths of fore tarsal segments as 3.1-3.8 : 1.4-1.7:1.1-1.3:0.9-1.0:1. Postero-dorsal bristles of hind tibia moderately developed, spines in apical comb simple. Wing length $1.35-2.1 \mathrm{~mm}$. CI $0.46-$ 0.52 . CR 2.1-3.1 : 1.6-2.4: 1. Longest cc $0.10-0.17 \mathrm{~mm}$. 3-6 cal. Hair at base of Rs $0.012-$ $0.035 \mathrm{~mm}$ long, rarely absent. Wing veins brown, membrane tinged brownish. First thin vein originates beyond, or tarely at fork of Rs.

Female. Similar to male but differs as follows: ant tend to be a little more approximated to upper sa than in male. Third antennal segment smaller, its diameter less than half frontal width. Number of SPS slightly reduced. Bristles of palps longer, the longest one $0.085-0.11 \mathrm{~mm}$ long. Labrum more strongly developed, distinctly broader than diameter of third antennal segment. Anterior scutellar bristles $0.45-0.85 \mathrm{x}$ as long as posterior ones. Width of abdominal tergites gradually decreasing from T2 to T6. The latter is $0.85-1.1 \mathrm{x}$ as broad as long, its anterior notch $0.15-0.27 \mathrm{x}$ as broad as width of tergite. T7 as Fig. 58. T8 rectangular, with 14-33 hairs that are mostly inserted near lateral margins. S7 with (3-) 4 terminal hairs (Fig. 65). Segment 8 micropubescent throughout whole surface except margins of posterior lobes of sternum (Fig. 71). On ventral face microtrichia becoming smaller and sparser anteriorly. Posterior lobes of sternum 8 only slightly bulging. The enlarged hairs only narrowly separated from apical edge of bulge. Internal sclerotisation extending up to base of lobes. Epiproct with 4 long hairs at posterior 
margin plus 1-5 shorter ones on disc. Hairs of hypoproct crowded towards anterior margin. Cerci cylindrical, about $3 x$ as long as broad. Each cercus with the normal $5+1$ long hairs plus a group of (4-)5-6 short, blunt-tipped hairs at apex. Vaginal sclerite only about $0.025 \mathrm{~mm}$ long, oblong, with a hole in posterior half (Fig. 102). Dufour's crop mechanism (Fig. 125). Wing length $1.75-2.6 \mathrm{~mm}$. CI 0.51-0.53. CR 2.7-3.8: 2.1-2.6 : 1. 48 cal.

\section{Distribution}

At present only known from Germany and the Netherlands.

\section{Megaselia immodensior DISNEY sp. $n$.}

(Figs 38, 81, 106)

Megaselia densior auctt., nec SCHMITZ, 1927. DiSNEY, 1985: 244 (partim); 1986: 115; 1989a.

\section{Type material}

Holotype: $\sigma^{\star}$. Great Britain: Scotland, Morroch, grid reference 17/658857, 16.-17.vii.1981, birch-oak wood, leg. R.H.L. Disney (mounted on slide) (CUMZ). Paratypes: 17 o 14 ㅇ. Great Britain: England, North Yorkshire, o, Malham Tarn, grid ref. 34/893672, 2.4.vi.1984, (CUMZ); đ', Malham Tarn, Cowbeck birch cart, grid ref. 34/887672, 29.vi.2.vii.1981, both leg. R.H.L. Disney (both mounted on slides) (coll. MB). Germany: Baden-Württemberg, Langenau, 18.-29.vi.1998, $\sigma^{*}$, trap baited with agar plate, $\sigma^{*}$, trap baited with lignicolous fungus Dacrymyces stillatus growing on agar plate, ơ, 29.vi.-9.vii.1998, same but with fungus Opbiostoma piceae, leg. A. Kopf (mounted on slides) (coll. MB). Sweden: 12 o 14 o , Torne Lappmark, Abisko, 13.-17.vii.1991, yellow and white water traps, low Salix/Vacinium scrub, leg. M. von Tschirnhaus (6 o 7 i mounted on slides, rest in alcohol) (most in coll. MB, $10^{\text {* }} 1$ q CUMZ).

\section{Other material examined}

Germany: Baden-Württemberg, Langenau, 2 o , 9.iv.-7.x.1997, cone traps on artificial tree trunk, leg. A. Kopf (coll. MB). The Netherlands: ot, Limbricht, 4.vi.1917, labelled "M. (M.) densior" (ZFMK).

\section{Etymology}

The name refers to the resemblance to $M$. densior, but it not being this species. The prefix immo- meaning "by no means".

\section{Diagnosis}

A generally brown species. The ant about midway between upper sa and al. Third antennal segment with numerous SPS of small to medium size. Palps mainly yellow with short bristles. Male labella not inflated, somewhat spinose apicolaterally and extending onto ventral faces. Notopleuron with two bristles but no notopleural cleft. Anterior scutellars reduced to hairs in male, long in female. Mesopleuron bare. Abdominal venter hairy on segments 3-6 (in female sometimes also segment 2). Epandrium with hairs and a more bristle-like hair each side. Anal tube dusky yellow and almost as long as epandrium. Terminal hairs of proctiger at least as strong as strongest hair of epandrium. $\mathrm{Hy}$ pandrium with a shorter right and longer left lobe, the latter of which bears long, erect 
to recurved microtrichia. Female T6 subquadrate. T7 Y-shaped. T10 bare. S7 moderately broad. Posterior lobes of sternum 8 with three long hairs and without bulge. Long haits of sternal lobes inserted well before hind margin. Vaginal sclerite of roughly semi-circular shape, and with a small ring postero-laterally. Legs pale brownish yellow to yellowish brown. Hairs below basal half of hind femur longer than those of antero-ventral row in distal half. CI more than 0.44. Costal section 1 longer to shorter than sections $2+3$, usually subequal. cc long. Tip of subcosta fades away before reaching $\mathrm{R}_{1}$. Usually with a hair at base of Rs. With (1-)2-4 ax, of which the longest is subequal to $c c$ of section 3 . Haltere knob largely pale yellow. For differences with regard to the extremely similar M. mimodensior see below this species.

\section{Description}

As diagnosis plus following amplifications: Male. Frons brown with dense microtrichia (and hence dull), and with 30-100 hairs. ant a little closer to eye margin than to median furrow, rarely midway between them. Pre-ocellar bristles about twice as far apart as upper sa, and almost equidistant from each other as each is from a medio-lateral. All four bristles at approximately same level. Lower sa closer together and smaller than upper pair. Typically with three strong bristles on each jowl and three weaker ones on cheek, but sometimes only two in each situation. Thitd antennal segment subglobose, pale to medium brown, as broad as half width of frons. SPS distributed around base of third antennal segment but most numerous beneath inner face, there being arranged in 3-5 irregular rows. Total number of SPS at least 30, diameter 0.005-0.013 mm. Arista brown, the two basal segments a little more than twice as long as wide. Swollen basal section of third segment slightly shorter and usually with well separated sensilla. Cilia of third aristomere as long as diameter of basal joints. Palps pale dusky yellow with (4-)5$8(-9)$ increasingly robust bristles, which are relatively short (the longest one being 0.045$0.070 \mathrm{~mm}$ long). The palps at most only extend to level of tip of labrum. The latter pale brown and its greatest breadth distinctly less than greatest diameter of third antennal segment. Prementum with two pairs of hairs. Labella lightly tinged brown above, with 5 pseudotracheae, 13-21 spinules and some longer hairs below. Anterior scutellars longer than hairs of thoracic scutum, ca. 0.25-0.4x as long as posterior scutellars. Abdomen with dark brown tergites and brown venter. Hairs of tergites generally short, but a patch of longer ones postero-laterally on 'T2, and the posterior row on $\mathrm{T} 6$ are longer and stronger. Posterior row of hairs of venter of segment 6 also more bristle-like. Hairs of hypopygium weaker than those at rear of segment 6 (Fig. 38). Epandrium brown, with 8-24 hairs on left face. Hind margin of left face abruptly bent forward at ventral base of anal tube, forming an acute angle. Cerci with seven hairs that are at most as strong as strongest hair of epandrium. Micropubescence below proctiger semi-erect, pointing rearwards. Left hypandrial lobe $0.89-1.18 \mathrm{x}$ as long as proctiger (the length of the latter is measured at lower margin as the distance from the base to the insertion point of terminal hairs). Microtrichia of right lobe shorter than those of left one, semi-erect to decumbent. Internally with 2-3 rectal papillae. All five front tarsal segments with a postero-dorsal hair palisade. Dorsal hair palisade of mid tibia almost extends three quarters of length. Tip of hind femur typically darkened. With 5-9 of the hairs below basal half of hind femur longer than those of antero-ventral tow of outer half. Hind tibia with 612 differentiated postero-dorsals and simple spines in apical comb. Wing 1.15-1.95 mm long. CI 0.45-0.48. CR 2.2-3.7: 1.5-2.3:1. Section 3 cc 0.09-0.15 mm. (2-)3-4(-5) cal. Hair at base of Rs well developed $(0.032-0.069 \mathrm{~mm})$, sometimes missing. All veins brown, 
with the more anterior veins (especially the costa) more yellowish brown and membrane lightly tinged brownish grey. First thin vein originates at or beyond fork of Rs. Haltere with greyish brown stem and pale yellow knob, which may be lightly tinged pale brown in parts.

Female. Similar to male but differs as follows: SPS less numerous than in male, beneath inner face of third antennal segment only in 1-3 irregular rows. Labrum as broad as third antennal segment. Longest bristle of palps 0.073-0.093 mm long. Labella with 16-21 spinules below. Anterior scutellar bristles $0.73-0.93 \mathrm{x}$ as long as posterior ones. Width of abdominal tergites gradually decreasing from $\mathrm{T} 2$ to $\mathrm{T} 6$. The latter is subquadrate (1.0$1.15 \mathrm{x}$ as broad as long), and only a little broader anteriorly than posteriorly. Anterior notch small, its width being $0.1-0.2 \mathrm{x}$ tergal breadth. Hairs of abdominal venter scarce and short, except those at hind margin of segment 6. Hairs of segments 3-4 sometimes reduced to microscopic setulae. $T 7$ Y-shaped, moderately expanded anteriorly, similar to M. giraudii (Fig. 49). T8 rectangular, with 6-20 hairs. S7 similar to M. bexanopbila (Fig. 65), with 2-4(-5) long hairs posteriorly. Segment 8 covered in microtrichia except usually basal half to two thirds of ventral median area and bare margin of sternal lobes. Lobes with (2-) 3 long hairs, and margin between the lobes bordered by 4-8 smaller hairs (Fig. 81). Lobes more or less flat, not bulging ventrally. Internal face of lobes sometimes slightly sclerotised and tinged brownish. Hairs below hypoproct a little crowded towards anterior margin. Cerci 3-4x as long as broad, with the normal set of $5+1$ long hairs plus 2-4 short, blunt-tipped hairs near apex. Vaginal scletite convex towards left side (Fig. 106). It is well sclerotised except for the faint ring which is connected posteriorly to the right side. Dufour's crop mechanism with long lobes, similar to $M$. giraudii (Fig. 122). 3 4 rectal papillae. Wing length $1.45-2.1 \mathrm{~mm}$. CI 0.46-0.495. CR 2.6-3.5 :1.6-2.1 : 1 .

\section{Recognition}

This species is keyed out as $M$. densior at couplet 152 of the key to British Megaselia (DISNEY, 1989a). It is extremely similar to M. mimodensior with which it occurs sympatrically in Scandinavia (for differences see diagnosis of the latter).

\section{Distribution}

At present known from Britain (England and Scotland), Germany, Sweden, and the Netherlands.

\section{Megaselia labellaspinata DISNEY sp. $n$.}

(Figs 5, 22)

Megaselia septentrionalis auctt., nec (SCHMTTZ, 1919). DISNEY, 1986: 120; 1989 a.

M. septentrionalis was removed from the British List after comparing a specimen attributed to this species by Colyer "with a slide mount of the holotype's hind leg and a female paratype's wing" (DISNEY, 1985). However, the wing belongs to the holotype of septentrionalis (a female), and the leg is from a misidentified labellaspinata male from Finland (see below) which had been labelled as a "Prototype o" of septentrionalis (probably by Beyer). Subsequently the species was restored to the British List following procurement of a series of males from Scotland (DISNEY, 1986) which were conspecific with the male 
from Finland. Based on the different SPS of the third antennal segment it became clear that the males had been wrongly associated with the female, the males representing a new species, which is described below.

\section{Type material}

Holotype: $\sigma^{*}$. Great Britain: Scotland, Inverness, Loch Garten, grid ref. 28/9718, v.1981, leg. J.A. Owen (mounted on slide) (CUMZ). Paratypes: $80^{\circ}$. Great Britain: $60^{\circ}$ as holotype (4 o CUMZ, 1 o ZFMK, 1 o coll. MB); $\sigma^{\star}$, Scotland, Flanders Moss, grid ref. 26/ 623976, v.1981, leg. J.M. Nelson (mounted on slide) (CUMZ). Finland: ơ, Kantalaks [= Kantlax?], without date, leg. Hellén, left wing mounted on separate slide, left hind leg mounted on a another slide together with a wing of the holotype of $M$. septentrionalis (remounted) (ZFMK).

\section{Etymology}

The name refers to the spinose labella.

\section{Diagnosis}

A dark brown species with brown legs and greyish brown wings. ant a little closer to al than to upper sa but slightly lower on frons than either. 'The relatively large third antennal segment dark brown and with only a few small to medium-sized SPS internally. Palps dusky pale yellow to pale brown but with the field of sensilla on the external face darker brown. The labella enlarged a little, the undersides densely spinose but with some of the outermost spinules being greatly elongated. Two notopleural bristles but no cleft. Anterior scutellar bristles variable, ranging from being distinctly longer to distinctly shorter than half length of posterior ones. Mesopleuron bare. Venter greyish brown, and with hairs on segments 3-6. Epandrium almost symmetrical, with numerous hairs posterolaterally and a submarginal transverse row at rear of dorsal half. Hairs of epandrium of subequal length, without an enlarged hair near lower margin. Anal tube yellowish brown and subequal in length to epandrium. The left and right lobes of hypandrium short, subequal in length, and mainly with semi-erect micropubescence. Longest hair of antero-ventral row of hind femur subequal to or clearly shorter than longest hairs below basal half. CI 0.46-0.52. Costal section 1 subequal to or greater than 2+3. cc long. Subcosta ends free. With a minute hair at base of vein 3 and 3-5 ax. Haltere with brown stem and dusky yellow knob.

\section{Description}

Only male known. Frons wider than long (high), with dense microtrichia and with 52-96 hairs. ant closer to eye margin than to median furrow. Lower sa not as strong as upper pair, both pairs closer together than pre-ocellar bristles. Spacing of bristles of middle row variable, with the pre-ocellars being a little closer together than either is from a medio-lateral to being clearly further apart. All four bristles in an almost straight transverse row or medio-laterals slightly higher on frons. With 5-6 bristles on cheek and 2-3 longer ones on jowl. The dark brown third antennal segment as Fig. 5, and internally with only about a dozen SPS (diameter 0.005-0.010 mm). Arista brown, cilia of third aristomere as long as diameter of basal joints. Sensilla on swollen base of third aristomere broadly separated. Palps with (6-)7-9(-10) differentiated bristles, and as many hairs. 
Longest bristle about 1.6-1.7x as long (ca. $0.12 \mathrm{~mm}$ ) as breadth of palp. The pale sensilla of external face conspicuous against the darker surrounds. Prementum with two pairs of hairs. The maximum width of the brown labrum just over half the greatest diameter of third antennal segment. The labella brown above, somewhat enlarged and with dense fields of about 95-120 pale spinules below. Up to six of those in the outermost row on each labellum are developed as longer fine rigid bristles with curved tips. Each side of scutum with a humeral, two notopleural bristles, an intra-alar, a post-alar and a prescutellar dorsocentral bristle. Anterior scutellar setae $0.35-0.85 \mathrm{x}$ as long as posterior ones. Hairs of abdominal tergites short except at rear of T6 (Fig. 22). Venter hairy below on segments $3-6$, with posterior row of 6 being stronger, and with a few fine hairs behind the spiracle on 6 . Much smaller hairs behind spiracles on preceding segments. Hypopygium as Fig. 22. Cerci with seven hairs of about same strength as hairs of epandrium. Terminal hairs of proctiger a little stronger than hairs of cerci. Micropubescence below proctiger inclined rearwards. The hypandrium mainly brown with pale posterior lobes. Microtrichia of hypandrial lobes mainly semi-erect and inclined rearwards or inwards, those at hind margins erect to recurved. Legs brown but front legs paler, especially tips of coxae. All five segments of fore metatarsus with longitudinal postero-dorsal hair palisade. Ratios of lengths of front tarsal segments about $3.0: 1.6: 1.6: 1.0: 1$. Neardorsal longitudinal hair palisade of mid tibia extends about $0.7 x$ length. Hind tibia with about fifteen differentiated postero-dorsal hairs but no antero-dorsals. Spines of apical combs all simple. Wings $2.05-2.7 \mathrm{~mm}$ long. CI 0.46-0.52. CR 2.7-3.7 : 1.7-2.35:1. cc 0.12-0.15 mm long. 5-6 cal. Hair at base of Rs 0.018-0.024 mm. All veins brown, including 7 , but costa more yellowish.

\section{Distribution}

So far only known from Great Britain (Scotland) and Finland.

\section{Megaselia malhamensis DISNEY, 1986}

(Fig. 1)

Megaselia malhamensis DISNEY, 1986: $116\left(0^{*}\right)$.

\section{Type material}

Holotype: o . Great Britain: England, North Yorkshire, Malham Tarn, grid ref. 34/887674, 31.viii.1975, on window, leg. R.H.L. Disney (mounted on slide) (CUMZ).

\section{Other material examined}

Germany: o*, Baden-Württemberg, Ulm, Eselsberg, 6.-20.v.1981, window trap, deciduous forest, leg. R. Grimm (coll. MB); 2 , Rhineland-Palatinate, Altenahr, NSG Ahrschleife, 12.x.1988-27.v.1989, emergence trap over bark of living tree, leg. W. Büchs (CUMZ and coll. S. Prescher). Great Britain: o*, England, New Forest, Hartford Wood, 19.-25.vi.1984, leg. G. Forrester (CUMZ).

\section{Description}

Only male known. The description given by DISNEY (1986) can be complemented as follows: Third antennal segment with numerous $(>30)$ small to medium-sized SPS $(0.008-$ $0.013 \mathrm{~mm}$ ). SPS distributed around base of segment but sparse except for inner face 
where they are arranged in ca. three irregular rows. Sensilla on swollen base of third aristomere usually broadly separated. Palps a little inflated, $0.073 \mathrm{~mm}$ broad, with $8-9$ conspicuously shortened bristles (Fig. 1). The longest of these only measures 0.054 $0.069 \mathrm{~mm}$. Labella normal, apart some longer hairs with 18-19 short blunt spines below. Notopleural cleft simple, straight in posterior half, and without distinctly sclerotised ridges. Hypopygium see DISNEY (1989a: Fig. 393). Left face of epandrium with 18-29 hairs, none of which is bristle-like and clearly stronger than the other hairs. Proctiger (measured on lower surface) a little longer than dorsal face of epandrium. Micropubescence below proctiger semi-erect; pointing rearwards. Left hypandrial lobe shorter than right one, both with short decumbent microtrichia. Four rectal papillae. Wing length 1.5-1.75 mm. CI 0.425-0.445. CR 3.1-3.3:1.4-1.6: 1. Longest cc 0.105-0.135 mm. Four cal, 3-4 ax. Hair at base of Rs vestigial $(0.016-0.020 \mathrm{~mm})$.

\section{Distribution}

At present only known from Great Britain and Germany. The only record from Israel (DISNEY \& NUSSBAUM, 1990) represents a misidentification.

\section{Megaselia mimodensior BUCK sp. $\mathbf{n}$.}

(Figs 39, 82, 107)

\section{Type material}

Holotype: đ. Sweden: Torne Lappmark, Abisko, 13.-17.vii.1991, yellow water trap, low Salix/Vaccinium scrub, leg. M. von Tschirnhaus (critical-point dried and glued to the side of a pin) (ZFMK). Paratypes: 95 o 35 ㅇ. 94 o 34 으, same data as holotype, white and

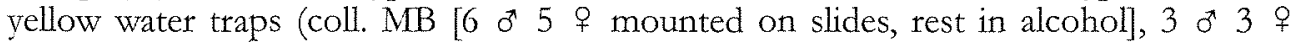
CUMZ [slide-mounted], $1 \% 2$ \&FMK [critical-point dried and glued to the side of a pin]). Norway: $1 \sigma^{*} 1$ \%, Dovrefjell, Kongsvold, 11.-18.viii.1972, white and yellow water traps, boreal birch forest, leg. Vermehren (slide-mounted) (coll. MB).

\section{Other material examined}

ð, same data as holotype, hypopygium deformed (coll. MB).

\section{Etymology}

The name refers to the great similarity with $M$. immodensior.

\section{Diagnosis}

This species is extremely similar to $M$. immodensior. It can be distinguished from the latter only by the following characters: On the average smaller and darker. Anal tube of male shorter than in $M$. immodensior. Left hypandrial lobe shorter, and with shorter micropubescence than in $M$. immodensior. Vaginal sclerite of female semicircular and convex towards right side, of less irregular shape than in $M$. immodensior. T10 usually bare but sometimes with 1-2 hairs. Female sternum 8 completely covered in microtrichia (except bare hind margin of posterior lobes). Sternal lobes with small ventral bulges. Lobes of Dufour's crop mechanism shorter than in $M$. immodensior. On the average CI lower than in $M$. immodensior. 


\section{Description}

Male. Differs from $M$. immodensior as follows: ant normally a little closer to upper sa than to al or midway between them, rarely a little closer to al. Frons with 30-75 hairs. Hypopygium as in Fig. 39. Epandrium with 7-20 hairs. Anal tube pale to medium brown. Left hypandrial lobe $0.55-0.75 \mathrm{x}$ as long as proctiger (the length of the latter is measured at lower margin as the distance from the base to the insertion point of terminal hairs). Microtrichia of left lobe moderately long (shorter than in $M$. immodensior), decumbent to semi-erect, those in outer half pointing rearwards, those beneath inner half usually curved medially. Legs brown, hind femur a little darkened towards tip. Longest hairs below basal half of hind femur a little longer to subequal to those of antero-ventral row in distal half. Wing length $1.0-1.6 \mathrm{~mm}$. CI $0.42-0.455$. CR 2.2-3.3 : 1.3-1.8 : 1. Longest cc $0.085-0.135 \mathrm{~mm}$. 2-4 cal. Hair at base of Rs usually well developed $(0.022-0.064 \mathrm{~mm})$, sometimes absent.

Female. Differs from $M$. immodensior as follows: In some specimens there may be as few as ca. 15 SPS inside third antennal segment. Longest bristle of palp $0.057-0.104 \mathrm{~mm}$. Labella with 13-21 spinules below. Anterior scutellar bristles $0.74-0.84 \mathrm{x}$ as long as posterior ones. T6 subquadrate, $1.0-1.2 \mathrm{x}$ as broad as long. Width of anterior notch 0.14 $0.23 x$ tergal breadth. T7 anteriorly expanded, similar to Fig. 55. T8 rectangular, with 9-30 hairs. T10 usually bare, occasionally with 1-2 hairs. 57 usually narrower than in $M$. immodensior, similar to Fig. 63, with (2-)4 long hairs posteriorly. Segment 8 completely covered in microtrichia except bare hind margin to sternal lobes (Fig. 82). Lobes similar to M. immodensior but more bulging. Each lobe with 3 enlarged hairs, and margin between the lobes only bordered by 2-3 smaller hairs. Vaginal sclerite (Fig. 107) more slender than in $M$. immodensior, with more regular surface, and convex towards right side. The weakly sclerotised ring on right side smaller. Dufour's crop mechanism similar to $M$. citrinella (Fig. 124). Wing length 1.25-2.15 mm. CI 0.45-0.475. CR 2.6-3.5: 1.6-1.9: 1. Up to six cal.

\section{Distribution}

At present only known from Sweden and Norway.

\section{Megaselia offuscata (SCHMITZ, 1921)}

(Figs 14, 19)

Apbiocbata offuscata SCHANTZ, 1921: $4\left(0^{\circ}\right)$.

Megaselia offuscata (SCHMiтz). SCHMTT, 1928: 145.

Apbiocbaeta pseudorata SCHMTZ, 1922: 100 (ơ). SCHMITZ, 1929: 142 (synonymy).

\section{Type material}

M. offuscata. Lectotype (herewith designated by RHLD): $\sigma^{*}$. The Netherlands: Linschoten, 3.vi.1920, leg. J.C.H. de Meijere (remounted, one wing on a separate slide) (ZFMK). Paralectotype: 10 . Same data as holotype (remounted) (ZMAN). The third type specimen mentioned by SCHMITZ (1921) is neither in the ZFMK nor the ZMAN. It is presumably lost.

M. pseudorata. Holotype: $0^{\star}$. The Netherlands: Linschoten, 14.V.1921, leg. J.C.H. de Meijere (ZFMK). A slide-mounted wing is all what seems to be left from the specimen. 


\section{Other material examined}

Germany: o*, North Rhine-Westphalia, Köln-Dünnwald, NSG "Am Hornpottweg", 2.-9.v. 1987, malaise trap, leg. J. Franzen (ZFMK).

\section{Description}

The original description is to be complemented as follows: ant a little closer to al than to upper sa and closer to eye margin than to median furrow. Third antennal segment of usual size, diameter a little less than half breadth of frons. Only ca. eight SPS of small to medium size $(0.004-0.011 \mathrm{~mm})$ beneath inner face of third segment. Palps not inflated, dusky yellow. Longest bristles of palps almost twice as long as maximum diameter of palp. Labella enlarged, each with ca. 90-100 short spinules below. Notopleural cleft straight in posterior two thirds and without strongly sclerotised ridges (Fig. 14). Abdominal venter hairy on segments 3-6. Hypopygium as in Fig. 19. Left side of epandrium with ca. 23 hairs that are weaker than those of posterior row of T6. This side acute-angled at ventral base of anal tube. Anal tube brownish. Cerci with 7-8 hairs which are almost as strong as strongest ones of epandrium. Terminal hairs of proctiger a little stronger than other hairs of hypopygium. Microtrichia below proctiger semi-erect, inclined rearwards. Left hypandrial lobe longer than right one, and with erect to recurved micropubescence. Micropubescence of right lobe predominantly semi-erect but with some erect to recurved microtrichia in marginal zone. Three rectal papillae. Legs brown, tip of hind femur darkened. Front tarsus with postero-dorsal hair palisade on all five segments. Ratios of lengths of tarsal segments $2.4: 1.2: 1.1: 0.9: 1$. Postero-dorsal bristles of hind tibia moderately developed, spines in apical comb simple. Longest hair of antero-ventral row in distal half of hind femur subequal to shorter than longest hairs below basal half. Wing length $1.55-1.85 \mathrm{~mm}$. CI $0.45-0.49$. CR 2.6-4.0 : 1.5-2.3: 1 . Longest cc $0.110-0.115$ mm. 4-5 cal, 3-4 ax. Hair at base of Rs long $(0.054-0.072 \mathrm{~mm})$. Wing membrane tinged brownish. First thin vein originates beyond fork of Rs. Knob of haltere dusky yellow to pale brownish, stem brown.

\section{Distribution}

Verified records are from the Netherlands and Germany.

\section{Megaselia parnassia DISNEY, 1986}

(Figs 20, 70, 117)

Megaselia parnassia DISNEY, 1986: $119\left(0^{*}\right)$.

Megaselia giraudii auctt., nec (EGGER, 1862). BUCK, 1997b (only o*, partim).

\section{Type material}

Holotype: $\sigma^{\star}$. Great Britain: England, North Yorkshire, Malham Tarn, West Fen, grid ref. 34/883672, 11.ix.1975, at flower of Parnassia palustris, leg. R.H.L. Disney (mounted on slide) (CUMZ).

\section{Other material examined}

Germany: Bavaria, Senden Hittistetten, 1 o 1 q, 21.iv.-5.v.1994, 4 q, 19.v.-3.vi.1994, 3 q, 11.vi.-1.vii.1993, 6 \% , 22.vii.-12.viii.1993, 2 \%, 9.-23.ix.1993, carrion traps baited with kidney; + , 13.-19.v.1993, \&, 24.v.-1.vi.1993, 2 o , 14.-28.vi.1993, o*, 9.-16.viii.1993, 2 o*, 6.-13.ix. 1993, odour traps baited with n-hexane, leg. M. Buck (coll. MB, 2 \& CUMZ); 
Baden-Württemberg, Ulm, Eselsberg, ơ, 20.-27.vi.1979, white water trap, 4 ơ 2 ㅇ, 6.v.10.vi.1981, window trap, deciduous forest, leg. R. Grimm (coll. MB); Lower Saxony, o", Solling, 25.v.-1.vi.1967, emergence trap over soil, beech forest (coll. $0^{*}$. Weber); Rhineland-Palatinate, Mainz, Lennebergwald, 1 o 1 o , 10.-26.iv.1989, o, 10.-26.v.1989, emergence traps set over soil, leg. R. Feldmann (NHMM, 1 o coll. MB). Great Britain: ot, England, North Yorkshire, 6.viii.1975; o*, Kilhope, grid ref. 35/800432, 23.vi.1976, leg. J.C. Coulson; $0^{7}$ Scotland, Inverness, Feshiebridge, 16.vi.1982, leg. P.J. Chandler (all CUMZ). Norway: $1 o^{*} 1$ ㅇ, Trollstigheimen, Langfielldalen, ca. $1100 \mathrm{~m}, 24$.vii. $1973 ; 3$ o 2 ㅇ, Jotunheimen, Leirvassbu, $1450 \mathrm{~m}, 27 .-28$.vii.1973, yellow water traps; 1 o 3 क , Hardangervidda, south slope of Stigstuvtuva, $1250-1270 \mathrm{~m}$, 30.vii.-1.viii.1973, white and yellow water traps, all leg. M. von Tschirnhaus (coll. MB). Sweden: Torne Lappmark, Abisko, ơ 18./28.vi.1988, sweep netting, 111 o 57 o , 13.-17.vii.1991, white and yellow water traps, leg. M. von Tschirnhaus (coll. MB, 3 o 3 o CUMZ, 2 o 2 ㅇ ZFMK), 0 , 1994, at flower of Parnassia palustris, leg. H. Gieseler (CUMZ). Canada: ơ, Yukon Territory, Dempster Hwy km 141, 1.vii.1987, dung on scree slope, leg. S.A. Marshall (DEBU); ơ, Ontario, St. George's Lake, 22.viii.1992, pitfall trap, leg. S.-O. Ulefors (DEBU) (Note: due to improper mounting the specimen is in poor condition but the hypopygium is sufficiently preserved as to facilitate species recognition).

\section{Description}

ant closer to upper sa than to al, about midway between median furrow and eye margin. SPS distributed around whole base of third antennal segment, but most numerous on inner face where they are arranged in 3-6 (male), or 1-3 irregular rows (female). Number of SPS at least 30, but usually much more, diameter $0.004-0.015 \mathrm{~mm}$. Sensilla on swollen base of third aristomere not closely approximated but distance between them variable. Labella each with 15-25 blunt spinules. Notopleural cleft similar to $M$. girandii (Fig. 13), with a small $\mathrm{V}$-shaped ridge posteriorly. Anterior scutellars usually $0.35-0.6 \mathrm{x}$ (male), or 0.65-0.8x (female) as long as posterior ones. Hypopygium see DISNEY (1989a: Fig. 399. 400, left faces) and Fig. 20 (right face). Left side of epandrium bearing 12-28 hairs (i.e. number of hairs not higher than in M. giraudii). Male cerci with 8-11(-12) hairs. Microtrichia of ventral edge of proctiger recurved (cf. Fig. 42). Left hypandrial lobe tinged brown, with long, erect to recurved microtrichia. Micropubescence of right lobe semierect to decumbent, pointing rearwards. Female abdominal tergites gradually decreasing in width from T2 to T6. Abdominal venter hairy on segments (2-)3-6. T6 1.26-1.41x as broad as long. Anterior notch one fifth to one seventh as wide as maximum width of tergite. T7 similar to $M$. giraudii (Fig. 49). T8 rectangular, with 9-26 hairs. T10 bare. S7 similar to $M$. giraudii (Fig. 64), but anteriorly less frequently with a stronger sclerotised median stripe; posterior margin with (2-)3-4(-5) enlarged hairs. Micropubescence of sternum 8 restricted to postero-lateral areas, medially (including area between posterior lobes) bare. Sternal lobes only slightly bulging, internal surface sclerotised (Fig. 70). Hairs of hypoproct crowded towards anterior margin (cf. Fig. 94). Cerci cylindrical, about $3 \mathrm{x}$ as long as broad, with usual $5+1$ long hairs plus group of $3(-4)$ short blunt hairs at apex. Vaginal sclerite represented by a weakly sclerotised strip that is not clearly delimited posteriorly (Fig. 117). Dufour's crop mechanism similar to M. girandii (Figs 122-123). (3-)4 rectal papillae. Wing length 1.2-1.95 mm (male), 1.3-2.3 mm (female). CI 0.43-0.475 (male), 0.44-0.49 (female). CR 2.5-3.45:1.6-2.1 : 1 (male), 2.5-3.5: 1.4-2.1: 1 (female). Maximum length of cc 0.095-0.18 mm. (2-)4-6(-7) cal, (3-)4-5(-6) ax. Hair at base of Rs long (0.041-0.107 mm) rarely missing. 


\section{Distribution}

Holarctic. The above mentioned specimens from Canada represent the first records of M. parnassia for the Nearctic Region. Other records are from Britain, Germany, Norway, and Sweden. $M$. parnassia seems to replace the closely related $M$. giraudii in boreo-alpine habitats of northern Europe.

\section{Megaselia quadriseta (ScHMITZ, 1918)}

(Figs 9, 30-31, 46, 54, 84, 109, 126)

Aphiochaeta lutea var. quadriseta SCHMTTZ, 1918: 143 ( 9 ).

Aphiocbaeta quadriseta SCHMTZ. SCHMITZ, 1919: 186.

Megaselia quadriseta (SCHMITZ), SCHMTZ, 1928: 145.

Aphiochaeta phoenicura SCHMITZ, 1926: 81 (0). Syn. n.

Megaselia badia SCHMITZ, 1938: $193\left(0^{\star}\right)$. Syn n.

Megaselia bayleyensis DISNEX, 1987a: 27 (đ). Syn. n.

Megaselia septentrionalis auctt., nec (SCHMITZ, 1919). PRESCHER \& WEBER, 1996: 418; in press.

\section{Type material}

M. quadriseta. Lectotype (herewith designated by MB): 9 . The Netherlands: Limbricht, 4.vi.1917 (remounted) (ZFMK). Paralectotypes: 3 o . The Netherlands: \&, Scheveningen, vii.1900. The other two paralectotypes are not conspecific: $q$ (belongs to $M$. bexanophila sp. n.), Maastricht, without date, leg. H. Schmitz; + (belongs to M. citrinella sp. n.), without locality (according to ScHMTTZ, 1918: Holland), 25.1i.1913, "Aphiochaeta lutea var. quadriseta? det. Schmitz", "Type", "Paratypoid", "Type' bedeutet hier: war unter den Typen von quadriseta SCHMITZ; 1939 schien es mir aber eine sanguinea zu sein!" (all remounted) (all ZFMK).

M. phoenicura. Lectotype (herewith designated by MB): $\sigma^{*}$. The Netherlands: Valkenburg, 1.vii.1924, leg. H. Schmitz (remounted) (a wing mounted on a separate slide labelled "phoenicura S ${ }^{*}$ Type 6518 " probably belongs to one of the paralectotypes) (ZFMK). Paralectotypes: SCHMITZ (1926) mentions 3 đ. Austria: Vorarlberg, Feldkirch, o 7.viii.1920, $0^{*}, 22$.viii.1920. The Netherlands: $0^{*}$, Watersleyde, 15.1x.1916. None of these specimens could be located in the ZFMK.

M. badia. Holotype: ơ. Ireland: Tullamore, Charleville [ $=$ Ráth Luirc], 17.vi.1937, one wing mounted on separate slide (remounted) (ZFMK). Paratypes: 2 *. Poland ("East Prussia"): $\sigma^{*}$, Gross-Raum, 3.vi.1927, leg. P. Speiser (mounted on slide). Ireland: 0 (misidentified $M$. baraldlundi), Tullamore, 15.vi.1937, (remounted) (both ZFMK).

M. bayleyensis. Holotype: o . Great Britain: England, Cambridgeshire, Hayley Wood, 11.18.viii.1980, leg. D.M. Unwin (mounted on slide) (CUMZ). Paratypes: 4 đ. Great Britain: $20^{*}$, same data as holotype (CUMZ); England, o* Cambridgeshire, Abbots Ripton, Monks Wood, 23.-30.vii.1981, leg. R.S. George (CUMZ); ¿* Cheshire, Delamere Forest, 17.vi.1959, leg. C.N. Colyer (BMNH) (all mounted on slides).

\section{Other material examined}

The Netherlands: o , Limbrichter bosch, 23.v.1916 (ZFMK). Austria: 2 o , Upper Austria, Kremsmünster, 25.vi.1935 and 12.viii.1935, leg. L. Czerny, one labelled "phoenicu$r a$ ", one without determination label but standing with $M$. phoenicura (ZFMK). Germany: 
Bavaria, Senden Hittistetten, $20,13 .-20.1 x .1993$, trap baited with n-hexane, leg. M. Buck (coll. MB); ㅇ, 24.vi.-1.vii.1993, 14 ㅇ, 26.viii.-9.ix.1993, 2 o , 16.-23.ix.1993, traps baited with decaying kidney or dead snails, leg. M. Buck (coll. MB, 2 o CUMZ); Baden-Württemberg, o , Langenau, 15.vii.-5.viii.1993, trap baited with lignicolous fungus Dacrymyces stillatus growing on agar plate, leg. R. Sipple (coll. MB); 5 o 6 \%, Ulm, Eselsberg, 6.v.10.vi.1981, window trap, deciduous forest, leg. R. Grimm (coll. MB); Rhineland-Palatinate, $4 \sigma^{*}$, Altenahr, NSG Ahrschleife, 27.v.-28.vi.1988, pitfall traps, leg. W. Büchs (coll. S. Prescher); Mainz, Lennebergwald, 2 ㅇ, 11.vii.-10.viii.1988, 2 o 1 우 , 11.vii.-15.viii.1989, emergence traps over soil, pine forest, leg. R. Feldmann (coll. MB, $10^{*} 1$ क NHMM); $\sigma^{*}$, North Rhine-Westphalia, Köln-Dünnwald, NSG "Am Hornpottweg", 9.-16.v.1987, malaise trap, leg. J. Franzen (coll. o. Weber). Great Britain: 10 \%, 1 q, England, Cambridgeshire, Hayley Wood (included in the records for $M$. badia and $M$. bayleyensis in Disney, 1987a) (CUMZ, 1 o ZFMK, 1 \% coll. G. Weber); 5 \%, Cambridgeshire (Monks Wood), Hampshire (New Forest), North Yorkshire (Escrick Estate) and Warwickshire (Stoneleigh) (CUMZ, 1 \% ZFMK); 2 ๙, Scotland, Invernesshire, Craigellachie N.N.R., 13.-16.vii.1982, leg. R.H.L. Disney (CUMZ). Ireland: 2 ot, Rosslare [P], 14.vi.1939 (ZFMK). Denmark: $\sigma^{*}$, Hær Mølle [?], without date, leg. W. Lundbeck (ZFMK). Norway: 2 \%, without locality, 20.viii.1991, leg. M. Drolshammer (CUMZ). Spain: ơ, Aragón, Jaca, Santa Cilia, by Río Gas, 21.vi.1980, leg. P.J. Chandler (CUMZ).

M. quadrista was described by SCHMITZ on basis of about six females from Holland (SCHMITZ, 1918). Four syntypes of his species were found in the ZFMK. They represent three different species. Two specimens belong to $M$. quadriseta (as defined by the present lectotype designation), the other two belong to the newly described $M$. bexanophila and $M$. citrinella (see above). On designating a lectotype for $M$. quadriseta the female belonging to the species now named $M$. citrinella had to be discarded because in 1939 SCHMITZ himself remarked on a label (see above) that it was probably not a $M$. quadriseta but the later described $M$. sanguinea (again a misidentification). The remaining three syntypes agree just as well with the original description except that only in two of them (including the designated lectotype) costal section 1 is $1.5-1.75 \mathrm{x}$ as long as section 2 , and longer than costal sections $2+3$ (as stated by SCHMITZ, 1918). In the other syntype (belonging to $M$. bexanophila) $\mathrm{Cs} 1$ is only $1.38 \mathrm{x}$ as long as Cs 2 , and $0.94 \mathrm{x}$ as long as Cs $2+3$.

The description of $M$. phoenicura was based on males only, the females never having been reported in the literature. Unexpectedly, several females attributed to $M$. phoenicura were found in the Schmitz collection. While one of them is a $M$. bexanophila (of which the male is already known), two specimens from Austria were found to be $M$. quadriseta (only known in the female sex). Based on the great similarity of $M$. quadriseta/phoenicura it is very likely that they represent opposite sexes of the same species. The synonymy of $M$. phoenicura is thus being proposed.

$M$. hayleyensis (only known in the male sex) is synonymised with $M$. quadriseta because of the identical hypopygium and enlarged SPS of the third antennal segment. The only significant difference between the two species is the coloration of the thorax (almost uniformly brown in $M$. hayleyensis, largely reddish brown in $M$. pboenicura). As a series of $M$. quadriseta females taken by MB (see above) also shows a high variability with regard to this character (but identical genitalia) it seems of little taxonomic value. 


\section{Description}

The descriptions by DISNEY (1987a), SCHMITZ (1926) (male) and SCHMITZ \& DEIAGE (1981) (female) are to be complemented as follows: ant closer to eye margin than to median furrow. SPS numerous and unusually large $(0.010-0.024 \mathrm{~mm}$ ) (Fig. 9), located in basal two thirds of third antennal segment. Vesicles most numerous on inner face of segment where they are arranged in ca. four (male), or 1-2 irregular rows (female). Number of SPS $>30$, in female sometimes as few as 20 . Sensilla on swollen base of third antennal segment not closely approximated. Labella with 14-25 blunt spinules below. Coloration of thorax very variable: uniformly brown to brown with yellow areas (especially humerus, notopleuron, supra-alar area, postalar callus, lateral margins of scutellum and lower parts of the pleura). In females the yellowish area is usually more extended, the thorax of some specimens being almost completely orange-yellow. Notopleuron without cleft. Anterior scutellar setae 0.29-0.43x (male), or 0.57-0.73x (female) as long as posterior ones. Abdominal venter hairy on segments (2-)3-6. Hairs at hind margin of segment 6 enlarged (but normally weaker than in Fig. 30). Hypopygium as in Figs 30-31 and in DISNEY (1989a: Fig. 454). Left face of epandrium with 19-33 hairs which only gradually differ in strength, without a differentiated bristly hair. Left face with broad postero-ventral lobe (Fig. 30). On right side hind margin of epandrium arched (Fig. 31). Anal tube slightly shorter than dorsal face of epandrium. Cerci with 7(-8) hairs. Microtrichia below proctiger semi-erect, pointing rearwards. Right hypandrial lobe a little shorter than left one. Both lobes with short decumbent microtrichia. Margin of left lobe apically and laterally bare. Female abdomen: T6 $0.95-1.15 \mathrm{x}$ as broad as long and its anterior notch $0.20-0.26 \mathrm{x}$ as broad as maximum width of tergite (Fig. 46). T7 Y-shaped, but only shallowly notched anteriorly (Fig. 54). T8 rectangular, with 10-28 hairs. T10 with (1-)2-4(-6) hairs on disc. S7 similar to M. bexanophila (cf. Fig. 65), with (3-)4(-5) terminal hairs. Segment 8 completely covered in micropubescence, except margins of posterior lobes of sternum. Sternal lobes bulging, each of which with three enlarged hairs close to edge (Fig. 84). Hairs of hypoproct not crowded towards anterior margin. Cerci about $3-4 \mathrm{x}$ as long as broad, with the normal $5+1$ hairs (i.e. only with one, not two, long terminal hairs, as stated by SCHMITZ \& DELAGE, 1981). Furthermore with (2-)3(-4) short, blunt-tipped hairs at apex. Variable vaginal sclerite developed as a vertically oriented plate which is convex towards left side (Fig. 109). Posteriorly with a large, weakly sclerotised loop on right side. Dufour's crop mechanism with moderately long lobes (Fig. 126). Number of rectal papillae: 2-4 (male), 4 (female). Wing length $1.2-2.1 \mathrm{~mm}$ (male), 1.5-2.5 mm (female). CI 0.45-0.485 (male), 0.48-0.50 (female). CR 2.3-3.3: 1.5$2.1: 1$ (male), 2.7-3.6:1.6-2.3: 1 (female). Longest cc $0.12-0.175 \mathrm{~mm}$. (3-)4-5(-8) cal, 34(-5) ax, longest of the latter slightly shorter than longest cc. Hair at base of Rs well developed $(0.045-0.108 \mathrm{~mm})$.

\section{Distribution}

M. quadriseta seems to be widely distributed in Europe. Revised material was collected in Austria, Britain, Denmark, Germany, Ireland, the Netherlands, Norway, Spain, and Poland. Due to confusion with $M$. bexanophila sp. $\mathrm{n}$. and $M$. citrinella $\mathrm{sp}$. $\mathrm{n}$. older records need confirmation. Based on a misinterpreted data label $M$. quadriseta was erroneously reported from Madeira (SCHMITZ \& DELAGE, 1981; and subsequently DISNEY, 1991). 


\section{Megaselia raruvesiculae DISNEY sp. $\mathrm{n}$.}

(Figs 4, 7, 21, 95, 121)

Megaselïa densior auctt., nec SCHMITZ, 1927. DiSNEY, 1985: 244 (partim).

\section{Type material}

Holotype: ơ. Great Britain: Scotland, Perthshire, Flanders Moss, grid ref. 26/6297, 26.v.4.vi.1983, leg. J.M. Nelson (CUMZ). Paratypes: $8 \sigma^{\circ}$. Great Britain: $3 \sigma^{\circ}$, Scotland, Perthshire, Flanders Moss, grid ref. 26/6297, 27.v.-2.vi.1982 and 26.v.-4.vi.1983, leg. J.M. Nelson (CUMZ, 1 o ZFMK); England, o*, Essex, Dagnam Park, grid ref. 51/550930, 22.v.1977, leg. D.A. Smith (CUMZ); o, North Yorkshire, Malham Tarn, grid ref. 34/ 893672, 12.-13.v.1982, leg. R.H.L. Disney (CUMZ). Germany: ơ, Rhineland-Palatinate, Altenahr, NSG Ahrschleife, 2.-23.v.1987, leg. W. Büchs (SNMB). Switzerland: $\sigma^{\star}$, nr. Neuchâtel, 7.-8.vi.1983, leg. Y. Basset (CUMZ). Norway: ơ, without locality; 28.vi.1991, ex sheep carcass, leg. M. Drolshammer (mounted on slide) (CUMZ).

\section{Other material examined}

Great Britain: o , Scotland, Perthshire, Flanders Moss, grid ref. 26/623976, v.1981, leg. J.M. Nelson (CUMZ).

\section{Etymology}

The name refers to the reduced number of SPS in the third antennal segment.

\section{Diagnosis}

Male. ant slightly lower than al or upper sa, about midway between them or a little nearer latter than former. The brown third antennal segment not enlarged, with only about a dozen small to medium-sized SPS inside. Palps yellow with short bristles. Labella densely spinose below. Thorax brown, with two bristles on notopleuron and no cleft. Anterior scutellars not quite half as long as posterior pair of bristles. Mesopleuron bare. Abdominal tergites, venter and hypopygium (apart from left hypandrial lobe and anal tube, which are more yellowish) brown. Venter hairy on segments 3-6. Epandrium with a differentiated hair on left side. Anal tube yellow, lightly tinged brown. Right lobe of hypandrium clearly shorter than left lobe. The latter bears erect to recurved microtrichia below. Legs pale yellowish brown. The longest hairs below basal half of hind femur scarcely longer than those of antero-ventral row of outer half. Costa just under half wing length. Costal section 1 longer than sections $2+3$. cc long. Hair at base of Rs about $0.05 \mathrm{~mm}$ long. 3-4 ax. Halteres with dusky yellow knob.

\section{Description}

Frons brown, broader than long (high), with 56-58 hairs and fine but dense microtrichia. ant about midway between eye margin than to median furrow. Lower sa at most $0.6 \mathrm{x}$ as long as upper pair. Pre-ocellars slightly further apart than either is from a medio-lateral bristle, and all four in an almost straight transverse row. Two bristles on cheek about as strong as lower sa. 2-3 stronger bristles on jowl. Antennae little narrower than half frontal width, greatest diameter less than $0.15 \mathrm{~mm}$ (Fig. 4). The SPS beneath its inner face as Fig. 7, diameter 0.004-0.014 mm. Sensilla at base of third segment of arista well separated. Palps with 6-9 bristles, the longest one being 1.3-1.6x as long $(0.07-0.09 \mathrm{~mm})$ as diameter of palp. About 50-90 pale brown blunt spinules below each labellum. Grea- 
test breadth of the pale brown labrum at most $0.1 \mathrm{~mm}$, and thus less than greatest width of third antennal segment. Anterior scutellars a little longer than hairs at rear of scutum. Each side of latter, in addition to notopleurals, with a humeral, an intra-alar, a postalar and a prescutellar dorsocentral bristle. Hair of abdominal tergites 1-6 short and sparse, but stronger at rear of 6 . The bristle-like hairs at rear margin of sternum 6 stronger than those at rear of T6. Epandrium with 14-21 hairs on left face, a postero-ventral lobe not being developed (Fig, 21). Cerci with seven hairs. Microtrichia below proctiger semierect, pointing rearwards. Microtrichia below right hypandrial lobe mostly semi-erect, with some at lateral and posterior margins erect to recurved. Internally with two rectal papillae. Postero-dorsal hair palisades on all five front tarsal segments. Ratios of lengths of fore-tarsal segments about $2.95: 1.5: 1.3: 1.05: 1$. Near dorsal hair palisade of mid tibia extends just over three quarters of length. Hind tibia with a dozen differentiated postero-dorsal hairs, but only those in lower half are robust. Spines of apical combs of posterior face all simple. Wing 1.7-1.9 mm long. CI 0.46-0.48. CR 2.6-3.7 : 1.4-2.4 : 1 . Section 3 longest cc $0.11-0.155 \mathrm{~mm}$. 3-6 cal. Hair at base of Rs is $0.051-0.062 \mathrm{~mm}$ long, and on one wing there is a second minute hair (only $0.02 \mathrm{~mm}$ long). All veins, including 7, yellowish brown. Membrane lightly tinged greyish brown. Haltere with dusky pale yellow distal two thirds of knob, a darker basal third and a brown stem.

Female. Similar to male but differs as follows: Fewer SPS than in male. Greatest breadth of labrum about $0.11 \mathrm{~mm}$ and thus about $1.16 \mathrm{x}$ as broad as third antennal segment. Labella only with 28 blunt spinules. Anterior scutellars $0.84 \mathrm{x}$ as long as posterior ones. Abdominal venter hairy on segments 3-6, those of segments 3-5 reduced to microscopic setulae. Width of abdominal tergites gradually decreasing from $T 2$ to $T 6$. T8 with 10 hairs. T10 bare. Microtrichia of sternum 8 restricted to posterior lobes (but hind margin bare). Sternal lobes not bulging, with many hairs (Fig. 95). Hairs of hypoproct not crowded towards anterior margin. Cerci about $2.6 \mathrm{x}$ as long as broad, with $5+1$ usual long hairs plus apical group of 5 short blunt-tipped hairs. Vaginal sclerite as Fig. 121. Dufour's crop mechanism bilobed behind. 3(-4?) rectal papillae. Wing length $1.6 \mathrm{~mm}$. CI 0.48 . CR $3.2: 1.9: 1.2-3 \mathrm{cal}$.

\section{Distribution}

Known from Great Britain (Scotland, England), Norway, Germany and Switzerland.

\section{Megaselia rubricornis (SCHMITZ, 1919)}

(Figs 23-24, 57, 61, 80, 113, 130)

Apbiochaeta mulricornis SCHMTZ, 1919: $193($ ( $)$.

Megaselia rubriconis (SCHMTZ). SCHMTZ, 1928: 145.

\section{Type material}

Holotype: 9 . Germany: Berlin, Pichelsberg, "15.viii.57" (the original description has 13.viii.1907), "Holotypus", "Apbiochaeta rubricornis Type of det. Schmitz" (remounted) (ZFMK). Paratype: the other type specimen mentioned by SCHMITZ is not in the ZFMK.

\section{Other material examined}

Without locality: ơ, 25.vii.1921 (ZFMK). 
Three years after describing M. rubricornis from the female sex alone Schmitz received the first male of this species ("Das erste on sah ich von Dr. Speiser 1921, Tucheler Heide [= Tucholskie Bory, Poland] 1896-1897, ․․H. Rübsaamen leg.", hand-written remark on Schmitz's personal copy of the original work, which is deposited in the ZFMK). However, a description of the male has never been published. One of the males in the Schmitz Collection is described below. It is very likely that Schmitz's determination is correct because the male shares two unique characters with the female (antennae reddish, and completely lacking the SPS).

\section{Description}

As given by SCHMITZ \& DELAGE (1981) plus following amplifications: ant about midway between al and upper sa. In the examined male there is only one pair of very unequal sa. Third antennal segment reddish and without SPS in both sexes. Diameter about half width of frons, same size in male and female. Arista longer than frons at mid-line. Sensilla at base of third aristomere not approximated (distance between them 0.008 $0.012 \mathrm{~mm}$ ). Longest bristle of palp 1.7x longer (ca. $0.12 \mathrm{~mm}$ ) than diameter of palp. Labella normal, each bearing 32 (male), or 26-31 (female) blunt spinules. Thorax with two notopleural bristles and without cleft. Scutellum with four equal bristles in both sexes. Abdominal venter hairy on segments 3-6. Bristles at rear margin of T6 stronger than any hair of hypopygium (Figs 23-24). Left side of epandrium with ca. 21 relatively short hairs. Hairs of epandrium weaker than stronger hairs of cerci. Left face of epandrium without postero-ventral lobe. Cerci with seven hairs. Micropubescence below proctiger predominantly semi-erect and pointing rearwards, partially erect in apical half. Left hypandrial lobe longer than right one, with erect to recurved microtrichia underneath. Micropubescence below right lobe semi-erect, pointing rearwards. Aedeagus with a short slender process that is a little longer than right hypandrial lobe. Process down-curved at tip. Abdominal venter of female hairy on segments 3-6, but hairs small and scattered except one enlarged hair at hind margin of segment 6 . T6 subquadrate, a little narrower than T5. Breadth of anterior notch of T6 about one fourth to one fifth of breadth of tergite. T7 unusually short and broad (Fig. 57). T8 very small, with 11 hairs on lateral and posterior margins. T10 bare. S7 broad, anteriorly with a sclerotised median strip (Fig. 61). Posterior lobes of sternum 8 broad, with several hairs of subequal length, terminal hairs not clearly differentiated from surrounding hairs (Fig. 80). Lobes not bulging and without distinct sclerotisations. Whole of segment 8 covered in microtrichia except posterior border of sternal lobes. Hairs of hypoproct not crowded towards anterior margin. Cerci $3 x$ as long as broad, with usual $5+1$ long hairs and an apical group of 5-6 short blunt hairs. Vaginal sclerite transverse, lying behind a lightly sclerotised cylindrical structure (ventral receptacle?) (Fig. 113). Dufour's crop mechanism large, emarginate posteriorly (Fig. 130). Fourth segment of front tarsus slightly shorter than fifth. Most hairs below basal half of hind femur longer than antero-ventral hairs in distal half. Wing length $2.75 \mathrm{~mm}$ (male), $3.0 \mathrm{~mm}$ (female). CI 0.49 (male), 0.54 (female). CR $3.4: 2.4: 1$ (male), $2.8: 1.9: 1$ (female). Longest cc ca. $0.20 \mathrm{~mm}$. Seven cal, $5-8$ ax. Subcosta fades away in distal half. Hair at base of Rs small $(0.030-0.051 \mathrm{~mm})$ or absent.

\section{Remarks}

See below M. breviseta. 


\section{Distribution}

M. rubricornis has been reported from various European countries, but records from other countries than Germany require confirmation.

\section{Megaselia sanguinea (SCHMITZ, 1922)}

(Figs 36-37, 52, 86, 116)

Apbiocbaeta sanguinea SCHNITZ, 1922: 98 () .

Megaselia sanguinea (SCHMITZ). SCHMTTZ, 1928: 145.

Megaselia sanguinea (SCHMTZ). SCHMITZ \& DELAGE, 1981: 707 (०\%).

Megaselia rubida auctt., nec (SCHMITZ, 1918).

\section{Type material}

Holotype: ㅇ. The Netherlands: Ommen, 11.vi.1921, leg. J.C.H. de Meijere (right wing mounted on separate slide) (remounted) (ZFMK).

\section{Other material examined}

The Netherlands: \&, Linschoten, 3.vi.1920, leg. J.C.H. de Meijere, "rubida" (ZFMK). Austria: ㅇ, Upper Austria, Kremsmünster, 6.vii.1904, leg. L. Czerny, without determination label but standing with M. rubida (ZFMK). Germany: o", Bavaria, Senden Hittistetten, emerged 21.-28.v.1992, reared from dead wood (stump of deciduous tree covered by moss); ơ, Bavaria, Senden, 3.vii.1992, on house window, both leg. M. Buck (coll. $\mathrm{MB})$.

M. sanguinea is another species which was described from females only. Six decades after its discovery DELAGE provided a description of a male found in the Schmitz collection (SCHMTTZ \& DELAGE, 1981). This specimen was determined by Schmitz himself as $M$. sanguinea but its discovery was never published. Judging from the (somewhat schematic) figure of the hypopygium (SCHMITZ \& DELAGE, 1981: Fig. 455) and some peculiarities of the description (colour of third antennal segment tending to reddish brown, left hypandrial lobe much longer than right one) it seems more probable that the investigated male belongs to $M$. bexanopbila. This hypothesis is supported by the fact that a $M$. hexanophila female was collected at the same locality only five days later (Valkenburg, o: $20 . v \cdot 1942$, $9: 25 . v \cdot 1942)$. Unfortunately only an empty pin of the male was found in the ZFMK so its identity remains uncertain. Below, two specimens are described which much more likely represent the male of $M$. sanguinea. In particular, they have the yellow third antennal segment of $M$. sanguinea, a character not found in any other species of the examined group.

\section{Description}

The description only includes characters which have not already been mentioned by SCHMITZ (1922) or SCHMITZ \& DELAGE (1981): Position of ant approximately midway between upper sa and al. Third antennal segment clear yellow (male) to dusky yellow (female holotype), rather than 'pale red' as stated by SCHMITZ (1922). Third antennal segment of male only slightly larger than in female. Only with $1(-2)$ rows of small to 
medium-sized SPS (0.004-0.011 mm) beneath inner face of segment, numbering about 10-20. Sensilla on base of third aristomere well separated. Labella not enlarged, with 3942 short spines in male and ca. 22 in female. Thorax yellow, without notopleural cleft. Anterior scutellar setae about one third (male) to two thirds (female) of length of posterior ones. Abdominal venter with hairs on segments 3-6 (male) or 2-6 (female). Hairs short but numerous in female. Male hypopygium (Figs 36-37) very similar to $M$. immodensior but anal tube relatively shorter when compared to length of dorsal face of epandrium. Hairs of hypopygium weaker than those at rear of abdominal segment 6. Epandrium brown, with 14-15 hairs on left face. Strongest bristle on each side about as strong as hairs of proctiger, a little stronger than those of cerci. Hind margin of left side forming an acute angle at ventral edge of anal tube. Postero-ventral lobe of right side of epandrium less produced than in $M$. citrinella. Cerci less than half as long as dorsal face of epandrium. Microtrichia below proctiger semi-erect, pointing rearwards. Hypandrial lobes with long and erect micropubescence, right lobe distinctly shorter than left one. Female abdomen: T6 about $1.25 \mathrm{x}$ as broad as long, breadth of anterior notch about one fifth of maximum width of tergite. T7 as in Fig. 52, but may be broader and distinctly notched anteriorly. T8 rectangular, with 23 hairs. T10 bare. S7 similar to $M$. bexanopbila (cf. Fig. 65). Posterior lobes of sternum 8 broad and with many hairs (Fig. 86). The enlarged hairs of the sternal lobes inserted well before margin, relatively spaced. Micropubescence of the lobes long, stopping shortly before the margin. Hairs of hypoproct not crowded towards anterior margin. Cerci of usual shape and chactotaxy, $3 \mathrm{x}$ as long as broad, with four short blunt-tipped hairs at apex. Vaginal sclerite large (Fig. 116), roughly semicircular and convex towards left side. Four rectal papillae in both sexes. Wing length 2.0-2.15 $\mathrm{mm}$ (male), $2.35 \mathrm{~mm}$ (female). CI 0.47-0.49 (male), 0.50 (female). CR 2.8-3.7:2.0-2.5: 1 (male), not measurable in holotype female because of poor condition, but surely not 5:3:1 as stated by SCHMITZ (1922). Longest cc 0.15-0.175 mm. With 4-8 cal and 3-4 ax, longest of the latter slightly shorter than longest cc. Hair at base of Rs $0.065-0.100 \mathrm{~mm}$.

\section{Distribution}

Hitherto only known from the Netherlands and (if the above described males in fact belong to $M$. sanguinea) Germany.

\section{Megaselia septentrionalis (SCHMITZ, 1919)}

(Figs 91, 104)

Apbiochaeta septentrionalis SCHMTTZ, 1919: 194 ( $\%)$.

Megaselia septentrionalis (SCHMTTZ). SCHMITZ, 1928: 145.

\section{Type material}

Holotype: ․ Sweden: Gellivare, vii.1910, right wing mounted on separate slide together with a hind leg of a $M$. labellaspinata male (see below this species) (remounted) (ZFMK).

\section{Other material examined}

Germany: Bavaria, Berchtesgaden National Park, Watzmann, o, 790 m, 5.v.-29.v.1997, ㅇ, $1380 \mathrm{~m}, 29$.v.-29.vi.1997, emergence traps over soil, spruce forest, leg. K. Liepold \& P. von Wrangell (coll. MB). 


\section{Description}

Only female known. The original description is to be complemented as follows: ant a little closer to al than to upper sa. Third antennal segment a little less than half as wide as frons, with a single irregular row of about twenty SPS around base. SPS medium to large size $(0.009-0.030 \mathrm{~mm})$. Cilia of arista about as long as diameter of basal aristomeres. Sensilla on swollen base of third aristomere well separated to closely approximated. Palps yellowish brown, longest bristle about twice as long as breadth of palp. Labrum a little broader than third antennal segment. Each labellum with 6-7 pseudotracheae and 40-51 spinules below. Notopleuron with two bristles. Abdominal venter hairy on segments 2-6, with those of segment 2 reduced to microscopic setulae. Hairs at hind margin of segment 6 enlarged. T6 trapezoid, $1.0-1.2 \mathrm{x}$ as broad as long. Width of anterior notch ca. one fourth to one fifth of width of tergite. T7 expanded anteriorly, at most shallowly notched, similar to $M$. densior (Fig. 55). T8 rectangular, with 17-25 hairs. T10 bare. S7 moderately broad, with 3-4 enlarged hairs posteriorly, similar to $M$. bexanophila (Fig. 65). Segment 8 micropubescent over whole surface except posterior border of sternal lobes (Fig. 91). Posterior lobes with (2-) 3 enlarged hairs, at least one of which is well separated from hind margin. Lobes a little bulging laterally. Hairs of hypoproct a little crowded towards anterior margin. Cerci with $5+1$ long hairs plus $3(-4)$ short blunttipped ones near apex. Vaginal sclerite a small and lightly sclerotised ring (Fig. 104). Dufour's crop mechanism with two posterior lobes. (?3-)4 rectal papillae. Longest hairs below basal half of hind femur as long as, or longer than hairs of antero-ventral row in distal half. Wing length $2.4-2.9 \mathrm{~mm}$. CI $0.49-0.50$. CR 2.7-3.7: 1.4-2.1 : 1. Longest cc 0.15-0.17 mm. 5-9 cal, 3-6 ax. Hair at base of Rs small (0.034-0.054 mm) or absent.

\section{Distribution}

M. septentrionalis apparently has a boreo-alpine distribution, at present being known from northern Sweden and the German Alps.

\section{Megaselia trojani DISNEY, 1998}

(Figs 10, 40-41)

Megaselia trojani Disney in DISNEY \& DURSKA, 1998: $445\left(0^{\star}\right)$.

Megaselia badia auctt., nec SCHMITZ, 1938: PRESCHER \& BELLSTEDT, 1994: 46.

This species was described from a single male from Poland. We now report further males from Germany, Scotland and Wales and add further comments on its recognition.

\section{Type material}

Holotype: $0^{7}$. Poland: Białowieska Forest, 26.ix.1986, leg. ㅇ. . Durska (mounted on slide) (CUMZ).

\section{Other material examined}

Germany: Bavaria, $\sigma^{\star}$, Senden Hittistetten, 19.viii.-2.ix.1992, pitfall trap, spruce forest; o, same locality, 26.viii.-9.ix.1993, carrion trap baited with kidney, deciduous forest, both leg. M. Buck (coll. MB); ơ, Berchtesgaden National Park, Watzmann, 1180 m, 26.vii.20.viii.1997, emergence trap over soil, spruce forest, leg. K. Liepold \& P. von Wrangell (coll. MB); Baden-Württemberg, Langenau, 2 o, 13.-27.viii.1996, 2 o*; 9.-23.ix.1996, 
2 o $^{*}$,26.viii.-11.ix.1997, cone trap (eclector) on artificial tree trunk, on, 4.-18.vi.1998, trap baited with agar plate, leg. A. Kopf (coll. MB); on, Thuringia, Luisenthal, Kernwasser, 15.viii.1982, leg. R. Bellstedt (coll. S. Prescher). Great Britain: $\sigma^{2}$, Scotland, Loch Garten, Tore Hill, grid ref. 28/982175, vii.1981, leg. J.A. Owen (CUMZ); ot, Wales, Merioneth, Cae Safydd, grid ref. 23/6146, 14.vii.1976, leg. P.J. Chandler (CUMZ).

\section{Description}

Only male known with certainty. However, Megaselia sp. 1 females (see below) which were collected together with $M$. trojani males at two collecting sites could belong to this species. For description of the male refer to DISNEY \& DURSKA (1998) plus following amendments: SPS very numerous ( $>30$ ), distributed around base of third antennal segment, but most numerous on inner face; there being arranged in 3-6 irregular rows. SPS of small to medium size, diameter $0.006-0.015 \mathrm{~mm}$. Sensilla on swollen base of third aristomere broadly separated. Labella with 14-22 brownish spinules and some longer hairs below. Thorax (including internal metafurcae, Fig. 10) brown, of same colour as frons and abdominal tergites. Hypopygium as in Figs 40-41. Left side of epandrium with 10-19 hairs. Postero-ventral lobe of right side of epandrium not strongly convex (as in M. citrinella), not distinctly raised above level of hind margin. Cerci with (6-)7 hairs. Micropubescence below proctiger semi-erect, inclined rearwards (Fig. 40). When the aedeagus is somewhat extruded a peculiar brush-like structure becomes visible on the right side (Fig. 40). (3-) 4 rectal papillae. Wing length $1.35-1.8 \mathrm{~mm}$. CI 0.445-0.48. CR 2.7$3.6: 1.4-2.0: 1$. Longest cc $0.10-0.135 \mathrm{~mm}$ long. $4-6 \mathrm{cal}, 3-4 \mathrm{ax}$. Hair at base of Rs small to medium size $(0.026-0.054 \mathrm{~mm})$, exceptionally absent or two hairs present.

\section{Distribution}

Reported from Poland, Germany and Britain.

\section{Megaselia xanthophila BUCK sp. n.}

(Figs 32, 77, 114, 133-135)

Megaselia badia auctt., nec SCHMTTZ, 1938: DISNEY \& IRWIN, 1978: 378.

\section{Type material}

Holotype: ơ. Sweden: Torne Lappmark, Abisko, 13.-17.vii.1991, yellow water trap, low Salix/Vacinium scrub, leg. M. von Tschirnhaus (critical-point dried and glued to the side of a pin) (ZFMK). Paratypes: 83 o, 38 \%. Same data as holotype except some specimens collected in white water traps (coll. MB [6 $60^{\star} 6$ \% mounted on slides, rest in alcohol], $3 \sigma^{*}$ 3 o CUMZ [mounted on slides], 2 of 3 ZFMK [critical-point dried and glued to the side of a pin]).

\section{Other material examined}

Germany: 9 , Baden-Württemberg, Ulm, Eselsberg, 27.v.-5.vi.1981, yellow water trap, deciduous forest, leg. R. Grimm (coll. MB). Great Britain: o, Scotland, Perthshire, Pass of Killiecrankie, grid ref. 27/9162, 19.vi.1976, leg. A.G. Irwin (CUMZ).

\section{Etymology}

The species is named for its preference for yellow water traps (see Table 3). 


\section{Diagnosis}

A generally brown species with yellow palps and pale brown front and middle legs. ant a little closer to al than to upper sa, rarely midway between them or slightly closer to the latter. Third antennal segment only with a few small to medium-sized SPS. Palps normal. Labella of male enlarged and with dense fields of short spines on lower face. Notopleuron with two bristles and no cleft. Anterior scutellar setae usually short in male, long in female. Abdominal venter hairy on segments 3-6. Epandrium only with short hairs that are at most as strong as those of cerci. Terminal hairs of proctiger indistinctly stronger than those of cerci. Anal tube short, pale brown. Left hypandrial lobe shorter than right one. Hypandrial lobes with decumbent to semi-erect microtrichia. Female T6 subquadrate with broad anterior notch. T7 anteriorly expanded. S7 moderately broad. Posterior lobes of sternum 8 each with a conspicuous laterally projecting bulge. Each bulge bears three enlarged hairs. Vaginal sclerite a large loop with an irregular posterior extension. Hind leg darker than middle and front leg. Longest hairs below basal half of hind femur a little longer than those of antero-ventral row in distal half, but relatively shorter and often subequal in female. CI more than 0.44. Costal section 1 longer than sections $2+3$. cc of normal length. Subcosta fades away in distal half. Normally with a hair at base of Rs. (1-)2-4 ax which are about as long as cc. Knob of haltere yellow, stem brown.

\section{Description}

Male. Frons a little broader than long, with 35-75 hairs and dense microtrichia. sa closer to eye margin than to median furrow. Third antennal segment subglobose, diameter less than half frontal width. Only 5-20 SPS which are arranged in 1(-2) irregular tows beneath inner face of segment, absent or scarce on outer face. Diameter of SPS 0.006$0.016 \mathrm{~mm}$. Arista brown, cilia a little longer than diameter of basal joints. Sensilla at base of third aristomere usually well separated. Palps with 5-8 bristles, the longest of which is about twice as long $(0.09-0.13 \mathrm{~mm})$ as breadth of palp. Prementum with two pairs of hairs. Labrum narrower than third antennal segment. Labella with 5 pseudotracheae, 60120 spinules and some longer hairs below. Anterior scutellar setae longer than hairs of thoracic scutum, length about one third to (rarely) four fifths of posterior ones. Abdominal tergites short-haired, with a group of somewhat enlarged hairs near postero-lateral corner of $\mathrm{T} 2$ and a row of long bristle-like hairs at rear of T6. Hairs of venter of segment 3 usually very small and those at rear of segment 6 strong. Bristles at hind margin of T6 conspicuously longer than any hair of hypopygium (Fig. 32). The latter appears somewhat laterally compressed with the surface of the left hypandrial lobe typically oriented in a more or less vertical plane. Epandrium with 16-31 hairs on left side. On this side hind margin of epandrium bent forward below ventral base of anal tube. Postero-ventral corner of epandrium devoid of microtrichia. Hind margin on right side of epandrium almost vertical to slightly convex below anal tube. Two rectal papillae (however, in most specimens the view on internal organs was obscured so this count might not be representative). Fore tarsus with postero-dorsal hair palisade on all five segments. Ratios of lengths of front tarsal segments about $2.9: 1.4: 1.2: 1.0: 1$. Postero-dorsal bristles of hind tibia moderately developed, spines in apical comb all simple. Wing length $1.4-1.95 \mathrm{~mm}$. CI $0.45-0.48$. CR 1.9-2.8: 1.1-1.9: 1 . Longest cc $0.10-0.15$ $\mathrm{mm}$. (2-)3-6 cal. Hair at base of Rs short to long $(0.022-0.080 \mathrm{~mm})$, rarely missing. Wing membrane tinged brownish. First thin vein originates beyond fork of Rs. 
Female. Similar to male but differs as follows: Labrum strong, broader than third antennal segment. Labella hardly enlarged, only with $22-44$ spinules below. Anterior scutellar bristles about two thirds as long as posterior ones. Width of abdominal tergites gradually decreasing from segment 2 to 6 . T6 1.1-1.3x as broad as long, width of anterior notch $0.3-0.45 \mathrm{x}$ breadth of tergite. Hairs of abdominal venter weak except those at rear of segment 6 . Hairs beneath segments 3 and 4 often reduced to microscopic setulae. T7 moderately expanded anteriorly, similar to $M$. giraudii (Fig. 49). T8 rectangular, with 1326 hairs. T10 bare. S7 somewhat variable, ranges from being as broad as in Fig. 64 to being as narrow as in Fig. 63. Posteriorly it is expanded and bears 3-4 long hairs. Posterior half of sternum 8 covered in microtrichia, except bare hind margin of posterior lobes (Fig. 77). Bulges of sternal lobes each with three long and sometimes a weaker fourth hair on edge. Hind margin of lobes sclerotised, darker brown. Hairs of hypoproct not crowded towards anterior margin. Cerci $3-4 \mathrm{x}$ as long as broad, with $5+1$ long hairs and a group of 3(-6) short blunt-tipped hairs at apex. Vaginal sclerite relatively large, as in Fig. 114. Dufour's crop mechanism variable, in Scandinavian specimens only slightly emarginate or with two short lobes (Figs 133-134). A female from Germany has longer lobes (Fig. 135) but otherwise is indistinguishable from the northern European specimens. Four rectal papillae. Wing length $1.65-2.3 \mathrm{~mm}$. CI 0.46-0.505. CR 2.2-3.6 : $1.3-2.4: 1$.

\section{Distribution}

Only known from Sweden, Great Britain (Scotland) and Germany.

Descriptions of unnamed females of the $M$. giraudii/densior group

\section{Megaselia sp. 1}

(Figs 75, 127)

\section{Material examined}

Germany: Bavaria, Senden Hittistetten, 6 ㅇ 9 9.-23.ix.1993, ㅇ, 7.-14.x.1993, carrion traps baited with kidney, deciduous forest, leg. M. Buck; 2 \%, Berchtesgaden National Park, Watzmann, $1180 \mathrm{~m}, 26 . v i i .-20 . v i i i .1997$, emergence trap over soil, spruce forest, leg. K. Liepold \& P. von Wrangell (all in coll. MB).

This could be the female of $M$. trojani.

\section{Diagnosis}

Generally similar to $M$. giraudii. Differs from this species as follows: ant midway between al and upper sa or a little closer to the latter. Labella with 15-19 blunt spinules below. Sternum 8 covered in microtrichia except sometimes small area near fore margin. Posterior lobes indistinct, broadly separated (Fig. 75). The three enlarged bristles of these lobes further apart than in M. giraudii. Differs from all other species of the present work by possessing a third, median lobe between the two postero-lateral lobes. Vaginal sclerite absent. Posterior lobes of Dufour's crop mechanism arising from a relatively long common base (Fig. 127). Wing length 1.5-2.15 mm. CI 0.45-0.49. (2-)3-4 ax. 
Megaselia sp. 2

(Figs 92, 105)

\section{Material examined}

Germany: $q$, Baden-Württemberg, Ulm, Eselsberg, 20.v.-10.vi.1981, window trap, deciduous forest, leg. R. Grimm; 9 , Bavaria, Senden Hittistetten, 8.-22.vii.1992, pitfall trap, spruce forest, leg. M. Buck (both in coll. MB).

\section{Diagnosis}

Very similar to $M$. giraudiz. Differs by the following details: ant a little closer to al than to upper sa. Labella with 13-17 spinules below. S7 narrow, similar to Fig. 67 but with four enlarged hairs at rear and 3-6 on disc. Posterior lobes of sternum 8 with relatively broad but not very much produced bulges (Fig. 92). Hind margin of sternal lobes translucent and delicate. Thus the bulges themselves appear to represent the hind margin of the lobes. The enlarged hairs of the bulges further apart than in M. giraudii. Hairs of hypoproct not crowded towards anterior margin. A very weakly sclerotised ring-like vaginal sclerite present (Fig. 105). 3-4 rectal papillae. Wing length $1.4-1.95 \mathrm{~mm}$. CI $0.43-0.455$. CR 3.0-3.2 : 1.3-1.5 : 1. 3-6 cal, 2-4 ax. Hair at base of Rs minute (ca. $0.020 \mathrm{~mm}$ ) or absent.

\section{Megaselia sp. 3}

(Figs 72, 101)

\section{Material examined}

Germany: + , Bavaria, Senden Hittistetten, 4.-11.vi.1993, carrion trap baited with kidney, spruce forest, leg. M. Buck (coll. MB).

\section{Diagnosis}

Very similar to $M$. giraudii. Differs from this species as follows: ant closer to al than to upper sa and closer to eye margin than to median furrow. S7 like in $M$. bexanopbila (Fig. 65). Posterior lobes of sternum 8 with small and projecting bulges, internal surface sclerotised (Fig. 72). Hairs of hypoproct not crowded towards anterior margin. Vaginal sclerite developed as a weakly sclerotised ring (Fig. 101). Wing length $1.7 \mathrm{~mm}$. CI 0.47. CR 4.3-4.4: $2.3: 1.4-5$ cal, three ax.

\section{Megaselia sp. 4}

(Figs 62, 89, 118)

\section{Material examined}

Without locality data (probably the Netherlands): ㅇ, 23.v.1919 (red label); ㅇ, 8.v.1920, + , 9.v.1920 (yellow labels), (misidentified as M. albicans) coll. Schmitz (ZFMK).

\section{Diagnosis}

Differs from $M$. giraudii as follows: ant approximately midway between al and upper sa and about midway between eye margin and median furrow. Diameter of SPS 0.005$0.017 \mathrm{~mm}$. T7 long and narrow, similar to M. cf. albicans (Fig. 51 ). S7 (Fig. 62) narrower 
than in $M$. girandii. Sternum 8 almost indistinguishable from $M$. giraudii but medially devoid of microtrichia (including area between posterior lobes) (Fig. 89). Hairs of hypoproct somewhat crowded towards anterior margin, but microtrichia between these crowded hairs present. Cerci with group of 6-9 blunt spines at apex. Vaginal sclerite long and weakly sclerotised, expanding posteriorly (Fig. 118). Lobes of Dufour's crop mechanism extremely long and narrow. Wing length $2.5-2.65 \mathrm{~mm}$. CI $0.48-0.49$. CR 2.8-3.3 : 1.4$2.0: 1.5-7 \mathrm{cal}, 4-5 \mathrm{ax}$. Hair at base of Rs $0.064-0.080 \mathrm{~mm}$.

\section{Megaselia sp. 5}

(Figs 83, 108, 128)

\section{Material examined}

Germany: Baden-Württemberg, Langenau, ㅇ, 9.-23.ix.1996, ㅇ, 14.-26.viii.1997, cone trap (eclector) on artificial tree trunk, leg. A. Kopf; Rhineland-Palatinate, Mainz, Lennebergwald, of, 23.vi.-11.vii.1988, \&, 10.-25.viii.1988, emergence trap over soil, pine forest, leg. R. Feldmann (all in coll. MB).

\section{Diagnosis}

Very similar to $M$. mimodensior, differs as follows: ant about midway between upper sa and al, sometimes closer to the former, sometimes closer to the latter. T10 usually bare, in one specimen with two hairs. S7 with 4(-6) long hairs posteriorly, similar to $M$. hexanophila (Fig. 65). Sternum 8 covered in microtrichia except sometimes medial area of anterior third. Sternal lobes (Fig. 83) indistinguishable from $M$. mimodensior. Cerci with apical group of four short blunt-tipped hairs apart usual 5+1 long hairs. Vaginal sclerite narrower than in $M$. mimodensior, developed as a flat transverse strip, sometimes a little upcurved on right side (Fig. 108). Dufour's crop mechanism with long lobes (Fig. 128). Four rectal papillae. Wing length $1.8-2.05 \mathrm{~mm}$. CI $0.455-0.49$. CR 3.0-3.7 : 1.8-2.3: 1. 4$5 \mathrm{cal}, 3-4$ ax. Longest cc $0.135-0.165 \mathrm{~mm}$. Hair at base of Rs long $(0.057-0.086 \mathrm{~mm})$.

\section{Megaselia sp. 6}

(Figs 90, 103)

\section{Material examined}

Sweden: ㅇ, Torne Lappmark, Abisko, 13.-17.vii.1991, yellow water trap, low Salix/Vaccinium scrub, leg. M. von Tschirnhaus (coll. MB).

\section{Diagnosis}

Differs from $M$. giraudii as follows: ant closer to eye margin than to median furrow. T6 as broad as long. T7 similar to Fig. 55. T10 with one hair. S7 similar to M. bexanopbila (Fig. 65). Segment 8 micropubescent on whole surface, except bare hind margin to sternal lobes. The three long hairs of the latter are more separated (Fig. 90) than in M. giraudii. Cerci with apical group of four short blunt hairs apart usual $5+1$ long hairs. Vaginal sclerite present, strongly sclerotised and with a hole on right side (Fig. 103). Dufour's crop mechanism similar to $M$. bexanophila (Fig. 125). Wing length $2.2 \mathrm{~mm}$. CI 0.475 . CR 3.5-3.7: 1.5-1.6: 1. Six cal, four ax. 


\section{Megaselia sp. 7}

(Figs 53, 73, 100)

\section{Material examined}

Great Britain: ㅇ, England, Norfolk, Catfield Fen, 5.viii.1982, leg. I.F.G. McLean (CUMZ).

\section{Diagnosis}

Differs from $M$. giraudii as follows: Frons with ant slightly nearer to al than to upper sa. T6 1.1 $\mathrm{x}$ as broad as long. The breadth of its notch is about one third of its maximum breadth. T7 Y-shaped (Fig. 53). T8 rectangular, with 10 hairs. S7 as in Megaselia sp. 4 (cf. Fig. 62). Sternal lobes of segment 8 only with two enlarged hairs posteriorly (Fig. 73). Hairs of hypoproct only a little more crowded in the extreme median anterior position. Vaginal sclerite fenestrate and strongly sclerotised (Fig. 100). Only three rectal papillae. Wing $2.1 \mathrm{~mm}$ long. CI 0.46 . CR $3.15: 1.95: 1.4-5 \mathrm{cal}$, three ax.

\subsection{Descriptions of other species}

M. rubida and $M$. ustulata were included in the present revision because from published descriptions it became not clear whether they belonged into the $M$. giraudii/ densior group. Upon examination of the holotype it was discovered, however that $M$. rubida has an ovipositor of the parasitic type and thus was to be excluded from the complex under study. The hypopygium of $M$. ustulata differs clearly from other species of the $M$. giraudii/densior group but in the absence of females it remains uncertain whether the species does belong to this group or not. Finally, $M$. nigrescens was re-examined because occasionally specimens belonging to the giraudii/densior complex have been wrongly assigned to this species. To enhance their recognition all three species are briefly characterised below.

\section{Megaselia nigrescens (WooD, 1910)}

(Figs 56, 96, 120, 132)

Phora nigrescens WOOD, 1910: 244 (

Apbiocbaeta nigrescens (WOOD). BRUES, 1915: 125.

Megaselia nigrescens (WOOD). SCHMTTZ, 1928: 145.

Specimens of several species of the $M$. giraudii complex were wrongly attributed to $M$. nigrescens prior to the designation of the lectotype (DISNEY, 1985) and the subsequent characterisation of the male (DISNEY, 1989a). Because of these confusions the records of $M$. nigrescens reared from fungi by I. Eisfelder (SCHMTTZ, 1948) were cited as Megaselia sp. by DISNEY (1994). However, since then samples of Eisfelder's material were found in the spirit collection of the ZFMK by RHLD. Males and females of her $M$. nigrescens were therefore mounted on slides and the identity of the males confirmed. The recognition of the female, which was not adequately characterised by WOOD, is clarified below.

\section{Material examined}

Germany: 7 đ̛ 5 \%, Bavaria, Dist. Erlangen, 20.vii.-3.ix.1945, leg. I. Eisfelder (ZFMK, CUMZ). 


\section{Recognition}

SPS absent. The male hypopygium has been figured by DISNEY (1989a: Fig. 453). The lack of a postero-dorsal hair palisade on the fifth fore tarsal segment will distinguish both sexes from species of the $M$. giraudii/ densior group. The simple Dufour's crop mechanism (Fig. 132), the characteristic vaginal sclerite (Fig. 120), and the short anterior scutellar setae will further distinguish the female. Lobes at rear of sternum 8 as Fig. 96. T7 as Fig. 56.

\section{Distribution}

Reported from England, Germany and the Netherlands.

\section{Megaselia rubida (SCHMITZ, 1918)}

(Figs 48, 59, 97-98)

Apbiochaeta mbida SCHMTZ, 1918: 144 (9).

Apbiocbaeta rubida SCHMITZ. LUNDBECK, 1922: 252 (ð + ).

Megaselia rubida (SCHMITZ). SCHMITZ, 1928: 145.

\section{Type material}

Holotype: $\&$ (head missing). Poland: Silesia, Nimptsch [= Niemcza], 24.vi.1911, leg. O. Duda (remounted) (ZFMK).

M. rubida was described from a single female collected in Poland. The only two other specimens in the Schmitz collection labelled as rubida, both females, are in fact $M$. sanguinea (see below this species). It remains to be proven whether the only described male from Lohals, Denmark (LUNDBECK, 1922) really is conspecific with the holotype.

\section{Description}

Differs from species of the $M$. giraudii/densior complex in possessing three notopleural setae and an ovipositor of the parasitic type. The original description can be complemented as follows: Abdominal venter hairy on segments 3-6 (segment 2 only bearing some vestigial pale setulae). T6 peculiar, with extremely broad and deep anterior notch (Fig. 48). Ovipositor very long (ca. $1.3 \mathrm{~mm}$ ), extruded almost as long as preabdomen. Segment 7 only with a few scattered setae. T7 oblong trapezoid (Fig. 59). T8 4x as long as broad, rectangular with rounded corners, and only with three hairs that are more or less directed anteriorly. T10 bare, with very long anterior apodemes (Fig. 98). Epiproct with about a dozen very fine and short setae, plus an apical pair of somewhat enlarged hairs. S7 wedge-shaped, expanded posteriorly, and with nine hairs. Its length is about $5 \mathrm{x}$ its width at posterior margin. Segment 8 devoid of microtrichia except anterior two fifths and margins of posterior lobes (Fig. 97). Each lobe only with 7-8 short hairs posteriorly. A row of 5-6 isolated hairs in front of these lobes extends about half-way towards anterior margin of segment. Segment 8 otherwise completely bare. Hypoproct with scattered short hairs on disc that are not crowded towards anterior margin. Apical pair of setae only slightly enlarged, a lateral pair of long hairs missing. Cerci stout, only about twice as long as broad. Dorsal surface of cerci only with four very short setae, lower side with four longer hairs plus three very short ones. Microtrichia restricted to lateral surface of cerci. Vaginal sclerite absent. Four rectal papillae. Wing length about 
$2.5 \mathrm{~mm}$. CI 0.52. CR 3.3-3.4:2.0:1. Longest cc at least $0.13 \mathrm{~mm}$ (most tips broken off). 5-6 cal and 3-4 ax, the latter slightly longer than costal cilia. Hair at base of Rs pale and vestigial (ca. $0.015 \mathrm{~mm}$ long).

\section{Recognition}

The female is easily recognised by its specialised ovipositor, missing vaginal sclerite and yellow third antennal segment. Most other Megaselia with an ovipositor of the parasitic type are distinguished from $M$. rubida by their hairy mesopleuron. Those with a bare mesopleuron differ from $M$. rubida in possessing very small anterior scutellar setae (M. nudipleura (BEYER, 1958)) or a differently shaped abdominal T6 plus a brown thorax (M. emarginata (WOOD, 1908)). M. furcilla (SCHMITZ, 1956) (only male described) can be distinguished by its fine and short vein $\mathrm{R}_{2+3}$ (fork of wing vein $\mathrm{Rs}$ unusually small).

\section{Distribution}

Hitherto only known from Poland.

\section{Megaselia ustulata (SCHMITz, 1920)}

Apbiocbaeta ustulata SCHMITZ, 1920:150( $\left.0^{\star}\right)$.

Megaselia ustulata (SCHNITZ). SCHMITZ, 1928: 145.

Apbiocbaeta pallida LUNDBECK, 1921: 138. LUNDBECK, 1922: 346 (synonymy).

\section{Type material}

Holotype: 0 . The Netherlands: Limbricht, $4 . v i .1917$ (pinned, right wing mounted on slide) (ZFMK). Note: the specimen is in very poor condition. Head, fore legs, one mid leg, one hind leg and left wing missing, left side of thorax eaten away.

The holotype is the only specimen of this species in the Schmitz collection. A female tentatively attributed by Schmitz to $M$. ustulata is not that species. It differs from $M$. ustulata in possessing three notopleural setae.

\section{Description}

The original description is to be complemented as follows: Thorax with two notopleural bristles and without cleft. Anterior scutellar setae only about one fourth of length of posterior ones. Abdominal venter with hairs on segments 3-6. Epandrium on both sides with one hair that is a little but distinctly stronger than those of proctiger. Left side of epandrium extending far below anal tube, with at least 12 additional weaker hairs. Anal tube longer than dorsal face of epandrium. Each cercus with at least 14 hairs that are weaker than those of proctiger. Wing length $1.7 \mathrm{~mm}$. CI 0.51. CR 2.6:1.9:1. Longest cc $0.10 \mathrm{~mm}$. Subcosta fading away before reaching $\mathrm{R}_{1}$. Three ax and three cal. No hair at base of Rs. Hairs below basal half of hind femur longer than those of antero-ventral row in distal half. Hind tibia with simple spines in apical comb.

\section{Recognition}

Easily distinguished from all other species mentioned in this paper by the combination of a very long anal tube and the high number of hairs on cerci. The yet unknown female will be distinguishable from $M$. sanguinea (which also has a yellow third antennal segment) by the missing hair at base of vein Rs. 


\section{Distribution}

Only recorded from the Netherlands, Denmark and 'Prussia' (= Germany or Poland) (SCHMTTZ, 1928).

\section{Biology}

\subsection{Materials and Methods}

Rearing experiments, baited and unbaited traps. Most specimens included in this revision were obtained by rearing and trapping experiments conducted by MB in 199294 (for more extensive information on the involved techniques see BUCK, 1997a, b). Experimental sites included a humid deciduous forest, a spruce stand, a meadow, and an arable field near Senden Hittistetten, Dist. Neu-Ulm, Bavaria, Germany $\left(48^{\circ} 20^{\prime} \mathrm{N}\right.$ $10^{\circ} 07^{\prime} \mathrm{E}$ ). In rearing experiments a variety of baits (see Table 1) and some substrates collected in the field (tents containing caterpillars and pupae of the ermine moth, Yponomenta sp. (Lep.); samples of dead wood) were used. Baits were exposed in the field and later set under laboratory emergence traps (see Fig. 1 in BUCK, 1997a) to collect the emerging fauna. Trapping involved bait traps (baits see Table 2), odour traps, emergence traps ('photo-eclectors') and pitfall traps. In odour traps three different chemicals were used: $10 \% 1$-phenylethanol (1-PE) in $\mathrm{n}$-hexane, pure $\mathrm{n}$-hexane, and capronic acid. The use of 1-PE and n-hexane was inspired by the study of KAMM et al. (1987) who observed an attraction of certain Megaselia species to 1-PE.

Table 1. Results of rearing experiments conducted in southern Germany - specimens per substrate and habitat.

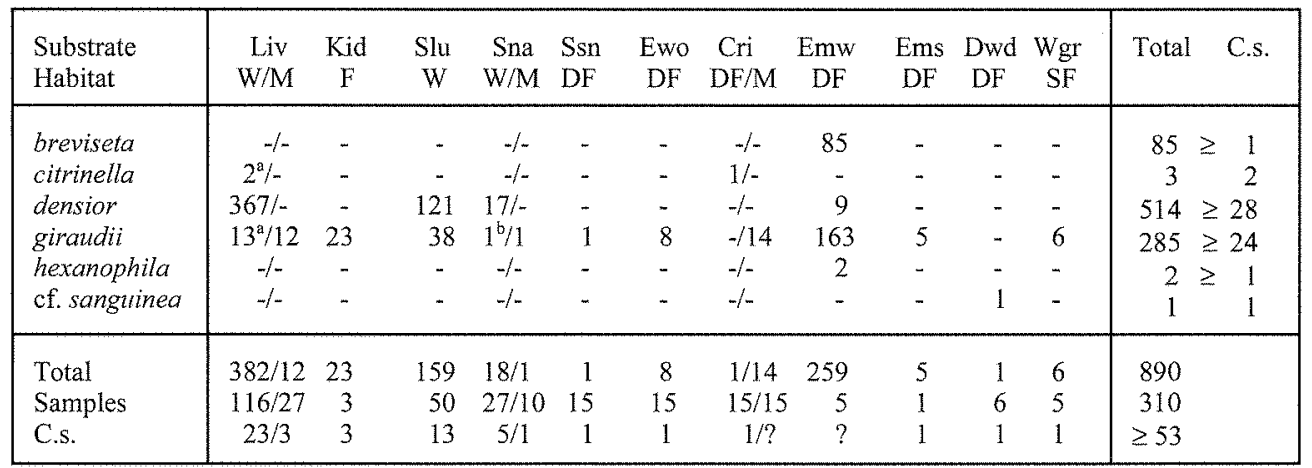

Note: all substrates except ermine moths and dead wood were baits. Abbreviations: Liv - liver; Kid kidney; Slu - slugs (Arion ater); Sna - snails (Arianta arbustorum); Ssn - small snails (Trichia villosa); Exo earthworm (Lumbricus sp.); Cri - crickets (Acbeta domesticus); Emw - larval/pupal tents of ermine moths (Yponomenta sp.), weakly decayed; Ems - dto., strongly decayed; Dwd - dead wood from deciduous trees; Wgr - wheat grains; C. s. - number of successfully colonised samples. Habitats: W - deciduous forest (DF) and/or spruce forest (SF), M - meadow; $\mathrm{F}$ - arable field; ${ }^{*}$ - only in samples from site DF; ${ }^{b}$ - only in samples from site SF.

Coloured water traps. In 1991 an extensive experiment on colour preference in insects was conducted by M. von Tschirnhaus and collaborators in northern Sweden (MANNESMANN \& VON TSCHIRNHAUS, 1991). Phorids of this experiment were kindly send to MB 
for identification and results concerning the $M$. giraudii/densior group are presented below. The experiment was conducted near the shore of Lake Torneträsk, Abisko, Torne Lappmark, Sweden ( $\left.68^{\circ} 20^{\prime} \mathrm{N} 18^{\circ} 52^{\prime} \mathrm{E}\right), 440 \mathrm{~m}$ a. s. 1., on a northern-exposed slope with tundra-like vegetation (low scrub of various Salix and Vacinium species). In this habitat

Table 2. Catches of baited and unbaited traps operated in southern Germany - specimens per trap type and habitat

\begin{tabular}{|c|c|c|c|c|c|c|c|c|c|c|c|c|c|c|c|}
\hline & \multicolumn{9}{|c|}{ Bait traps } & \multicolumn{2}{|c|}{ Odour traps } & \multicolumn{3}{|c|}{ Unbaited traps } & \multirow{4}{*}{ Total } \\
\hline Bait/Trap type & & & & \multicolumn{3}{|c|}{ Kidney } & \multicolumn{3}{|c|}{ Sna Fng } & \multicolumn{2}{|c|}{ Phe Hex Cap } & \multicolumn{3}{|c|}{ Control ET PT } & \\
\hline Habitat & SF & DF & DF & $\mathrm{DF}$ & $\mathrm{DF}$ & M & $\mathrm{F} \mathrm{D}$ & DF 1 & DF & DF $\quad \mathrm{DF}$ & $\mathrm{DF}$ & SF DF & $\mathrm{SF} S$ & SF & \\
\hline Height $(\mathrm{cm})$ & 0 & 0 & 60 & 180 & bur. & 0 & 0 & 0 & 0 & $0 \quad 0$ & 0 & $0 \quad 0$ & - & - & \\
\hline citrinella & 1 & 1 & 1 & 2 & - & - & - & - & 1 & - & - & - & 1 & - & 7 \\
\hline densior & 127 & 31 & 15 & 24 & 3 & 3 & -3 & 38 & 12 & - & - & - & 5 & - & 258 \\
\hline giraudii & 24 & 17 & 45 & 132 & - & 9 & 102 & 23 & 4 & 133 & - & - & 4 & 5 & 307 \\
\hline hexanophila & 1 & - & 11 & 28 & _. & - & - & - & 1 & 17106 & 1 & - & - & - & 165 \\
\hline parnassia & 5 & - & 6 & 6 & - & - & - & - & - & -7 & - & - & - & - & 24 \\
\hline quadriseta & 1 & 9 & 1 & 5 & - & - & - & 1 & - & 2 & - & - & - & - & 19 \\
\hline trojani $\left(0^{\prime}\right)$ & - & - & - & 1 & - & - & - & - & - & - & - & - & - & 1 & 2 \\
\hline sp. $\left(0^{*}\right)$ & - & - & - & - & - & - & - & - & - & - & - & 1 & - & - & 2 \\
\hline sp. 1(q) & - & - & 2 & 5 & - & - & - & - & - & - & - & - & - & - & 7 \\
\hline sp. 2() & - & - & - & - & - & - & - & - & - & - & - & - & - & 1 & 1 \\
\hline sp. 3(q) & 1 & - & - & - & - & - & - & - & - & - & - & - & - & - & 1 \\
\hline Total & 160 & 58 & 81 & 203 & 3 & 12 & 10 & 62 & 18 & $18 \quad 148$ & 1 & 11 & 10 & & 793 \\
\hline Trapping weeks & 52 & 50 & 52 & 52 & 16 & 52 & 47 & 50 & 13 & $923^{\mathrm{a}}$ & a 3 & $5254^{\mathrm{b}}$ & 52 & 52 & \\
\hline
\end{tabular}

Note: two traps of each type were operated, except for 'control' in spuce forest (one trap), emergence traps and pitfall traps (five traps each). Abbreviations: Baited traps: Kidney - hog kidney; Sna - snails (Helix pomatia); Fng - fungi (Agaricus bisporus). Height: height above ground of bait trap opening; bur. - buried (trap design see BuCK, 1997b: Fig. 5). Odour traps: Phe - 10\% 1-phenylethanol in n-hexane; Hex - nhexane; Cap - capronic acid. Unbaited traps: Control - same design as bait traps; ET - emergence trap ("photoeclector); PT - pitfall trap. Habitat abbreviations: see Table $1 .{ }^{a}$ - the second trap 20 weeks; ${ }^{b}$ - the second trap 26 weeks.

Table 3. Catches of coloured water traps operated in Swedish Lapland (experiment conducted by von Tschirnhaus et al.) - males/females per trap type.

\begin{tabular}{|l|cccc|cccc|c|}
\hline Trap type & YL & YS & WL & WS & $\begin{array}{c}\text { Y } \\
\text { L+S }\end{array}$ & $\begin{array}{c}\text { W } \\
\text { L+S }\end{array}$ & $\begin{array}{c}\text { L } \\
\text { Y+W }\end{array}$ & $\begin{array}{c}\text { S } \\
\text { YW }\end{array}$ & Total \\
\hline glabrimargo & $2 / 4$ & $1 /-$ & $1 /-$ & - & $3 / 4$ & $1 /-$ & $3 / 4$ & $1 /-$ & $4 / 4$ \\
immodensior & $8 / 10$ & - & $2 / 3$ & $1 /-$ & $8 / 10$ & $3 / 3$ & $10 / 13$ & $1 /-$ & $11 / 13$ \\
mimodensior & $23 / 8$ & $18 / 1$ & $27 / 15$ & $26 / 10$ & $41 / 9$ & $53 / 25$ & $50 / 23$ & $44 / 11$ & $94 / 34$ \\
parnassia & $29 / 23$ & $23 / 13$ & $34 / 10$ & $24 / 9$ & $51 / 36$ & $58 / 19$ & $63 / 33$ & $46 / 22$ & $109 / 55$ \\
xanthophila & $63 / 32$ & $8 /-$ & $2 / 1$ & $4 / 2$ & $71 / 32$ & $6 / 3$ & $65 / 33$ & $12 / 1$ & $\begin{array}{c}77 / 35 \\
\text { sp.6 }\end{array}$ \\
\hline Total & - & $-/ 1$ & - & - & $-/ 1$ & - & - & $-/ 1$ & $-/ 1$ \\
\hline
\end{tabular}

Note: Eighty-five traps of each type were operated. Abbreviations: Trap types: Y - yellow; W - white; L - latge (diameter: yellow - $99 \mathrm{~mm}$; white - $95 \mathrm{~mm}$ ); $\mathrm{S}$ - small (diameter: $65 \mathrm{~mm}$ ). 
400 cups filled with a $2-4 \%$ solution of formalin were installed at ground level, at a distance of $7-20 \mathrm{~m}$ from each other. Half of these traps were yellow, half white, half were large, and half small (diameters see Table 3), thus counting 100 traps in each group. Traps were operated during $120 \mathrm{~h}$, from 13. to 17.vii.1991. Eighty-five traps out of each group could be used for a quantitative evaluation, and their trapping results are presented in Table 3.

\subsection{Results}

Rearing experiments. Seven species were obtained in rearing experiments conducted by MB in southern Germany (Table 1). $M$. giraudii, the most catholic species, was reared from nine types of substrates including different kinds of carrion (liver, kidney, snails, slugs, earthworms, insects) and rotten wheat grains. $M$. densior was the most abundant species in small vertebrate and mollusc carrion baits. $M$. citrinella emerged only in very low numbers from small vertebrate and insect carrion. $M$. hexanopbila and $M$. breviseta were exclusive to the ermine moth (Yponomeuta sp.) samples, which yielded the highest number of species among all studied substrates. $M$. cf. sanguinea only emerged from rotten wood. Interesting rearing records from studies conducted by other authors include the following specimens (see also Material Examined in Taxonomic Section): various M. giraudii and $1 \sigma^{\top} M$. haraldlundi emerged from dead wood of spruce (leg. A. Kopf), 20 M. malhamensis emerged from bark of a living tree (leg. W. Büchs), 1 o $M$. haraldlundi, and $1 o^{*} M$. raruvesiculae emerged from sheep carcass (or the soil beneath) (leg. M. Drolshammer).

Bait, odour, emergence and pitfall traps. In trapping sessions conducted by MB eleven species of the $M$. giraudii/densior complex were collected (Table 2). Except $M$. breviseta and $M$. cf. sanguinea, all species from the rearing experiments turned up in the traps as well. $M$. giraudii and $M$. densior predominated in baited traps. A total of nine species was caught in the latter, four in odour traps, and six in unbaited traps. Unbaited traps were least efficient in collecting flies of the studied group. Trapping with n-hexane and 1-PE mainly yielded $M$. bexanophila and $M$. giraudii. Unlike the study of KAMM et al. (1987), n-hexane (which should only act as a solvent for 1-PE) proved to be the effective component in attracting phorid flies. The experiments also demonstrated that the position of the traps has a species-specific influence on trapping efficiency: e.g., kidneybaited traps installed $180 \mathrm{~cm}$ above ground yielded more $M$. giraudii and $M$. bexanophila than traps with the same bait installed at ground level or at $60 \mathrm{~cm}$. In contrast, trap catches of $M$. densior were almost evenly distributed over the three levels. Furthermore, it became obvious that traps were not equally attractive for both sexes: e.g., the sex ratios of $M$. giraudii and $M$. hexanophila were significantly biased towards females in elevated kidney traps ( $M . g .: 22.0 \% \sigma^{*}, \mathrm{n}=177 ; M$. $\left.h .: 15.4 \% \sigma^{*}, \mathrm{n}=39\right)$. However, in $\mathrm{n}-$ hexane $/ 1$ PE traps males dominated significantly $\left(M \cdot g: 75.0 \% \sigma^{*}, \mathrm{n}=40\right)$ or the sexes were equally represented ( $M$. . b.: $52.0 \%$ o, $\mathrm{n}=123$ ).

Noteworthy records from bait trapping studies conducted by other authors include the following species (see also Material Examined in Taxonomic Section): 1 ㅇ M. giraudii, 3 o $^{*}$ $4 \sigma^{*} M$. baraldlundi, $2 \sigma^{*} M$. immodensior, and 1 \% $M$. quadriseta collected in traps baited with lignicolous fungi (Dacrymyces stillatus, Fomitopsis pinicola, Opbiostama piceae) growing on agar plates (leg. A. Kopf and R. Sipple). However, $M$. haraldlundi and $M$. immodensior were also attracted to traps with bare agar plates. 
Habitat specificity. As can be seen from Table 1 and 2 most species preferred forested over open habitats. Only $M$. giraudii and $M$. densior were trapped or reared in the open habitats (a meadow and an arable field). Among the two types of woods under study the deciduous forest yielded a higher number of species than the spruce stand (eleven out of twelve species were collected in the former). Judging from the whole material available some species seem to colonise a wide variety of habitats. E.g., $M$. parnassia was collected in extreme boreo-alpine habitats as well as in different types of mesophilic forests (see records below this species).

Colour Preference. The experiment conducted by von Tschirnhaus et al. gave interesting insights in the colour preferences of different species and sexes (Table 3). On the average large traps (which had a surface about twice as large as small traps) caught about twice as many specimens as the small ones (however, in $M$. xanthopbila this number was more than ten times as high). Yellow and white traps yielded about the same number of specimens, except for $M$. xanthopbila which distinctly preferred yellow over white traps (As only the group totals were recorded these results could not be tested for significance). In the three most common species ( $M$. parnassia, $M$. mimodensior, $M$. xanthophila) males always dominated the trap catches. However, in $M$. parnassia the male bias was only significant in white traps. Only in this species the sex ratio was influenced by colour: white traps yielded a significantly higher proportion of males than did yellow traps. Trap size did not have any significant influence on the sex ratio of the studied species.

Other observations. The crop contents of a female of Megaselia sp. 7, which was collected in a fen habitat in eastern England, includes a mass of detrital material. This includes recognisable diatom frustules, spores and fungal bodies. It seems likely that it had ingested a moisture film from a mud surface or the surface film on a water body. Water films themselves are nutritious, apart from the microorganisms trapped in the lipo-protein film (GUTHRIE, 1989).

\section{Discussion}

\subsection{Taxonomy}

The results of the present study give a further example of difficult taxonomic problems within Phoridae being resolved by the tigorous use of genitalic chatacters and other microscopic details. Once more, traditional characters such as wing indices, coloration of thorax, and others used in previous keys (e.g., SCHMITZ \& DELAGE, 1981) proved to be of little taxonomic value. On the other hand, the search for new, more reliable characters was especially fruitful in the group under study. The antennal SPS, for instance, proved invaluable in distinguishing similar species and in correctly associating males with females in sexually dimorphic species. Furthermore, in the female sex considerable interspecific differences in vaginal sclerites and sterna 8 were discovered. It is emphasised that these characters are absolutely necessary for species identification in the huge genus Megaselia and we strongly encourage to routinely describe and illustrate these structures when describing or redescribing species. As most of the reliable characters are internal or can only be observed under a compound microscope (e.g., the inclination of microtrichia on various parts of the male hypopygium) pinned specimens could only be identified after being remounted on slides. 
The present study, as with a recent study of the M. pulicaria complex (DISNEY, 1999), further underlines the confusions that have resulted from type or voucher series that contain more than one species. Thus the original remounting of a voucher specimen of M. densior from the Schmitz Collection (DISNEY, 1985), instead of the now remounted lectotype (designated above) that proved to be a different species from the voucher specimen, set in train a set of misidentifications and the creation of unnecessary synonyms.

As a phylogenetic approach was beyond the scope of this work we only want to briefly comment on some issues here. While the phylogeny of the Megaseliini (of DISNEY, 1989b; = Megaselia group of BROWN, 1992) is far from being understood it is currently undisputed that one monophylum within this tribe can be recognised by the presence of a notopleural cleft in the male sex (DISNEY, 1989b; BROWN, 1992). This group (the Gymnophora subgroup of BROWN, 1992) comprises part of the paraphyletic genus Megaselia, as well as the genera Gymnophora and Woodiphora. However, the present work provides evidence that the notopleural cleft may have been lost in some lineages within the Gymnophora subgroup. An interesting example for this could be M. mimodensior and an undescribed species ${ }^{1}$ which were discovered during the present revision. These two species are so similar that they can hardly be distinguished from each other except for the presence/absence of the notopleural cleft. The most parsimonious explanation for this finding is a supposed loss of the cleft in one of the species (viz. M. mimodensior). The occurrence of reversals in such an important character further complicates the systematization of the Megaseliini. Future studies will have to uncover further synapomorphies in order to clarify the boundaries of the Gymnophora subgroup within Megaseliini.

\subsection{Biology}

Rearing experiments. Very little was known about the biology of the studied species group, except for the common and widely distributed $M$. giraudii. This species has been reported to breed in a great variety of decaying substrates such as dead or moribund insects, dead snails, vertebrate carrion, fungi, insect frass, vole and dog dung, nests of social Hymenoptera (wasps, bumble-bees, bees) and anthropogenic substrates (e.g., improperly washed millk bottles, Drosophila rearing medium) (DISNEY, 1994). M. densior is the only other species for which a larval breeding medium is reported in the literature. According to SCHMTZZ (1927) it was found developing in (already dead?) pupae of the geometrid moth Bupalus piniarius (L.). For both species the saprophagous breeding habits are confirmed by the present study. Furthermore, it turned out that $M$. citrinella, $M$. bexanophila, $M$. breviseta, and $M$. sanguinea are probably also saprophages (see Table 1). As for the species developing in the Yponomeuta samples it is not entirely clear whether their larvae were living as parasites or saprophages. Given the fact that the tents contained a high proportion of dead and moribund specimens (due to severe food scarcity and a high rate of parasitisation by hymenopterans) the latter possibility seems more likely. In any case it appears improbable that $M$. bexanopbila and $M$. breviseta (both exclusively reared from ermine moth tents during this study) could be specialised on this host. As ermine moth caterpillars are only available during spring the summer generation of flies must necessarily exploit another type of substrate.

This is one of the species that key out at lead two of couplet 7 in the key to males (see note there). 
TRAPPING EXPERIMENTS. The attractiveness of $\mathrm{n}$-hexane to $M$. bexanophila and $M$. girau$d i i$ was quite unexpected and remains to be explained. As certain other necrophagous phorids (e.g., Cbaetopleurophora erythronota, Hypocera mordellaria, Gymnophora arcuata) were also attracted to these traps it might be assumed that $n$-hexane is a possible side product of the microbial degradation of carcasses. Perhaps n-hexane is one of the various cue substances that leads these species to possible feeding places or breeding substrates. If this is not the case $n$-hexane apparently mimics one of these substances and stimulates the same receptors.

The different colour preferences among species and sexes (cf. M. xanthophila, M. parnassia) will probably also relate to some specific behavioural traits. Yet, too little is known about the biology of these species to allow speculations on the significance of this behaviour.

\section{Acknowledgements}

We are grateful to Drs H. UlRICH (ZFMK), P. BEUK \& H. DE JONG (ZMAN), B. V. BROWN (Natural History Museum of Los Angeles County), R. CONTRERAS-LichtenberG (NHMW), S. A. Marshall (DEBU), U. SCHMIDT (NHMM), N. WYATT (BMNH), S. PRESCHER, and G. WEBER for the loan of material from their institutions or private collections. Special thanks are due to H. ULRICH, B. V. BROWN, R. CONTRERAS-LICHTENBERG, H. DE JONG and N. WYATT for the kind permission to temount type material under their care. MB furthermore acknowledges the donation of valuable material by Dr M. vON TsCHrRNHAUS, and wishes to thank Prof. Dr W. FUNKE (University of Ulm) for providing working facilities. Part of MB's work was supported by a grant from the 'Studienstiftung des deutschen Volkes'. RHLD's studies of Phoridae are currently funded by the Isaac Newton Trust (Trinity College, Cambridge).

\section{References}

ARnetT, R. H.; SAMuUelson, G. A. \& NishidA, G. M. 1993: The insect and spider collections of the world. - Gainesville, Fla.: Sandhill Crane Press. (2nd ed.) - vi+310 pp. - Flora \& Fauna Handbook 11).

BEYER, E. 1958: Drei neue Phoriden aus Japan und Finnland. - Notul. Entomol. 38: 104-108.

BORGMEIER, T. 1962: Versuch einer Uebersicht ueber die neotropischen Megaselia-Arten, sowie neue oder wenig bekannte Phoriden verschiedener Gattungen (Dipt. Phoridae). - Studia Entomol. 5: 289-488.

BORGMeIER, T. 1966: Revision of the North American phorid flies. Part III. The species of the genus Megaselia, subgenus Megaselia (Diptera, Phoridae). - Studia Entomol. 8 [1965]: 1-160.

BORGMEIER, T. 1968: A catalogue of the Phoridae of the World (Diptera, Phoridae), - Studia Entomol. 11: $1-367$.

BROWN, B. V. 1992: Generic revision of Phoridae of the Nearctic Region and phylogenetic classification of Phoridae, Sciadoceridae, and Ironomyiidae (Diptera: Phoridea). - Merm. Entomol. Soc. Can. 164: 144 pp.

Brown, B. V. \& MARShalL, S. A. 1984: Phorid flies (Diptera: Phoridae) associated with mushrooms in southern Ontario. - Proc. Entomol. Soc. Ontario 115: 77-80.

BRUES, C. T. 1904: A monograph of the North American Phoridae. - Trans. Am. Entomol. Soc. 29 [1903]: 331.404.

BRUES, C. T. 1915: A synonymic catalogue of the dipterous family Phoridae. - Bull. Wisconsin Nat. Hist. Soc. 12 [1914]: 85-152.

BRues, C. T. 1950: Family Phoridae. In: Guide to the insects of Connecticut. Part 6 (4): Diptera. - Bull. Conn. Geol. Nat. Hist. Survey 75: 33-85.

BUCK, M. 1997a: Sphaeroceridae (Diptera) reared from various types of cartion and other decaying substrates in Southern Germany, including new faunistic data on some rarely collected species. - Eur. J. Entomol. 94: 137-151.

BUCK, M. 1997b: Untersuchungen zur ökologischen Einnischung saprophager Dipteren unter besonderer Berücksichtigung der Phoridae und Sphaeroceridae (Brachycera/Cyclorrhapha). - Göttingen: Cuvillier Verlag $-v+194+\mathrm{lv}$ pp. 
DISNEY, R. H. L. 1983: Scuttle flies - Diptera, Phoridae (except Megaselia). - Handbooks for the Identification of British Insects, Vol. 10 (6). London: Royal Entomological Society. - 81 pp.

Disney, R. H. L. 1985: Additions and amendments to the list of British Megaselia (Dipt., Phoridae). Entomologist's Mon. Mag. 121: 243-248.

DisNEY, R. H. L. 1986: Two new species of scuttle fly (Diptera, Phoridae) from Malham Tarn, North Yorkshire. - Naturalist, Hull 111: 113-121.

DISNEY, R. H. L. 1987a: A preliminary survey of the scuttle flies of Hayley Wood, with descriptions of three new species. - Proc. Trans. Br. Entomol. Nat. Hist. Soc. 20: 27-34.

Disney, R. H. L. 1987b: A new species of scuttle fly (Diptera, Phoridae) from Cumbria. - Naturalist, Hull 112: $135-137$.

Disney, R. H. L. 1989a: Scuttle flies Diptera, Phoridae genus Megaselia. - Handbooks for the Identification of British Insects, Vol. 10 (8). London: Royal Entomological Socicty - 155 pp.

DISNEY, R. H. L. 1989b: A key to Australasian and Oriental Woodiphora (Diptera: Phoridae), affinities of the genus and description of new species. - J. Nat. Hist. 23: 1137-1175.

DrSNeY, R. H. L. 1991: Family Phoridae. In Soós Á. \& Papp La (eds): Catalogue of Palaearctic Diptera Vol. 7. - Budapest: Akadémiai Kiadó - pp. 143-204.

Disney, R. H. L. 1993: Notes on European Phoridae (Diptera). - Br. J. Entomol. Nat. Hist. 6: 107-118.

DISNEY, R. H. L. 1994: Scuttle Flies: The Phoridae. - London: Chapman \& Hall. - xii + 467 pp.

Disney, R. H. L. 1995: Two new species of Megaselia (Diptera: Phoridae) from Europe. - Br. J. Entomol. Nat. Hist. 8: 113-119.

DISNEY, R. H. L. 1999: A troublesome sibling species complex of scuttle flies (Diptera: Phoridae) revisited. - J. Nat. Hist. 33: 1159-1216.

DISNEY, R. H. L. \& DURSKA, E. 1998: A new genus and new species of Phoridae (Diptera) from Poland. -Eur. J. Entomol. 95: 437-453.

DISNEY, R. H. L. \& IRWIN, A. G. 1978: Some scuttle flies (Diptera: Photidae) from Scotland. - Glasgow Nat. 19:377-383.

Disney, R. H. L. \& Nussbaunf, Y. 1990: Phoridae (Diptera) from Israel. - Istael J. Entomol. 24: 107-114.

DURSKA, E. 1996: The species composition and structure of scuttle fly communities (Diptera: Phoridae) in mature tree stands in pine forests at different stages of habitat degtadation. - Fragmenta Faunistica 39: 267-285.

EGGER, J. 1862: Dipterologische Beiträge. - Verh. Zool.-Bot. Ges. Wien 12: 1233-1236.

FAIN, A. \& GREENWOOD, M. T. 1991: Notes on a small collection of mites (Acari), phoretic on Diptera, mainly Phoridae, from the British Isles. - Bull. Inst. R. Sci. Nat. Belg. 61: 193-197.

FeldmanN, R. 1992: Die Bodenmakrofauna im Lennebergwald. 1. Die Dipteren. - Mainzer Naturwiss. Arch, 30: 171-241.

GUTHRIE, M. 1989: Animals of the surface film. - London: Richmond Publishing Co. Ltd. - 87 pp. (Naturalists' Handbooks Vol. 12).

KAMM, J. A.; BUTTERY, R. G. \& ROBINSON, W. H. 1987: An attractant for mushroom flies (Diptera: Phoridae). - Jl N. Y. Entomol. Soc. 95: 19-22.

LUNDBECK, W. 1921: New species of Phoridae from Denmark, together with remarks on Aphiochaeta groenlandica Lundb. - Vidensk. Meddr Dansk Naturh. Foren. 72: 129-143.

LUNDBECK, W. 1922: Diptera Danica. Genera and species of flies hitherto found in Denmark. Part VI Pipunculidae, Phoridae. - Copenhagen: G.E.C. Gad. - 455 pp.

MALLOCH, J. R. 1912: The insects of the dipterous family Phoridae in the United States National Museum. Proc. U. S. Natn. Mus. 43: 411-529.

MANNESMANN, R. \& TSCHIRNHAUS, M. vON 1991: Exkursionsbericht Nordskandinavien Juni-Juli 1991. Unpublished report, University of Bielefeld (Germany) - $109 \mathrm{pp}$.

MichaIl ovSKaYA, M. V. 1998: Phorid flies (Diptera, Phoridae) of the Kuril Islands. - Far Eastern Entomologist 55: $1-8$.

PFEIL, R. M.; WALSH, R. A. \& MUMMa, R. O. 1994: Scanning electron microscopic examination of the putative olfactory structures possessed by the phorid fly, Megaselia balterata (Diptera, Phoridae). - Scanning Microscopy 8: 687-694.

PRESCHER, S. \& BELISTEDT, R. 1994: Beitrag zur Kenntnis der Buckelfliegenfauna Thüringens (Dipt., Phoridae). - Entomol. Nachr. Ber. 38: 45-51.

PRESCHER, S. \& WEBER, G. 1996: Zur Kenntnis der Buckelfliegen-Fauna (Diptera: Phoridae) ausgewählter Standorte in Köln - Frühjahrsaspekt. - Decheniana Beihefte 35: 415-421.

PRESCHER, S. \& WEBER, G. in press: Biologie und Ökologie der Buckelfliegen (Phoridae, Diptera) des Naturschutzgebietes "Ahrschleife bei Altenahr". - Beitt. Landespfl. Rheinland-Pfalz. 
SAntos Abréu, E. 1921: Monografía de los Phótidos de las Islas Canatias. - Mems. R. Acad. Cienc. Artes, Barcelona 17: 1-90.

SANTOS ABRÉU, E. \& SCHMITZ, H. 1934: Catalogus Phoridarum Canariensium. - Notul. Entomol. 14: 65-69.

SCHMTZ, H. 1918: Die Phoriden von holländisch Limburg. Mit Bestimmungstabellen aller bisher kenntlich beschriebenen europäischen Phoriden. II. Teil. - Jaarb. Natuurh. Genoot. Limburg 1917: 130-150.

SCHMITZ, H. 1919: Über einige Phoriden der Oldenbergschen Sammlung. - Entomol. Ber., Amst. 5: 185. 196.

SchMmT, H. 1920: Die Phoriden von holländisch Limburg. Mit Bestimmungstabellen aller bisher kenntlich beschriebenen europäischen Phoriden. IV. Teil - Jaarb. Natuurh. Genoot. Limburg 1919: 91-153.

SCHMITZ, H. 1921: Neue europäische Apbiochata-Arten V. - Entomol. Ber., Amst. 6: 1-4.

SCHMTTZ, H. 1922: Neue europäische Apbiocbaeta-Arten VI. - Entomol. Ber., Amst. 6: 98-103.

SCHMTT, H. 1926: Neue Gattungen und Arten europaeischer Phoriden. - Encycl. Entomol. (B) Tome II: Diptera, Fasc. 2 [1925]. Paris: Lechevalier. - pp. 73-85.

SCHMITZ, H. 1927: Revision der Phoridengattungen mit Beschreibung neuer Gattungen und Arten. - Natuurh. Maandbl. 16: 30-40, 45-50, 59-68, 72-79, 92-100, 110-116, 128-132, 142-148, 164-176.

SCHMTTZ, H. 1928: Die geographische Verbreitung der eutopaeischen Phoridenarten. - Natuurh. Maandbl. 17: $139-148$.

SCHMTZ, H. 1929: Revision der Phoriden. - Bonn, Berlin: F. Dümmler - 211 pp.

SchMTZ, H. 1936: Phoridae. In Frey R.: Die Dipterenfauna der Kanarischen Inseln und ihre Probleme. Commentat. Biol. 6 (1): 70-82.

SchmTz, H. 1938: On the Irish species of the dipterous family Phoridae - Proc. R. Ir. Acad. (B) 44: 173204.

SCHMrTZ, H. 1948: Zur Kenntnis der fungicolen Buckelfliegen (Phoridae, Diptera). - Natuurh. Maandbl. 37: $37-44$.

SCHMITZ, H. 1956: Eine neue Plastophora-Art aus Kalksburg b. Wien (Diptera, Phoridae). - Brotéria 52: 43-47.

SCHMITZ, H. \& DELAGE, A. 1981: 33. Phoridae. In Lindner E. (ed.): Die Fliegen der palaearktischen Region Vol. 4 (7), Lief. 325. - Stuttgart: E. Schweizerbart - pp. 665-712.

SMITH, K. G. V. 1984: Review (of Disney 1983, HIBI 10(6)). - Entomologist's Mon. Mag. 120: 196.

Wood, J. H. 1908: On the British species of Phora (Part ID). - Entomologist's Mon. Mag. 44: 164-174, 215 218, 253-254.

WoOD, J. H. 1910: On the British species of Phora (contd.). - Entomologist's Mon. Mag. 46: 149-154, 195202, 243-249.

WOOD, J. H. 1912: Notes on British Phora (corrections and additions). - Entomologist's Mon. Mag: 48: 94-99, 166-181.

\section{Anschrift der Verfasser:}

DR. MATTHIAS BUCK

Department of Ecology and Morphology

of Animals, University of Ulm

Albert-Einstein-Allee 11

D-89069 Ulm, Germany

(Current address: Department of Environmental Biology

University of Guelph, Guelph, Ontario, Canada N1G 2W1

E-mail: mbuck@evb.uoguelph.ca)
DR. R. HENRY L. DISNEY

University Department of Zoology

Downing Street

Cambridge, CB2 3EJ

England

E-mail: rhld2@hermes.cam.ac.uk 

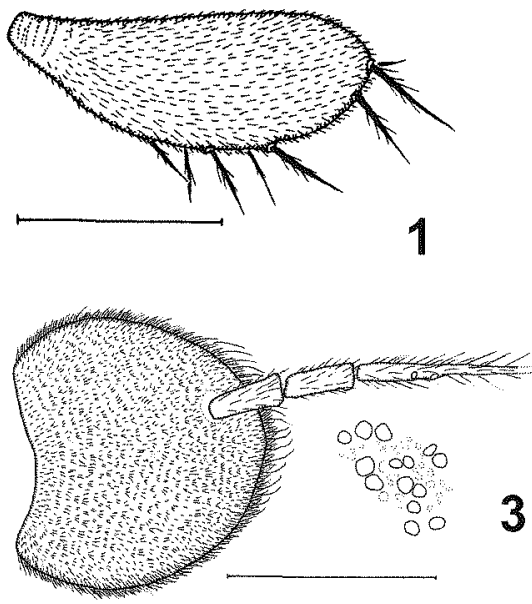
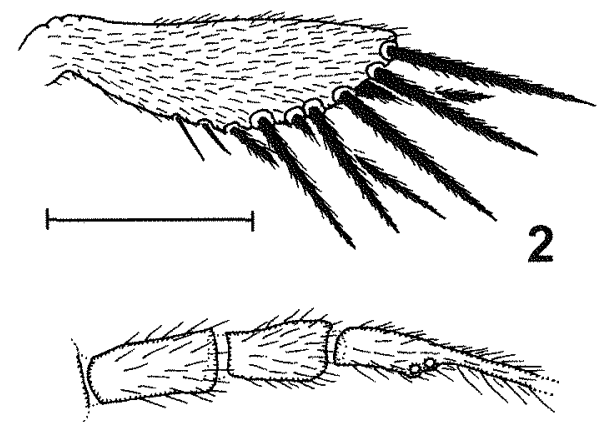

6
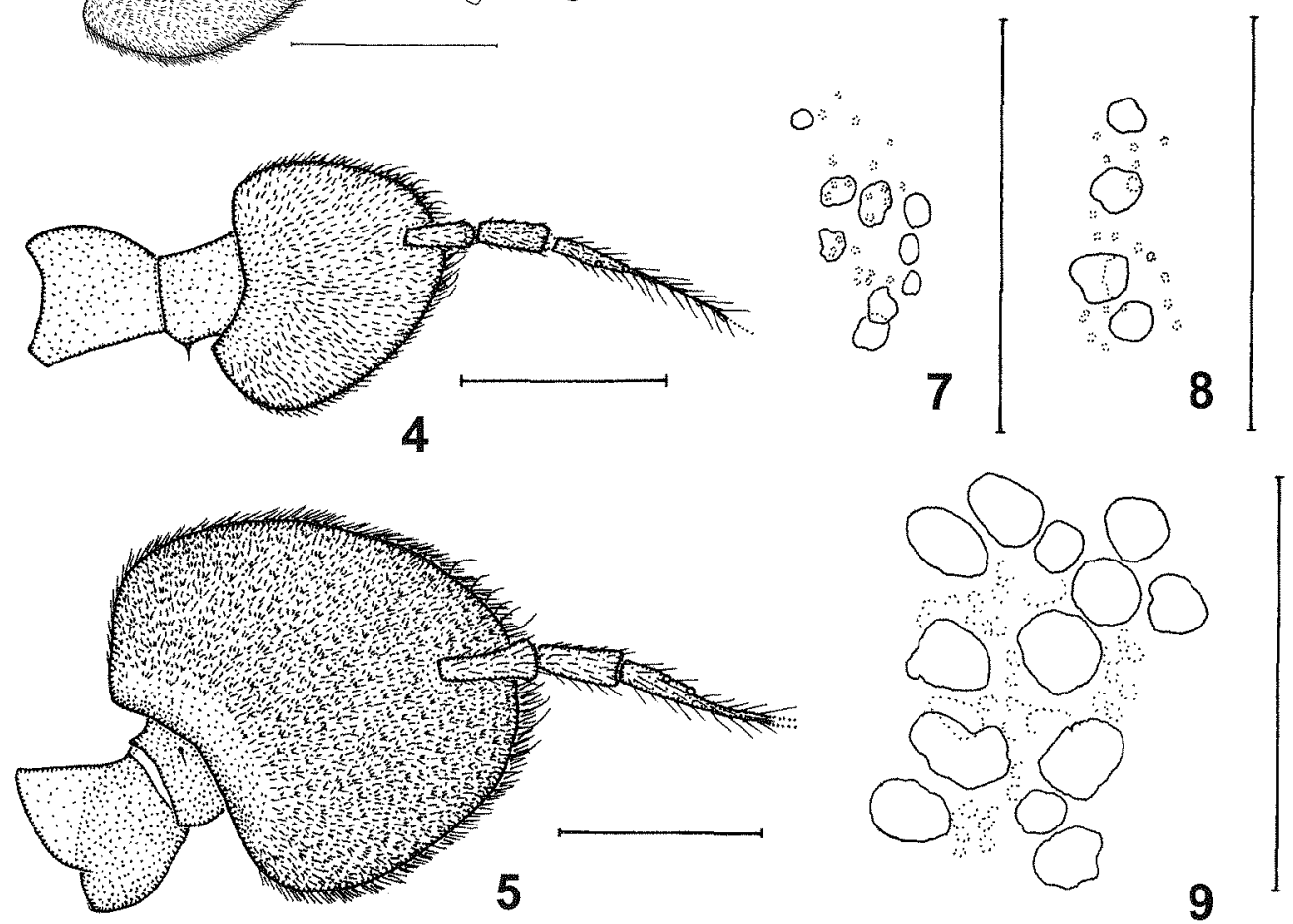

Figs 1-9. Megaselia males. Dorsal face of right palp: $1-M$. malhamensis; $2-M$. undescribed sp. (Germany). Third antennal segment and base of arista, with SPS shown below latter to right: $3-M$. densior. Right antenna: $4-M$. raruvesiculae sp. n.; $5-M$. labellaspinata sp. n. Base of arista: $6-M$. correlata. SPS inside third antennal segment: $7-M$. rartwesiculae sp. n.; $8-M$. haraldlundi; $9-M$. quadriseta. Scale bass $=0.1 \mathrm{~mm}$. 

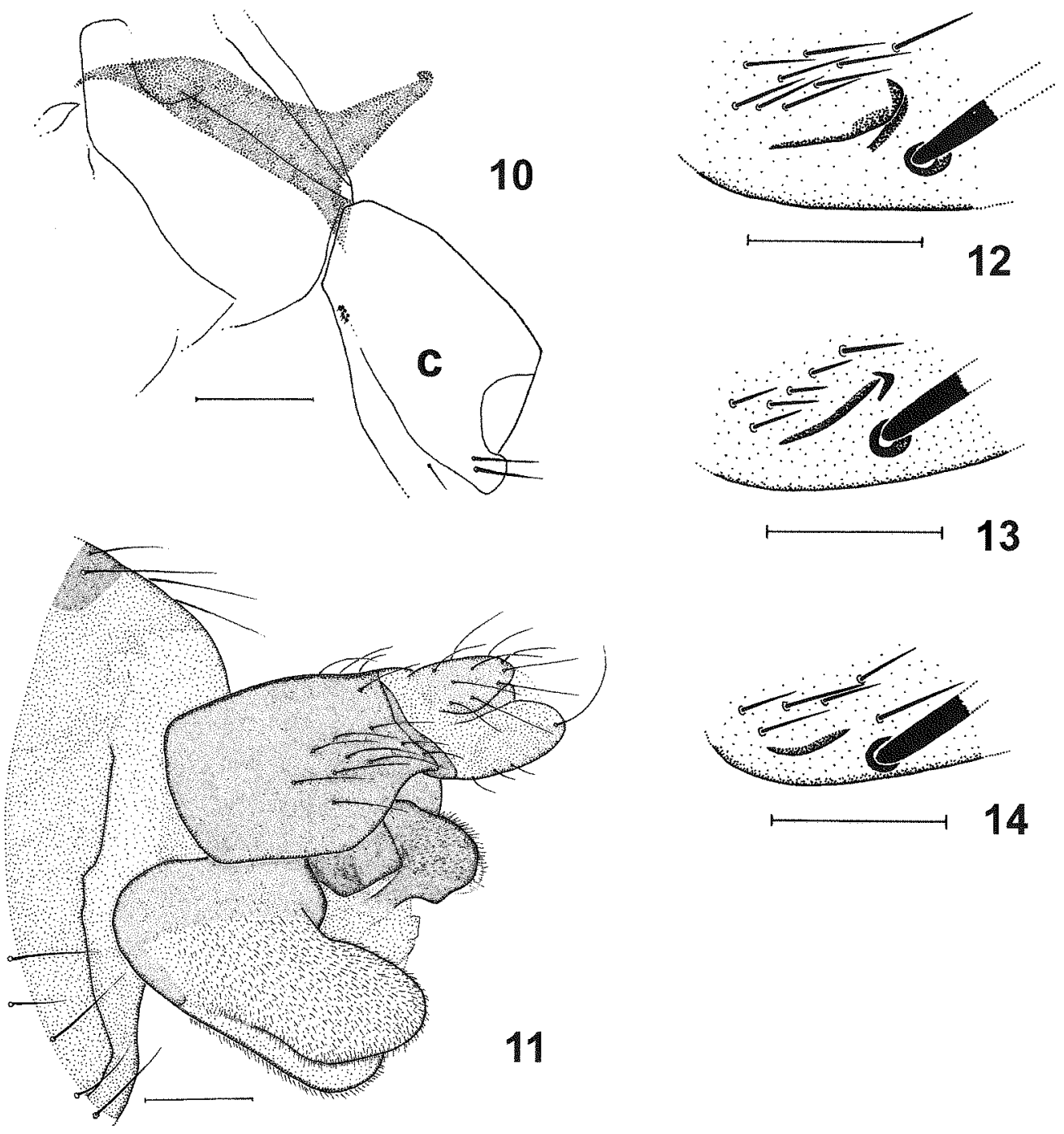

Figs 10-14. Megaselia males. Left metafurca (stippled) and hind coxa (c) from side: $10-M$. trojani. Hypopygium, left face: $11-M$. opacicomis. Notopleuron with cleft and anterior notopleural bristle: $12-M$. albicans; $13-M$. giraudii; $14-M$. offuscata. Scale bars $=0.1 \mathrm{~mm}$. 

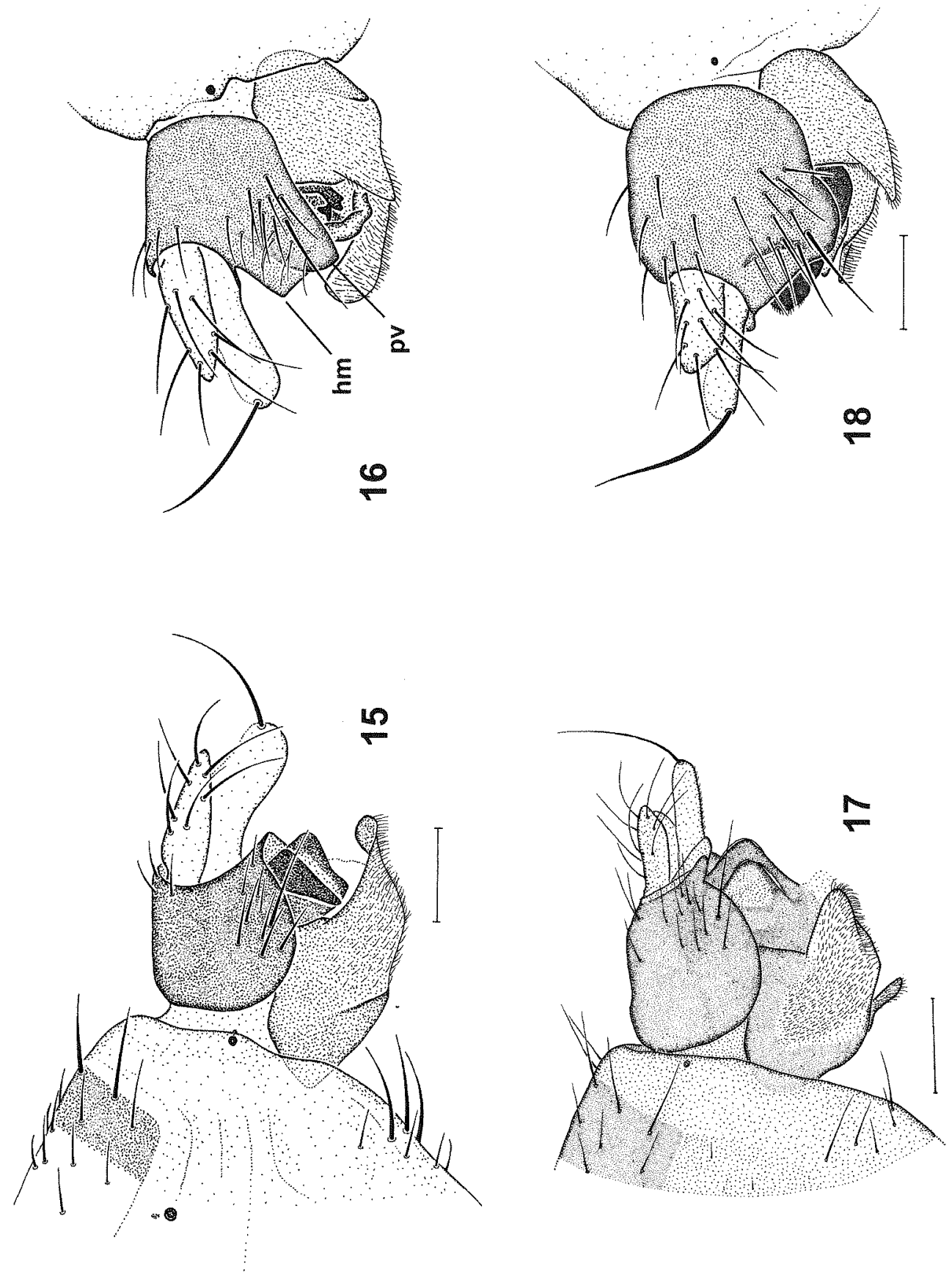

Figs 15-18. Megaselia males. Hypopygia, left and tight faces: 15-16 - M. bexanopbila sp. n.; 17-18-M. giraudii. $\mathrm{hm}=$ hind margin of epandrium; $\mathrm{pv}=$ postero-ventral lobe. Scale bars $=0.1 \mathrm{~mm}$. 

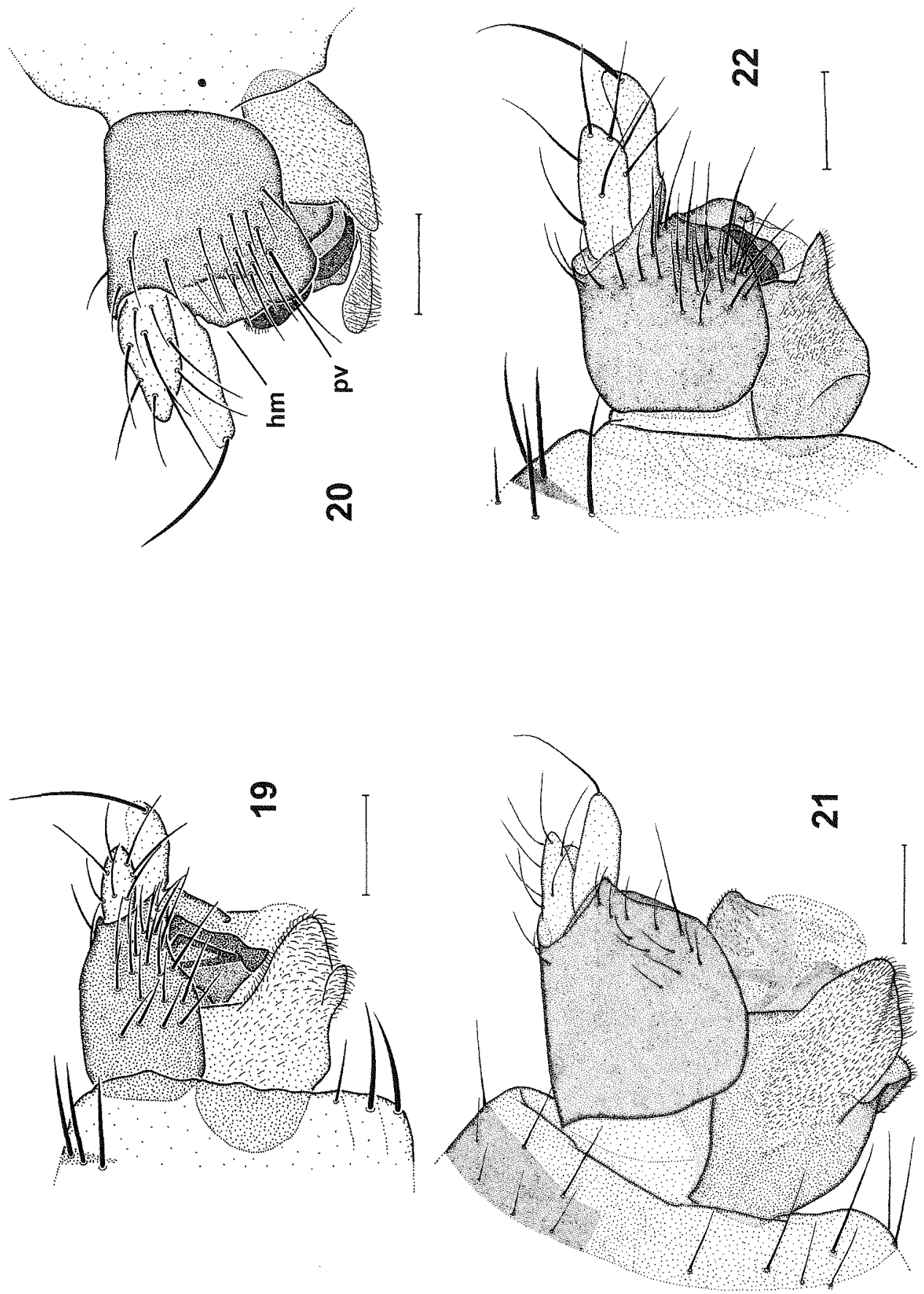

Figs 19-22. Megaselia males. Hypopygia: $19-M$. offuscata, left face; $20-M$. parnassia, right face; $21-M$. raruvesiculae $\mathrm{sp}$. n., left face; $22-M$. labellaspinata sp. $\mathrm{n}$., left face. $\mathrm{hm}=$ hind margin of epandrium; $\mathrm{pv}=$ postero-ventral lobe. Scale bars $=0.1 \mathrm{~mm}$. 

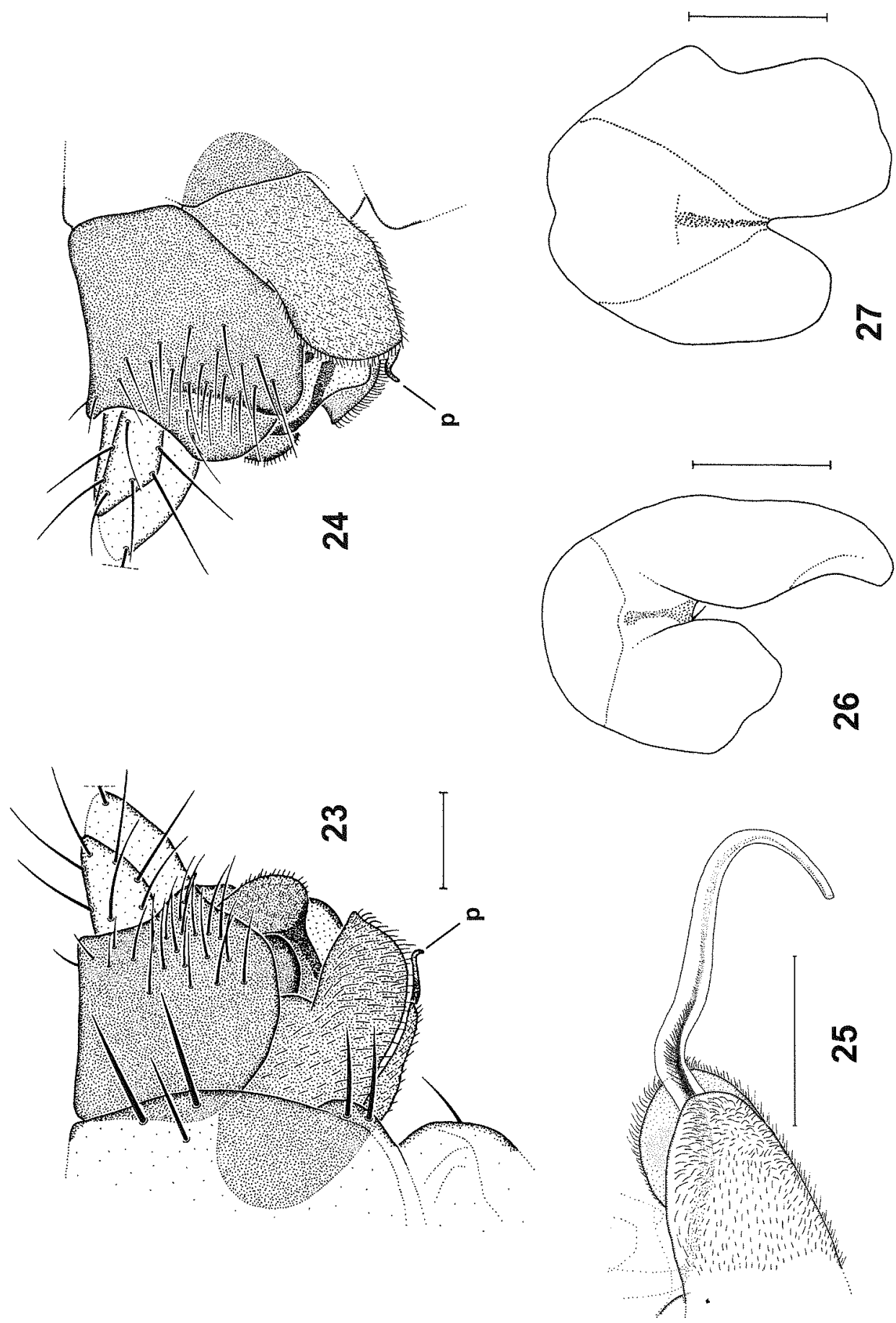

Figs 23-27. Megaselia males. Hypopygia, left and tight faces: 23-24-M. mbricomis. Left face of hypandrial lobes and process of penis complex: $25-M$. correlata. Hypandrium ventrally (micropubescence omitted): 26 - M. bexanopbila sp. n.; $27-$ M. giraudii. $\mathrm{p}=$ process of penis complex. Scale bars $=0.1 \mathrm{~mm}$. 

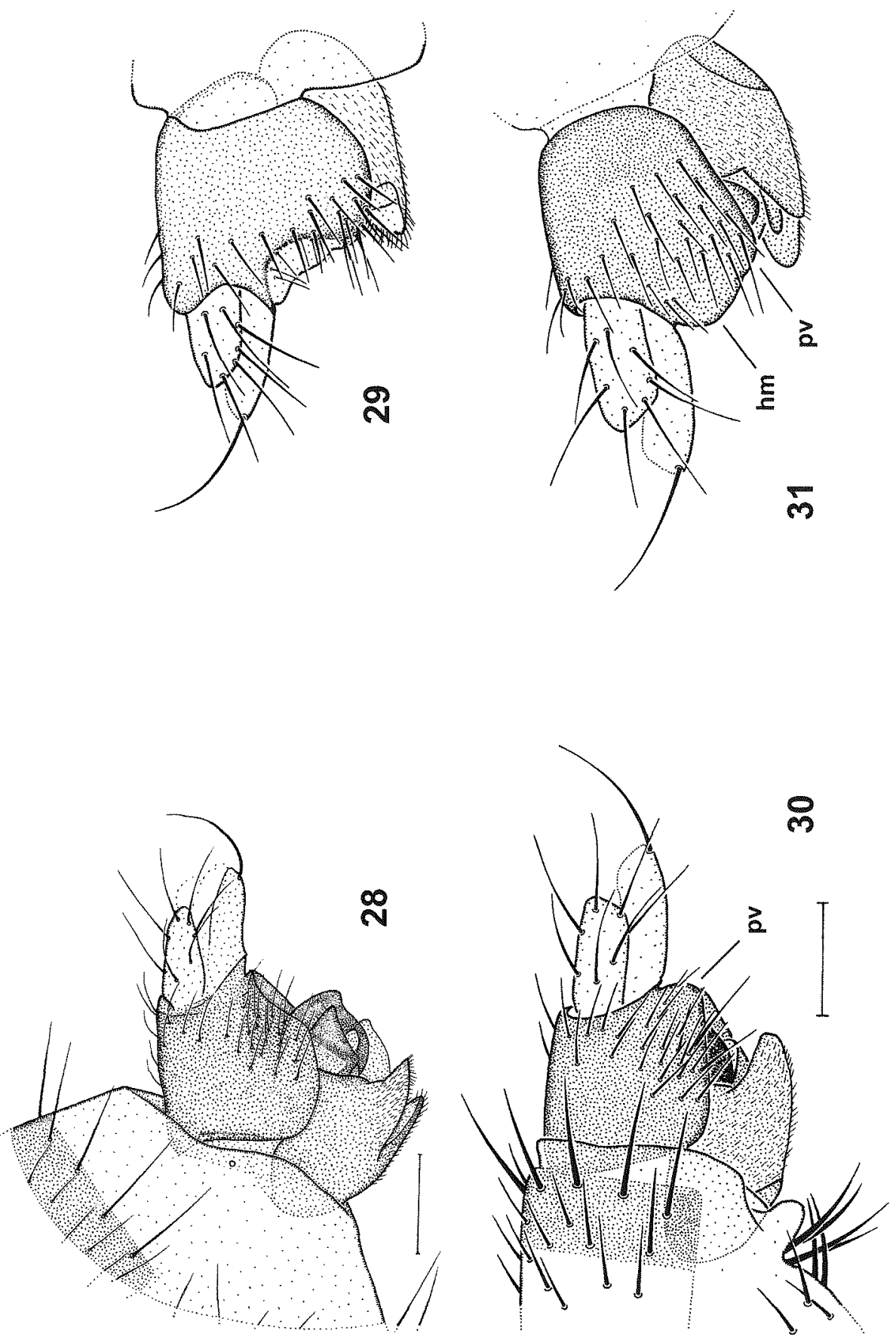

Figs 28-31. Megaselia males. Hypopygia, left and right faces: 28-29 - M. haraidlundi; 30-31 - M. quadriseta (lectotype of $M$. phoenicura syn. n.). hm = hind margin of epandrium; pv = postero-ventral lobe. Scale bars $=0.1 \mathrm{~mm}$. 

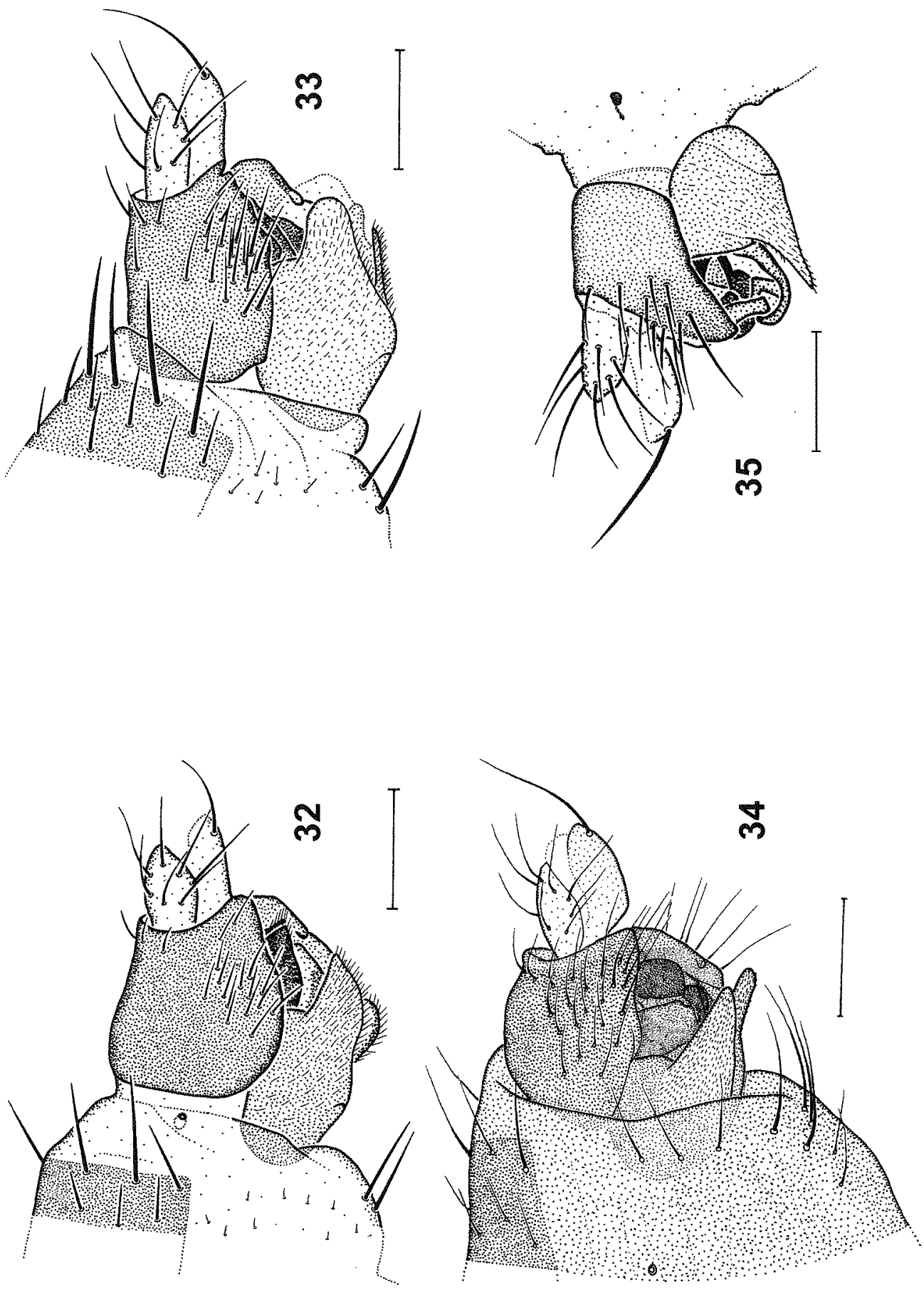

Figs 32-35. Megaselia males. Hypopygia: $32-M$. xanthopbila sp. n., left face; $33-M$. glabrimargo sp. n., left face; 34-35 $-M$. densior, left and right faces. Scale bars $=0.1 \mathrm{~mm}$. 

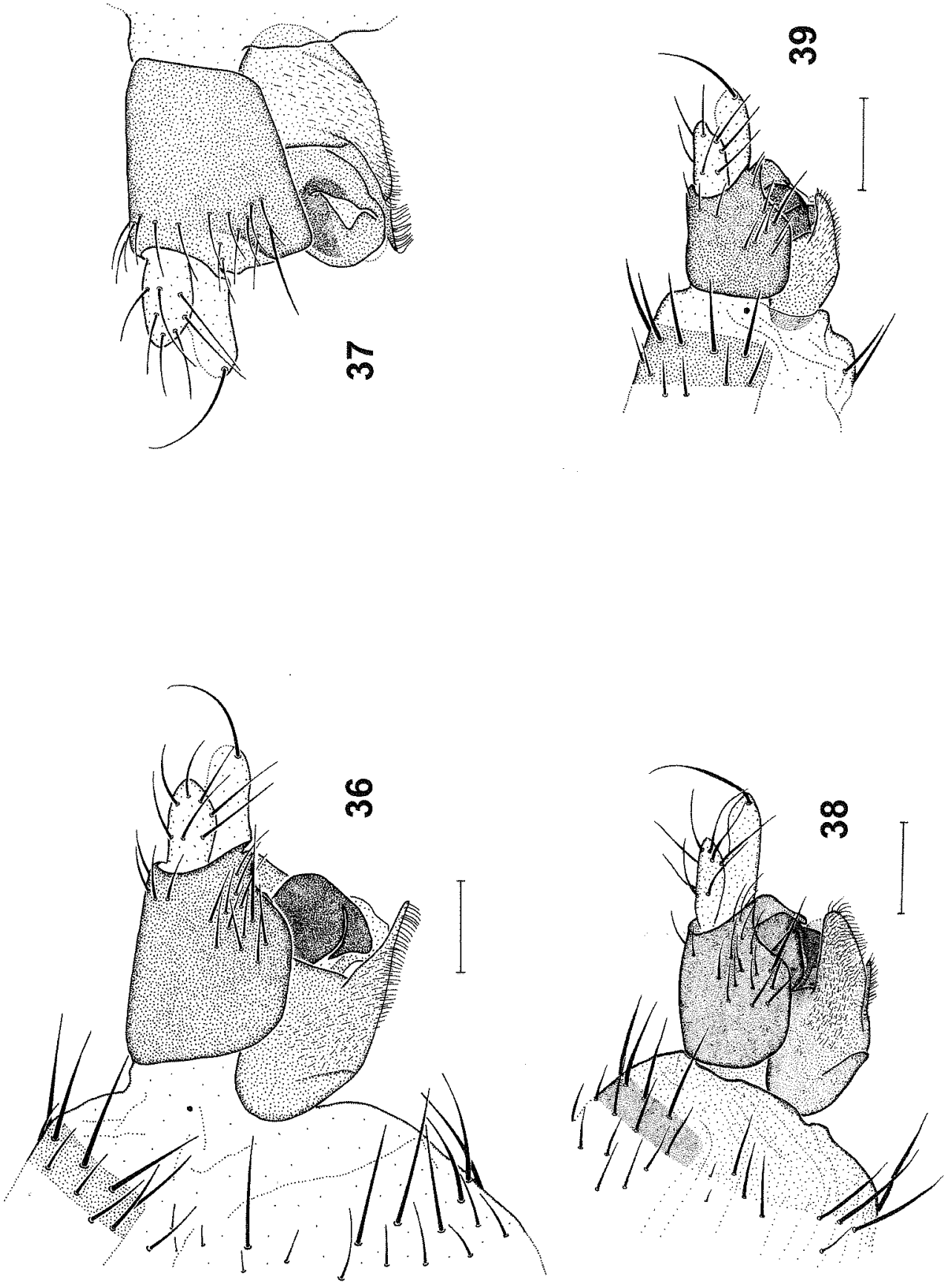

Figs 36-39. Megaselia males. Hypopygia: 36-37 $-M$. cf. sangzinea, left and tight faces; $38-M$. immodensior sp. n., left face; $39-$ M. mimodensior sp. n., left face. Scale bars $=0.1 \mathrm{~mm}$. 

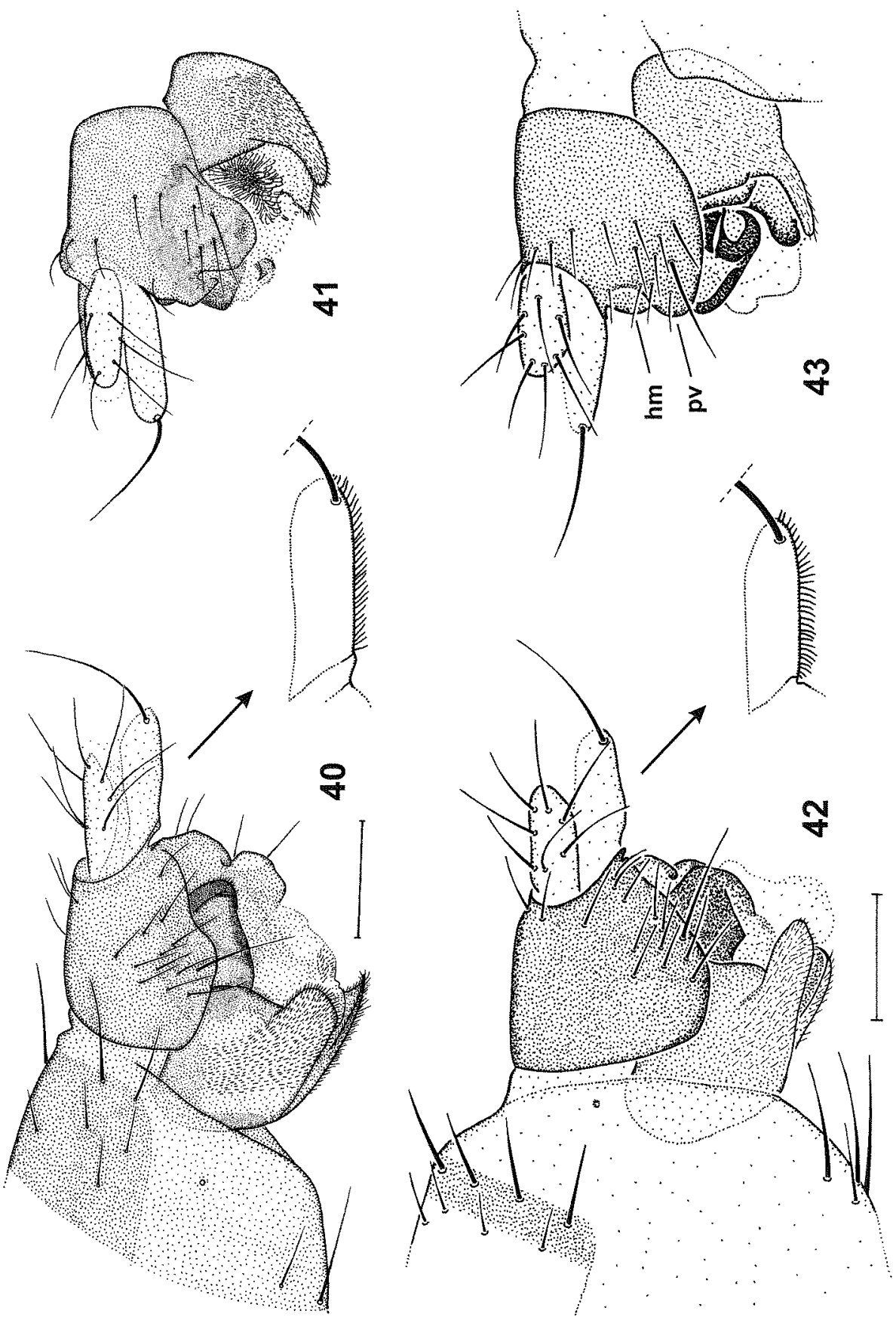

Figs 40-43. Megaselia males. Hypopygia, left and tight faces, enlargement showing orientation of microtrichia below proctiger: $40-41-M$. trojani; $42-43-M$. citrinella sp. $\mathrm{n} . . \mathrm{hm}=$ hind margin of epandrium; $\mathrm{pv}=$ posteto-ventral lobe. Scale bars $=0.1 \mathrm{~mm}$. 

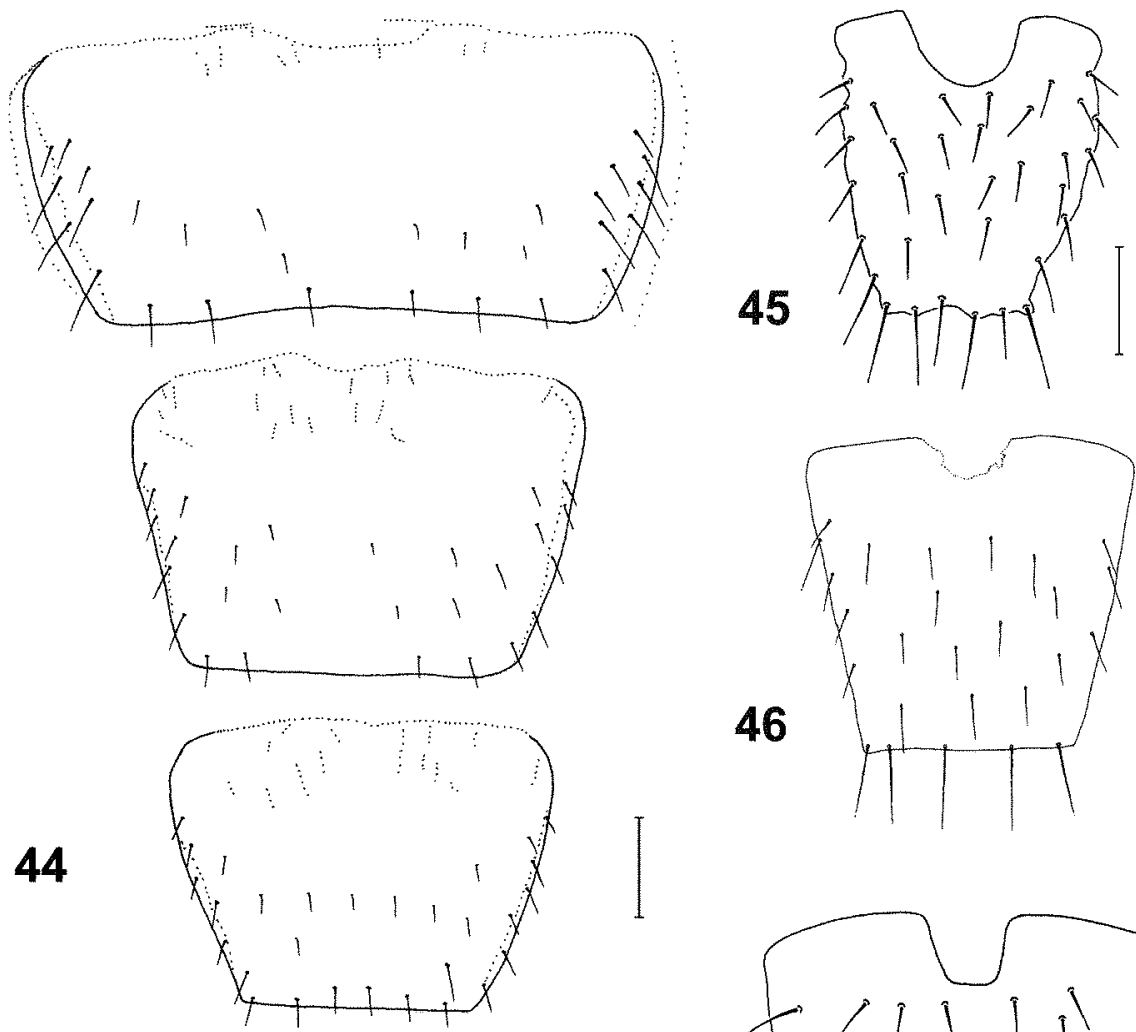

46
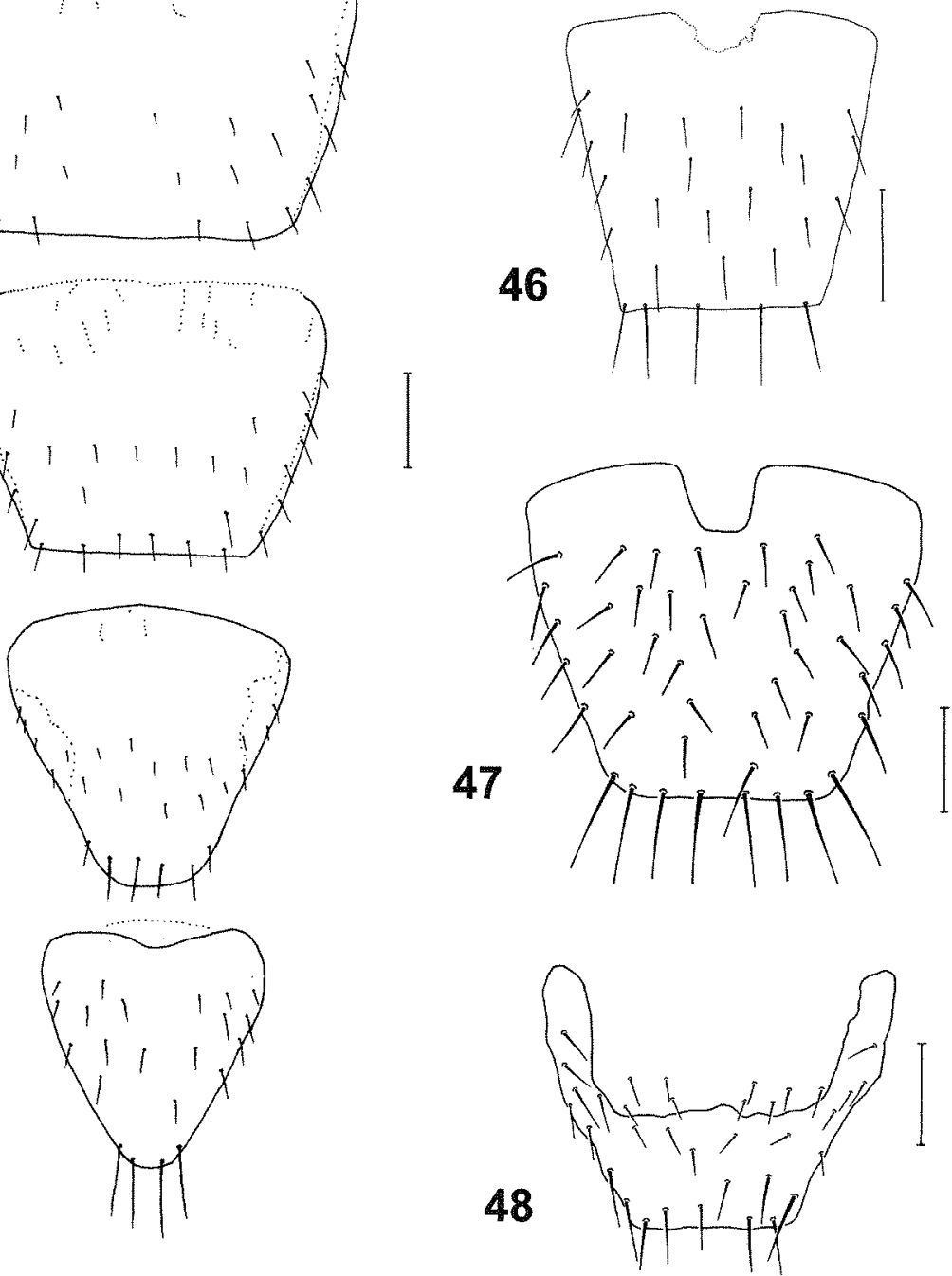

Figs 44-48. Megaselia females. Abdominal tergites 2-6:44-M. correlata. Abdominal tergite 6:45-M. densior, $46-M$. quadriseta; $47-M$. giraudiz; $48-M$. rubida. Scale bars $=0.1 \mathrm{~mm}$. 
Beitr. Ent. 51 (2001) 1
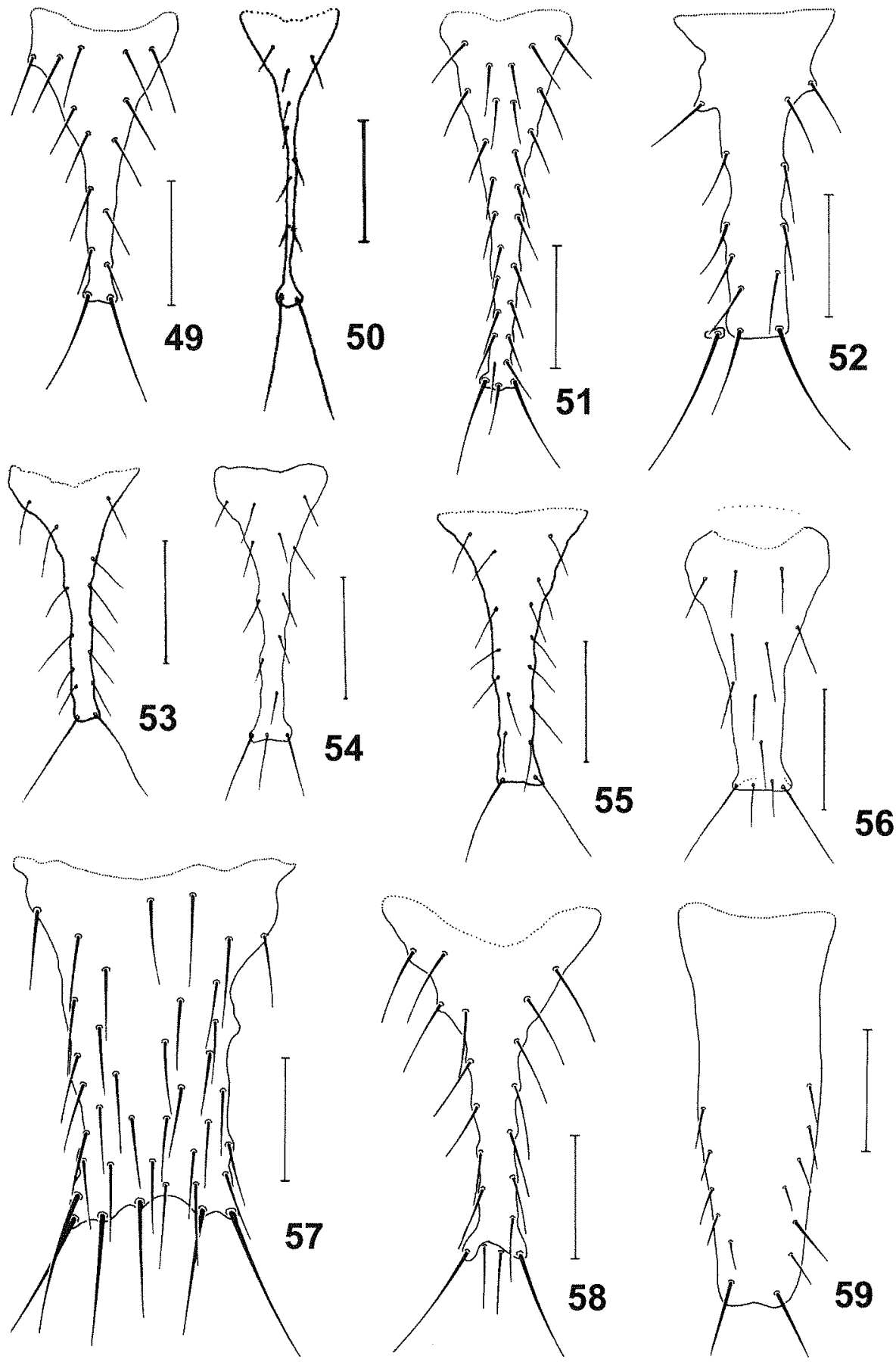

Figs 49-59. Megaselia females. Abdominal tergite 7:49-M. giraudii; $50-M$. correlata; $51-M$. cf. albicans; 52 - M. sanguinea (holotype); $53-M$. sp. $7 ; 54-M$. quadriseta, $55-M$. densior, $56-M$. nigrescens; $57-M$. rubricornis (holotype); $58-M$. bexanopbila sp. n.; $59-$ M. mibida (holotype). Scale bars $=0.1 \mathrm{~mm}$. 

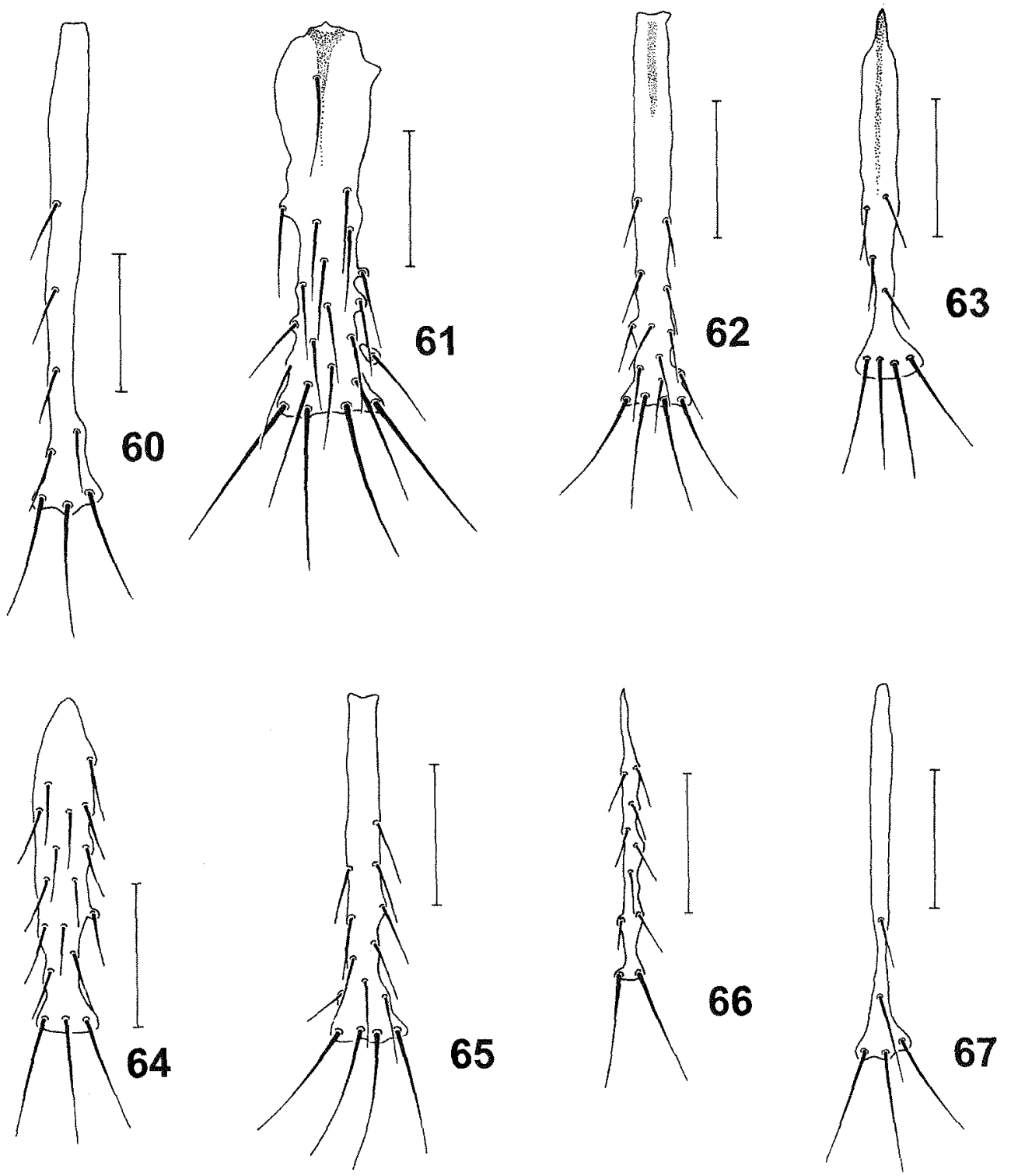

Figs 60-67. Megaselia females. Abdominal sternite 7:60-M. cf. albicans; $61-M$. rubricomis (holotype); $62-$ $M$. sp. $4 ; 63-M$. breviseta; $64-M$. girandii; $65-M$. bexanophila sp. n.; $66-M$. densior; $67-M$. fisberi (holotype). Scale bars $=0.1 \mathrm{~mm}$. 

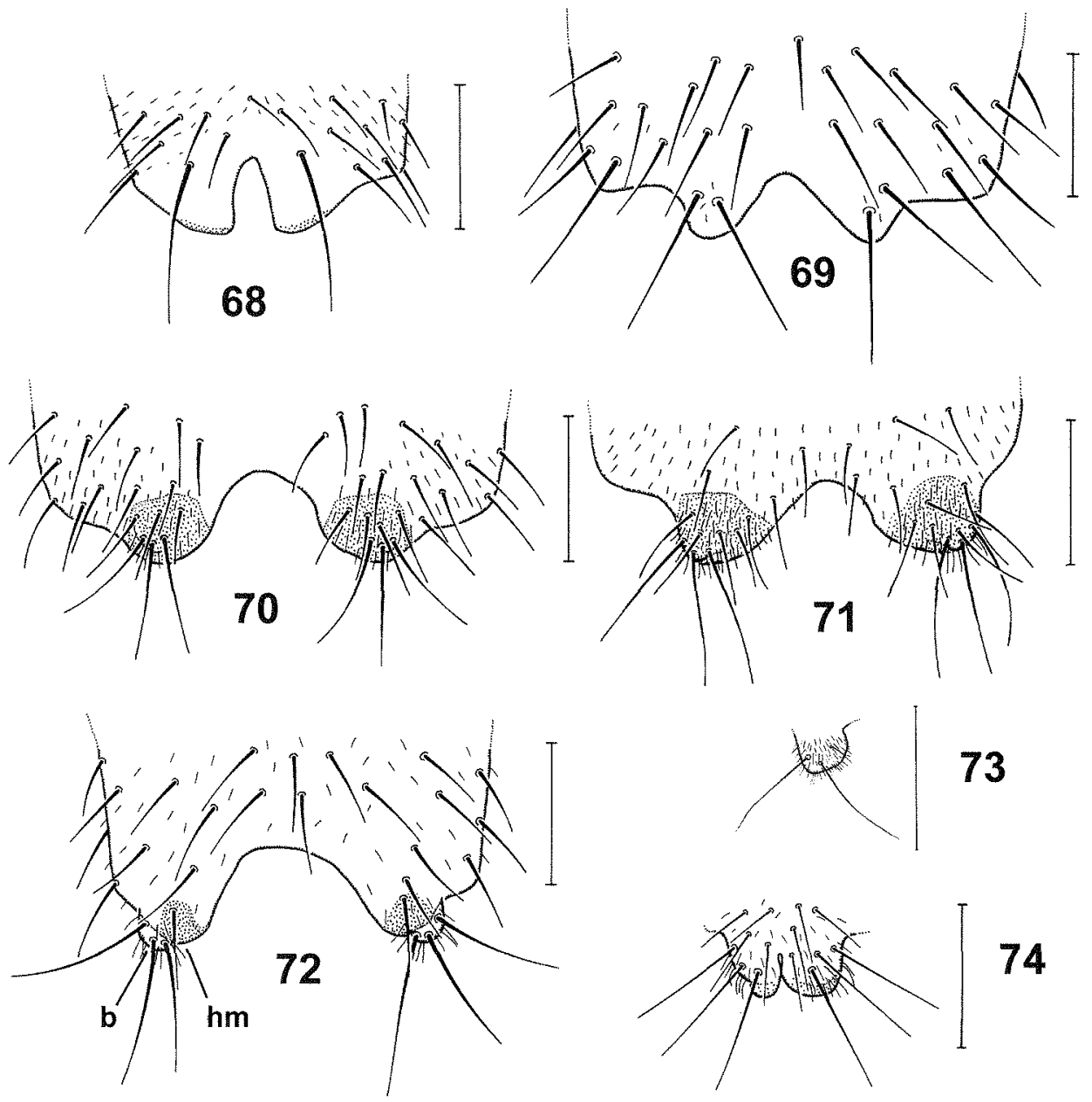

73
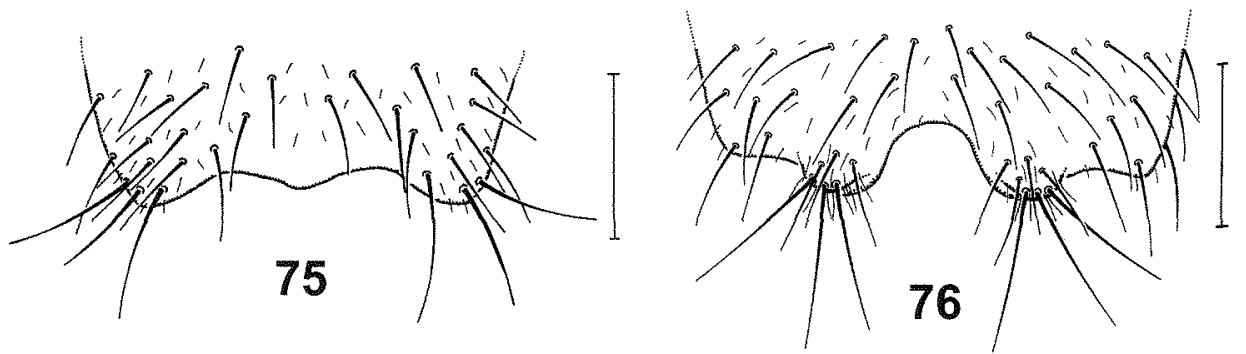

Figs 68-76. Megaselia females. Abdomen, posteriot portion of sternum 8: 68 - M. densior; 69-M. cf. albicans; $70-M$. pamassia; $71-M$. bexanopbila sp. 1 .; $72-M$. sp. 3; $73-M$. sp. 7, right posterior lobe of sternum 8 ; 74-M. fisheri (holotype); $75-M$. sp. 1; 76-M. giraudii. $\mathrm{b}=$ bulge of sternal lobe, $\mathrm{hm}=$ hind margin of sternal lobe. Scale bars $=0.1 \mathrm{~mm}$. 


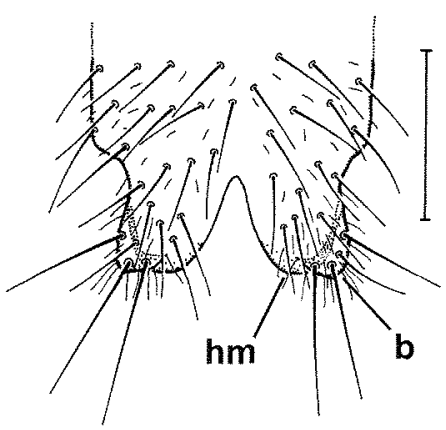

77
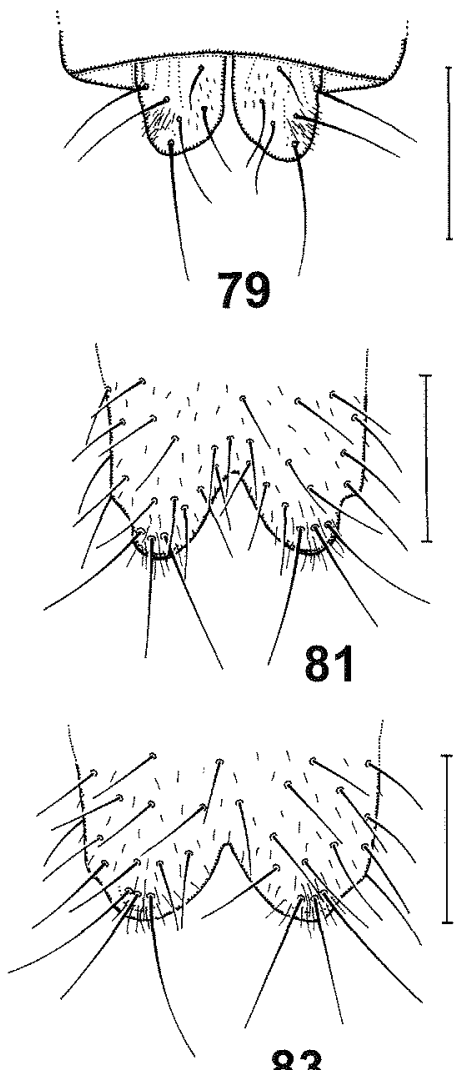
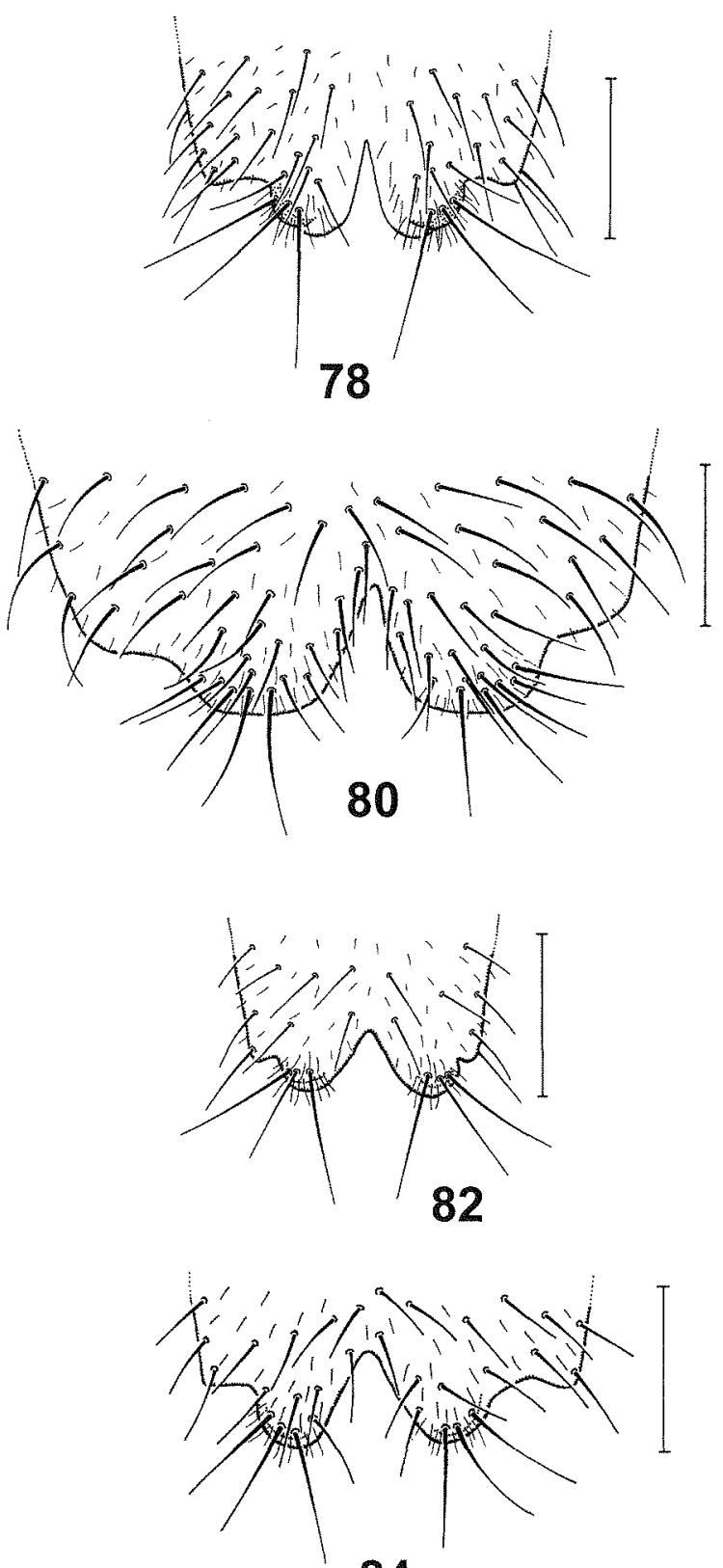

84

Figs 77-84. Megaselia females. Abdomen, posterior portion of sternum 8: $77-M$. xanthophila sp. n.; $78-M$. baraldlundi; $79-$ M. correlata; $80-M$. rubricomis (holotype); $81-M$. immodensior sp. n.; $82-M$. mimodensior sp. n.; $83-M$. sp. $5 ; 84-$ M. quadriseta. $\mathrm{b}=$ bulge of sternal lobe, $\mathrm{hm}=$ hind margin of sternal lobe. Scale bars $=0.1 \mathrm{~mm}$. 


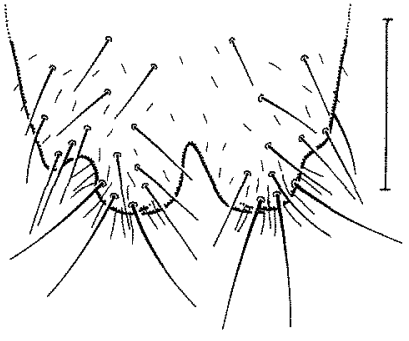

85
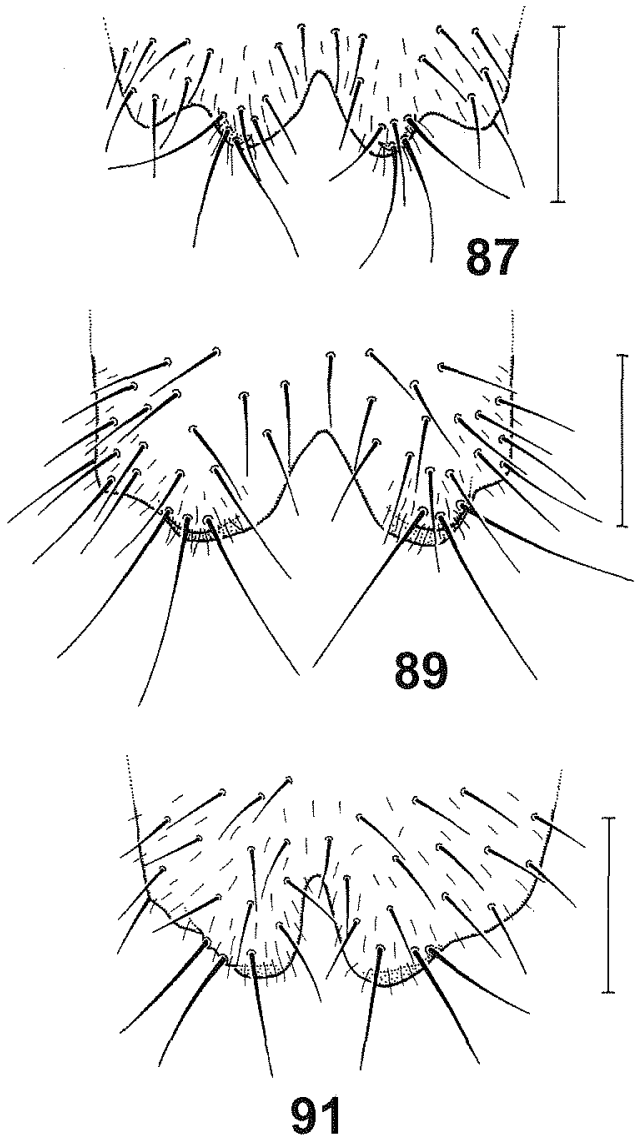
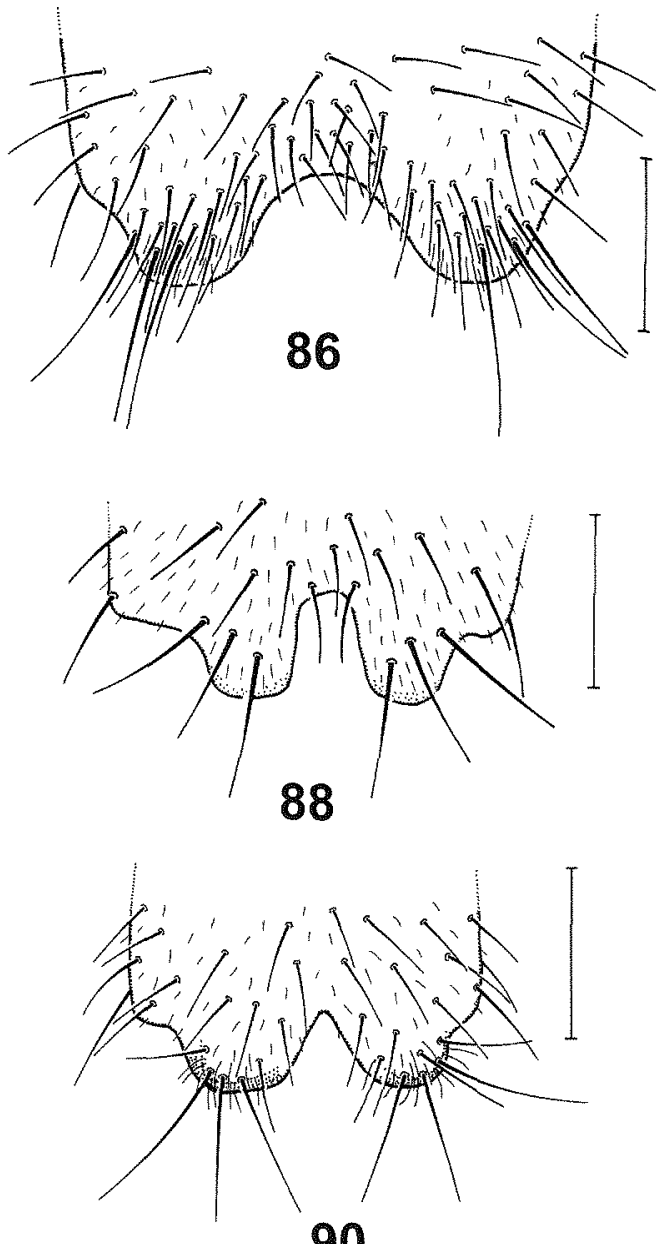

90

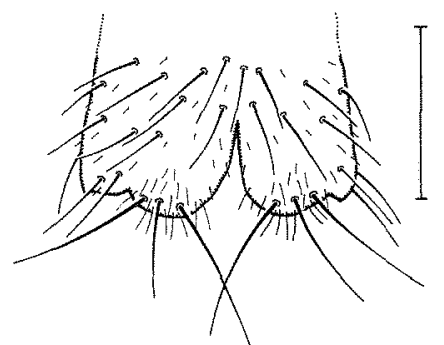

92

Figs 85-92. Megaselia females. Abdomen, posterior portion of sternum 8: 85-M. glabrimargo sp. n.; $86-M$. sanguinea (holotype); $87-M$. citrinella sp. n.;88-M. breviseta; $89-M$. sp. $4 ; 90-M$. sp. $6 ; 91-M$. septentrionalis; $92-M$. sp. 2. Scale bars $=0.1 \mathrm{~mm}$. 

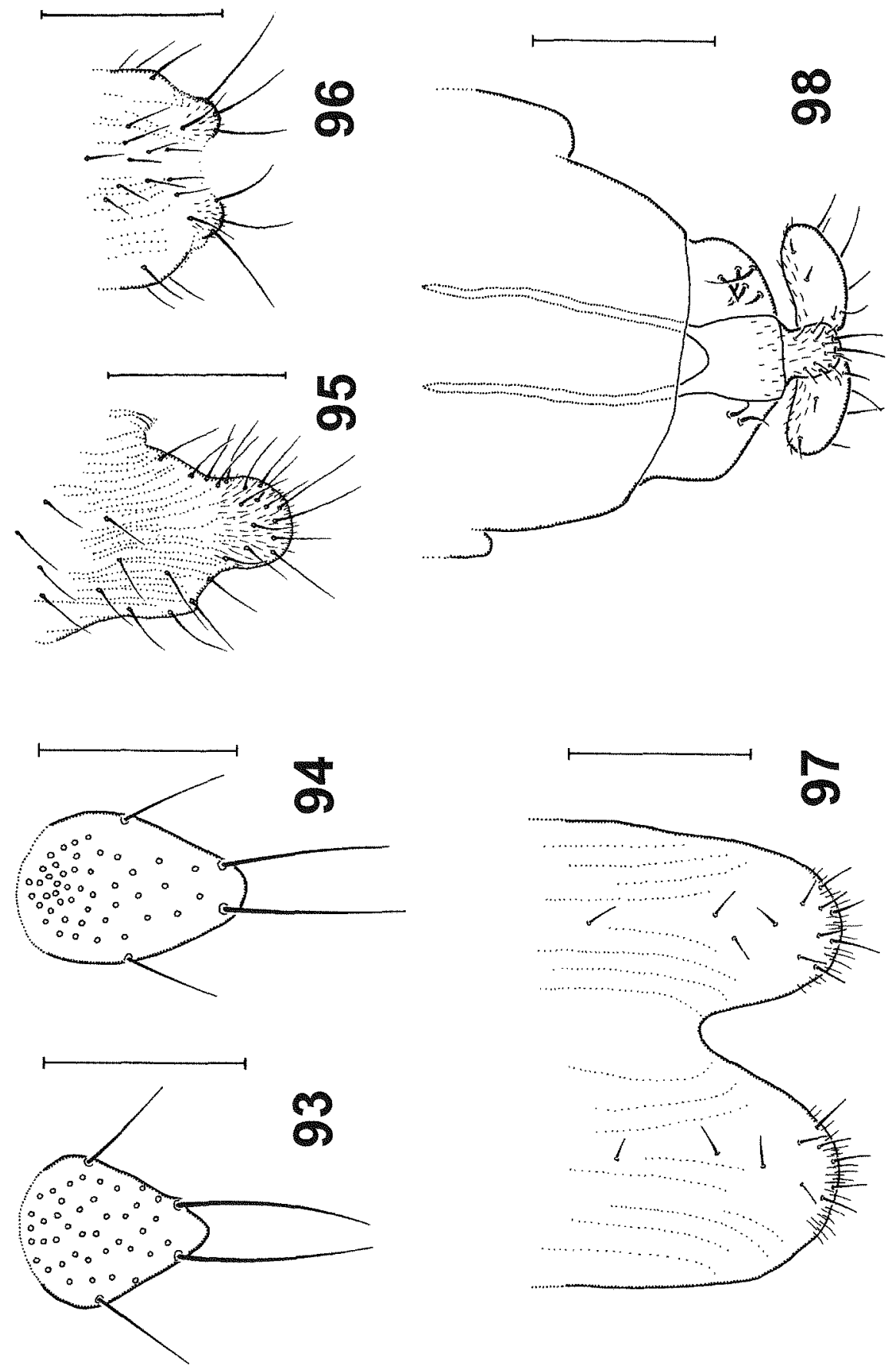

Figs 93-98. Megaselia females. Hypoproct (small circles represent sockets of hairs, hairing and micropubescence omitted): $93-M$. baraldlundi; $94-M$. giraudit. Abdomen, right postetior portion of sternum 8: $95-M$. raruvesialdae $\mathrm{sp}$. n. Abdomen, posterior portion of sternum 8: $96-M$. nigrescens; $97-M$. rubida. Tip of ovipositor, dorsal view: $98-$ M. rubida. Scale bars $=0.1 \mathrm{~mm}$. 


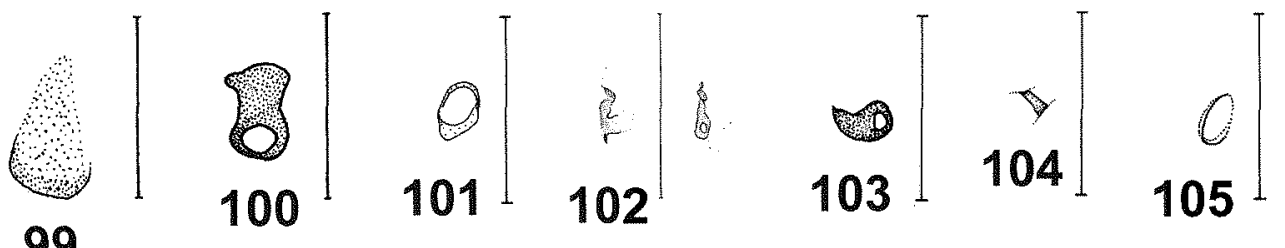

\section{9}
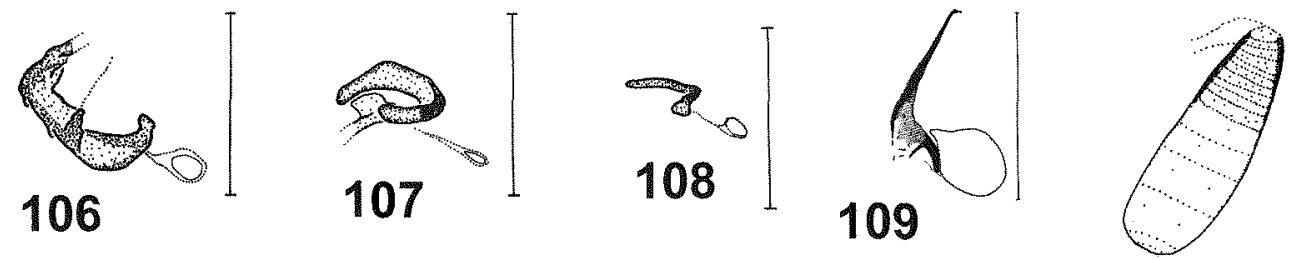

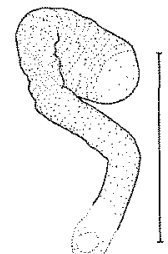

110

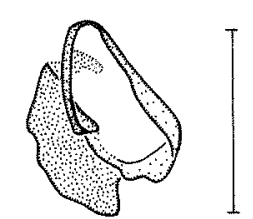

114

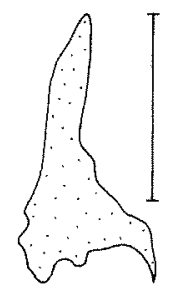

118

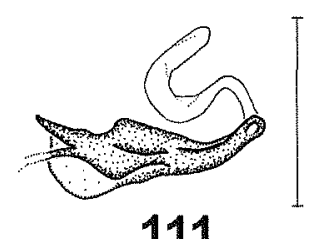

111
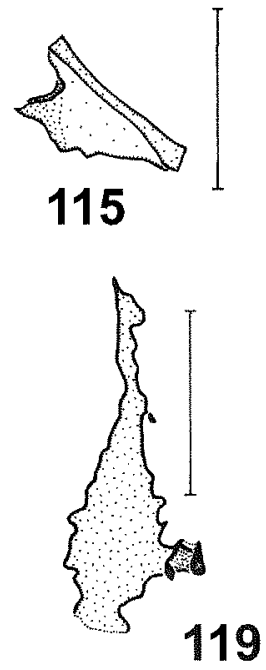

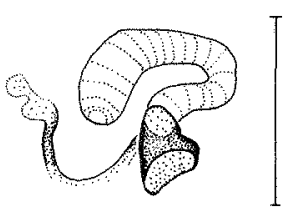

112

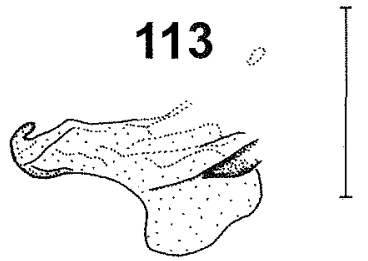

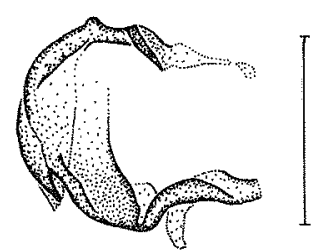

116

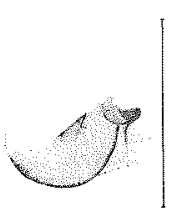

120
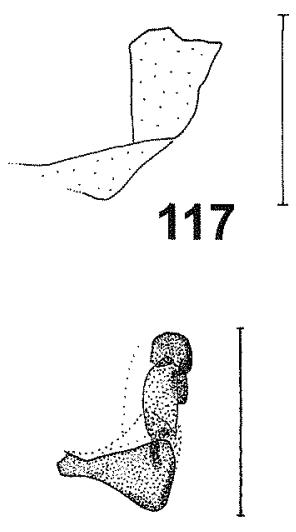

121

Figs 99-121. Megaselia females. Vaginal sclerite, dorsal view (except 102, 110, 121): 99-M. densior, 100 - $M$. sp. 7; 101-M. sp. 3;102-M. bexanopbila sp. n., dorsal view (left) and lateral view (tight); $103-M$. sp. 6; 104 $-M$. septentrionalis; $105-M$. sp. 2; $106-M$. immodensior sp. n.; $107-M$. mimodensior sp. n.; $108-M$. sp. 5; 109 - M. quadriseta; $110-$ M. correlata, tubular organ, dorsal view; $111-M$. citrinella sp. n.; $112-$ M. breviseta; 113 - M. rubricornis (holotype), $114-M$. xanthopbila sp. n.; $115-M$. glabrimargo sp. n.; $116-M$. sanguinea (holotype); $117-M$. parnassia; 118 - M. sp. 4; 119 - M. cf. albicans; 120 - M. nigrescens; 121 - M. raruvesiculae sp. n., right lateral view. Scale bars $=0.1 \mathrm{~mm}$. 


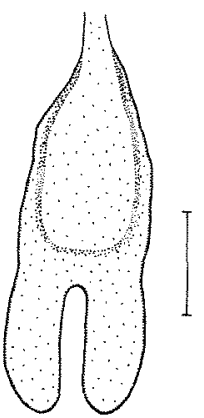

122

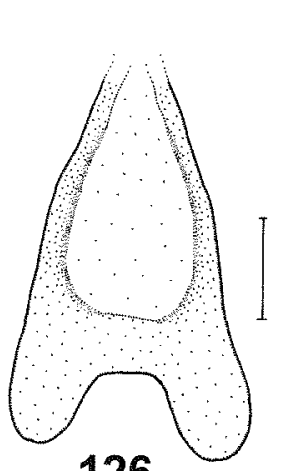

126

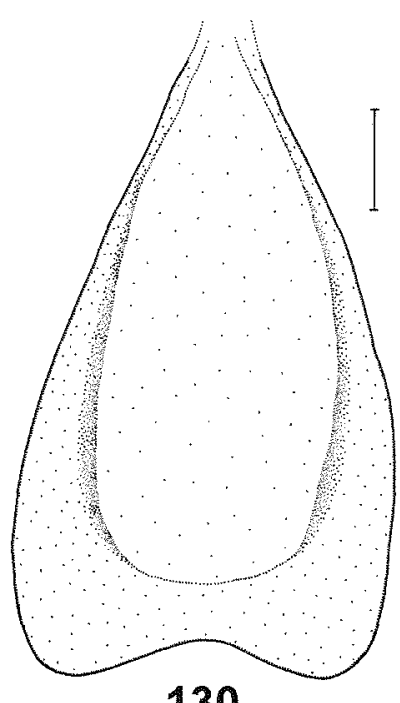

130
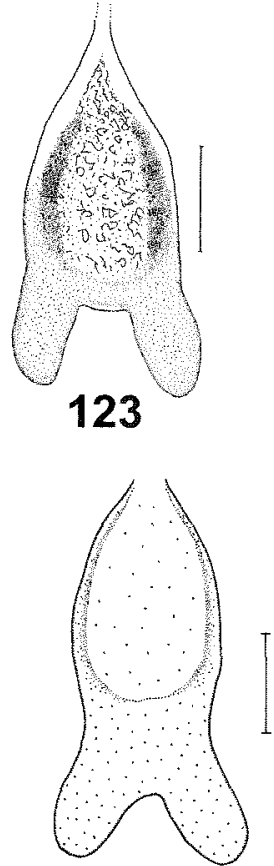

127
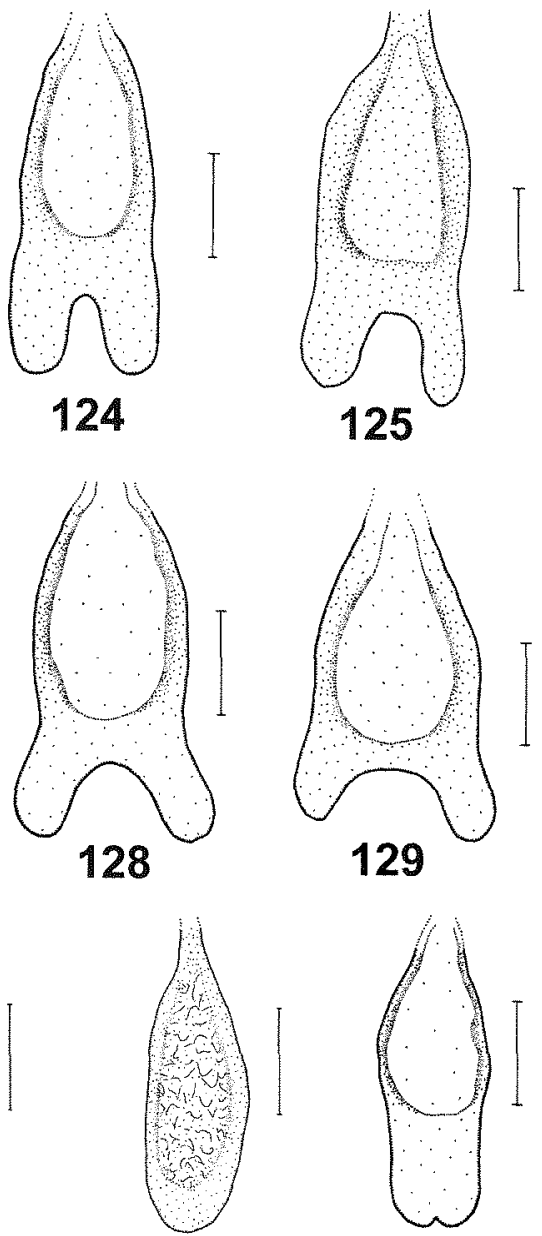

131

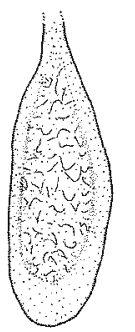

132
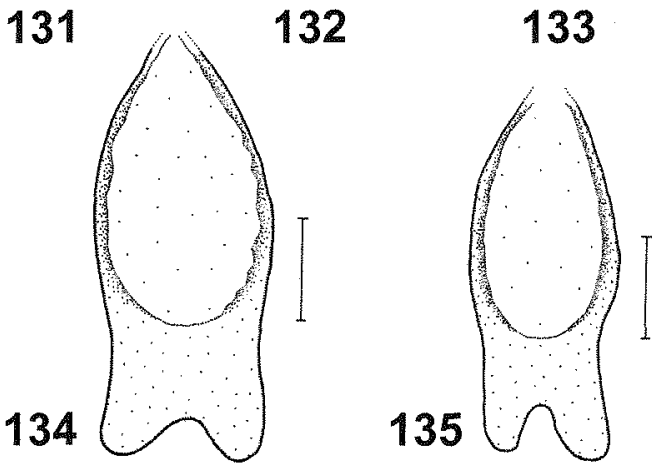

Figs 122-135. Megaselia females. Dufour's crop mechanism: 122-123 - M. girandii; 124 - M. citrinella sp. n.; 125 - M. bexanophila sp. n.; $126-$ M. quadriseta; $127-M$. sp. 1; $128-M$. sp. 5; 129-M. densior, $130-M$. rubricornis (holotype); $131-M$. correlata; 132 - M. nigrescens; 133-135 - M. xantbophila sp. n. (showing variability: 133-134 - Swedish Lapland; 135 - Germany). Scale bars $=0.1 \mathrm{~mm}$. 